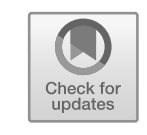

\title{
Kapitel 2: Rechtspflichten zum Support der Online-Komponenten
}

In diesem Kapitel wird untersucht, ob es eine Rechtspflicht zum Support der in Kapitel 1 dargestellten Online-Komponenten digitaler Spiele gibt und woraus eine solche Pflicht entsteht. Es wird außerdem geprüft, wie diese Pflicht rechtlich zu typologisieren ist. Die rechtliche Einordnung der Pflicht soll als Ausgangspunkt für die in Kapitel 3 behandelte Frage dienen, ob der Support ohne Weiteres beendet werden darf oder zumindest für eine bestimmte Zeit lang erbracht werden muss.

Kapitel 2 dieser Arbeit gliedert sich in drei Abschnitte. In Abschnitt A. wird untersucht, woraus sich eine Pflicht zum Support der Online-Komponenten von Inklusivspielen ergibt. Abschnitte B. und C. widmen sich der gleichen Frage, jedoch in Bezug auf Free-to-Play- sowie auf Abospiele.

\section{A. Inklusivspiele}

Um ein Inklusivspiel nutzen zu können, schließt der Erwerber verschiedene Verträge mit dem Publisher bzw. Händler ab. Neben dem Vertrag, welcher die Überlassung der Spielkopie zum Gegenstand hat, zählt dazu auch das sog. End User License Agreement (im Folgenden: EULA), welches im Wesentlichen den Umfang der erlaubten Nutzung des Spiels durch den Erwerber festlegt. Bei Inklusivspielen findet sich aber üblicherweise in keiner dieser Vereinbarungen eine eindeutige und ausdrückliche Regelung darüber, ob und wer zum Support der in Kapitel 1 dargestellten Online-Komponenten des digitalen Spiels verpflichtet ist. Erst recht sind keine Aussagen darüber ersichtlich, wie lange die Online-Komponenten Support erhalten werden.

Das Fehlen einer ausdrücklichen Regelung über eine Supportpflicht erstaunt, da der Support der Online-Komponenten - wie in der Einleitung und in Kapitel 1 deutlich wurde - von großer Bedeutung für die Nutzungsmöglichkeit des digitalen Spiels ist. Aus diesem Grund soll im Folgenden untersucht werden, ob bei Inklusivspielen dennoch eine Pflicht zum Support der Online-Komponenten besteht. Die Untersuchung erfolgt dabei sowohl mit Blick auf den Direkt- (dazu I.) als auch den Händlervertrieb (dazu II.) von Inklusivspielen. 


\section{Der Direktvertrieb}

Der Direktvertrieb von Inklusivspielen erfolgt regelmäßig im Internet über Publisher-eigene Plattformen. Beispiele hierfür sind der Online-Shop Origin $^{204}$ von EA sowie der UplayStore ${ }^{205}$ von Ubisoft. Zum Zweck des Erwerbs der Spielkopie schließt der Erwerber auf diesen Plattformen einen Überlassungsvertrag mit dem Publisher ab.

Fraglich ist, ob Teil dieses Vertrages auch eine Pflicht zum Support der OnlineKomponenten des Inklusivspiels ist.

Die Literatur und Rechtsprechung diskutieren Verträge über die Bereitstellung von spielbezogenen Online-Komponenten ganz überwiegend in Bezug auf Abospiele im hier verstandenen Sinn. ${ }^{206}$ Dabei wird jedoch nicht der Begriff „Mehrspielermodus“, sondern vielmehr die Bezeichnung „Online-Spiel“207, „,virtuelle Welt“"208 oder auch „virtuelle Umgebung des Spiels“209 verwendet. Es ist jedoch davon auszugehen, dass diese recht weit gefassten Begriffe auch spielbezogene Online-Komponenten wie den Online-Mehrspielermodus erfassen sollen.

204 Abrufbar unter http://www.ea.com/de/1/origin.

205 Abrufbar unter https://store.ubi.com/de/home.

206 Vgl. Psczolla, Onlinespielrecht, S. 5 ff.; Vetter, Virtuelle Welten, S. 7 f.; Schneider, Virtuelle Werte, S. 20 ff., 41; Koch, JurPC Web-Dok. 57/2006, Abs. 1-Abs. 60, Abs. 1 ff.; Völzmann-Stickelbrock, in FS Eisenhardt, S. 330; Redeker, in Hoeren/Sieber/Holznagel, Handbuch Multimedia-Recht, Teil 12, Rn. 441; AG Charlottenburg, MMR 2012, 598, 599; AG Karlsruhe, Urt. v. 19.05.2015 - Az. 8 C 377/14 - BeckRS 2015, 09351.

Oehler/von Ribbeck, in Duisberg/Picot, Recht der Computer- und Videospiele, Kap. 6, Rn. 10.

208 Creutz, Regeln virtueller Welten, S. 137 f.; Vetter, Virtuelle Welten, S. 115 f.; Preuß, Virtuelle Güter, S. 127; Schneider, Virtuelle Werte, S. 67; Weber, in Brandi-Dohrn/Lejeune, Recht 2.0, S. 207; ähnlich Koch, JurPC Web-Dok. 57/2006, Abs. 1-Abs. 60, Abs. 13; Krasemann, MMR 2006, 351, 352; Klickermann, MMR 2007, 766, 768; Striezel, Virtuelle Gegenstände, S. 199. 
Die herrschende Meinung ist dabei der Auffassung, dass zwischen dem Erwerber und dem „Spielanbieter“210 ein gesonderter Vertrag über die Nutzung der Online-Komponenten des Spiels zustande kommt ${ }^{211}$, der zeitlich erst nach dem Überlassungsvertrag abgeschlossen wird ${ }^{212}$. Einer vereinzelten und auch ohne nähere Begründung gebliebenen Minderansicht zufolge liegen dagegen nur dann zwei getrennt zu behandelnde Verträge vor, wenn sich das Spiel auch ohne die Online-Komponenten nutzen lässt. ${ }^{213}$

Lediglich Oehler/von Ribbeck nehmen ausdrücklich auf Inklusivspiele nach hiesigem Verständnis Bezug und sind diesbezüglich der Ansicht, dass ein gesonderter Vertrag abgeschlossen wird, welcher erst eine Pflicht zum Betrieb der notwendigen Server begründet. ${ }^{214}$ Diese Auffassung stößt jedoch auf Bedenken. Würde eine Pflicht zum Support der Online-Komponenten tatsächlich erst in einer vom Überlassungsvertrag unterschiedlichen Vereinbarung entstehen, liefe der Erwerber Gefahr, diesen Vertrag gar nicht mehr abschließen zu können, weil der Publisher beispielsweise in der Zwischenzeit den Support beendet hat. Darüber hinaus erbringt der Erwerber des Inklusivspiels das Entgelt für die Nutzung des digitalen Spiels bereits zum Zeitpunkt des Erwerbs des Spielclients. Danach kann der Erwerber das Spiel ohne zeitliche Begrenzung nutzen. Es stellt sich dann aber die Frage, wann ein gesonderter Vertrag über den Support der Online-Komponenten noch zustande kommen soll.

Darüber hinaus sind die beiden Leistungen - die Überlassung der Spielkopie und der Support ihrer Online-Komponenten - in tatsächlicher Hinsicht so eng miteinander verbunden, dass eine Aufspaltung in zwei getrennte Verträge lebensfremd erscheint. Dies gilt sowohl für den Online-Mehrspielermodus als auch und insbesondere für die Online-DRM-Systeme, mit deren Support sich die Literatur bisher nicht auseinandergesetzt hat.

210 Ein Gebrauch der Begriffe Publisher oder Entwickler erfolgt - soweit ersichtlich - nicht. Anstelle dessen wird der unscharfe Begriff des „Spielanbieters“ verwendet, wobei unklar bleibt, ob es sich hierbei um eine der soeben genannten Personen handelt.

211 Vgl. Oehler/von Ribbeck, in Duisberg/Picot, Recht der Computer- und Videospiele, Kap. 6, Rn. 10; Psczolla, Onlinespielrecht, S. 85; Creutz, Regeln virtueller Welten, S. 137; Vetter, Virtuelle Welten, S. 119 f.; Preuß, Virtuelle Güter, S. 127; Schneider, Virtuelle Werte, S. 67 f.; Koch, JurPC Web-Dok. 57/2006, Abs. 1-Abs. 60, Abs. 16; Krasemann, MMR 2006, 351, 352; Klickermann, MMR 2007, 766, 768; Weber, in Brandi-Dohrn/Lejeune, Recht 2.0, S. 207; Striezel, Virtuelle Gegenstände, S. 199; Berberich, Virtuelles Eigentum, S. 400; Moser, Browsergames, S. 70,74 .

212 Oehler/von Ribbeck, in Duisberg/Picot, Recht der Computer- und Videospiele, Rn. 10 (mit Einrichtung und Freischaltung des Benutzerkontos); Schneider, Virtuelle Werte, S. 68 (mit der erstmaligen Verbindung zwischen installierter Software und Server); vgl. auch Preuß, Virtuelle Güter, S. 126 f.; Koch, JurPC Web-Dok. 57/2006, Abs. 1-Abs. 60, Abs. 15.

213 Redeker, IT-Recht, Rn. 1165; Berberich, Virtuelles Eigentum, S. 400; vgl. auch Lober/Weber, MMR 2005, 653, 656, die davon ausgehen, dass die Überlassung und die "Nutzung der Onlinewelt" als "verbundenes Geschäft, als gemischter Vertrag mit zwei Komponenten" zusammenhängen, wobei jedoch unklar ist, auf welche Arten digitaler Spiele sie sich beziehen.

214 So Oehler/von Ribbeck, in Duisberg/Picot, Recht der Computer- und Videospiele, Kap. 6, Rn. 10 . 
Aus diesen Gründen ist zu prüfen, ob eine Pflicht zum Support der Online-Komponenten des Inklusivspiels bereits im Überlassungsvertrag entsteht.

\section{Die Richtlinie (EU) 2019/770 über bestimmte vertragsrechtliche As- pekte der Bereitstellung digitaler Inhalte und digitaler Dienstleistun- gen vom 20. Mai 2019}

Am 20. Mai 2019 wurde die Richtlinie (EU) 2019/770 über bestimmte vertragsrechtliche Aspekte der Bereitstellung digitaler Inhalte und digitaler Dienstleistungen (im Folgenden: „DI-RL“) verabschiedet. Sie trat am 11.06.2019 in Kraft und ist innerhalb von zwei Jahren in nationales Recht umzusetzen. ${ }^{215}$ Die DI-RL hat zum Ziel, bestimmte vertragsrechtliche Aspekte der Bereitstellung digitaler Inhalte innerhalb der EU zu vollharmonisieren. ${ }^{216}$

\section{a) Anwendungsbereich und Begriffsbestimmungen der DI-RL}

Die Richtlinie findet in persönlicher Hinsicht zwar nur auf Verträge Anwendung, die zwischen Verbrauchern und Unternehmern geschlossen werden (Art. 3 Abs. 1). ${ }^{217}$ Darüber hinaus hat sie jedoch einen sehr weiten sachlichen Anwendungsbereich ${ }^{218}$, denn zu den digitalen Inhalten gehören alle „Daten, die in digitaler Form erstellt und bereitgestellt werden“ ${ }^{\text {“219. }}$. Diese denkbar weite Definition erfasst eine Vielzahl von Produkten, wozu unter anderem ausdrücklich auch „digitale Spiele“ zählen. ${ }^{220}$ Auch der Begriff der „Bereitstellung“ der digitalen Inhalte ist ausweislich der Erwägungsgründe weit zu verstehen und bewusst technologieoffen gestaltet. ${ }^{221}$ Er beschränkt sich nicht auf bestimmte Vertriebsformen, sodass es nicht weiter darauf ankommt, ob der digitale Inhalt beispielsweise auf dem Endgerät des Verbrauchers installiert werden muss oder ob auf diesen im Rahmen einer Cloud-Computing-Umgebung zugegriffen werden kann. ${ }^{222}$

Die Richtlinie regelt die Bereitstellung sowohl digitaler Inhalte als auch digitaler Dienstleistungen und behandelt beide Gegenstände gleich. ${ }^{223}$ Dabei ist jedoch eine Dienstleistung nicht schon dann als ,digitale Dienstleistung“ i.S.d DI-RL anzusehen, wenn sie nur mithilfe von Digitaltechnik erbracht wird, wie Art. 5 Abs. 3 lit. a) DI-RL

\footnotetext{
215 Bach, NJW 2019, 1705, 1705.

216 Vgl. Erwägungsgrund 3 sowie Art. 3 der DI-RL, dazu auch Ehle/Kreß, CR 2019, 723, 723.

217 Spindler/Sein, MMR 2019, 415, 416.

218 Vgl. Staudenmayer, ZEuP 2019, 663, 671; Ehle/Kreß, CR 2019, 723, 723.

219 Art. 2 Nr. 1 DI-RL.

220 So Erwägungsgrund 19.

221 Vgl. Staudenmayer, ZEuP 2019, 663, 671.

222 Siehe Erwägungsgrund 19, vgl. auch Staudenmayer, ZEuP 2019, 663, 671; Metzger, JZ 2019, $577,583$.

223 Staudenmayer, ZEuP 2019, 663, 671.
} 
klarstellt. ${ }^{224}$ Kern der digitalen Dienstleistung muss vielmehr die digitale Erstellung, Verarbeitung, Speicherung oder Nutzung von Daten in digitaler Form sein (Art. $2 \mathrm{Nr}$. 2 DI-RL).

$\mathrm{Zu}$ beachten ist, dass die DI-RL nicht alle denkbaren vertragsrechtlichen Aspekte der Bereitstellung digitaler Inhalte und digitaler Dienstleistungen behandelt. So regelt die Richtlinie ausdrücklich nicht Fragen des Zustandekommens und der Wirksamkeit von Verträgen über die Bereitstellung digitaler Inhalte oder Dienstleistungen. ${ }^{225}$ Die Mitgliedsstaaten haben also nach wie vor die Möglichkeit, eigenständig Regelungen in dieser Hinsicht zu treffen.

\section{b) Die Vertragsmäßigkeit digitaler Inhalte und digitaler Dienstleistun- gen}

Kern der DI-RL sind die Regelungen der Art. 6 bis 9, welche die Vertragsmäßigkeit der digitalen Inhalte oder digitalen Dienstleistungen betreffen.

Art. 5 und 6 statuieren die Pflicht des Unternehmers, dem Verbraucher digitale Inhalte oder digitale Dienstleistungen bereitzustellen, welche den Anforderungen der Art. 7, 8 und 9 entsprechen. Art. 7 enthält subjektive und Art. 8 objektive Anforderungen an die Vertragsmäßigkeit. Art. 9 regelt darüber hinaus die Haftung des Unternehmers bei einer unsachgemäßen Integration digitaler Inhalte bzw. Dienstleistungen in die „digitale Umgebung des Verbrauchers“. Er enthält damit ein Äquivalent der sog. „IKEA-Klausel“, welche mit der Verbrauchsgüterkauf-Richtlinie eingeführt wurde.226 Die Beweislast dafür, dass digitale Inhalte bzw. Dienstleistungen vertragsgemäß bereitgestellt wurden, hat nach Art. 12 der Unternehmer zu tragen. ${ }^{227}$

Art. 8 Abs. 1 stellt mit Blick auf die objektiven Anforderungen an die Vertragsmäßigkeit maßgeblich auf die Zweckeignung ab und führt zur Bestimmung der einzuhaltenden Leistungsmerkmale mehrere Kriterien ein, wie z.B. die für digitale Inhalte bzw. Dienstleistungen derselben Art übliche und vom Verbraucher zu erwartende „Funktionalität“, „Kompatibilität“" und „Zugänglichkeit““. ${ }^{228}$ Ausweislich des Erwägungsgrundes 43 wird dabei der Begriff der „Funktionalität“ maßgeblich von der Verwendungsmöglichkeit des digitalen Inhalts bestimmt. Zur Funktionalität eines digitalen Inhalts kann daher auch der Austausch von Informationen mit anderer Hard- oder Software gehören, wie es z.B. in Client-Server-Umgebungen der Fall ist.

\section{c) Herleitung einer Supportpflicht}

Fraglich ist, ob sich mit Blick auf die Online-Komponenten digitaler Spiele eine Supportpflicht aus der neuen DI-RL ergibt. Die Antwort auf diese Frage hängt ent-

\footnotetext{
224 Ehle/Kreß, CR 2019, 723, $723 \mathrm{f}$.

225 Art. 3 Abs. 10; vgl. Metzger, JZ 2019, 577, 583; Staudenmayer, ZEuP, 2019, 663, 677.

226 Metzger, JZ 2019, 577, 581.

227 Metzger, JZ 2019, 577, 581.

228 Spindler/Sein, MMR 2019, 488, 488.
} 
scheidend davon ab, ob die Online-Komponenten je für sich als separate digitale Inhalte bzw. digitale Dienstleistungen einzuordnen sind oder ob sie untrennbare Bestandteile des digitalen Spiels selbst und damit eines einheitlichen digitalen Inhalts darstellen.

\section{aa) Vereinheitlichende Betrachtung von Spiel und Online-Kompo- nenten}

Im letzteren Fall bestünde stets und ohne weiteres mit der Bereitstellung des digitalen Spiels auch eine Pflicht zum Support (all) seiner Online-Komponenten. Gemäß Art. 5 Abs. 1 müsste der Support dann nämlich zeitgleich mit der Bereitstellung des digitalen Spielclients erbracht werden.

Für die einheitliche Betrachtung spricht zwar, dass es sich bei den Online-Komponenten um Bestandteile des digitalen Spiels handelt, die von wesentlicher Bedeutung für dessen Nutzungsmöglichkeit sind. ${ }^{229}$ Sie haben also maßgeblichen Einfluss auf die Funktionalität des digitalen Spiels.

Gegen die vereinheitlichende Betrachtung spricht jedoch das damit einhergehende erhebliche Haftungsrisiko für den Publisher. Würde er den Support nämlich gar nicht oder erst später als die Bereitstellung des Spielclients - etwa nach Zahlung eines zusätzlichen Entgelts - erbringen, liefe der Publisher Gefahr, wegen der Bereitstellung eines nicht vertragsgemäßen digitalen Inhalts zu haften.

Neben diesem erheblichen Haftungsrisiko würde die vereinheitlichende Betrachtung auch dazu führen, dass der in hohem Maße ausdifferenzierte Markt digitaler Spiele und die verschiedenen Geschäftsmodelle, welche sich mittlerweile dort etabliert haben, nicht mehr aufrecht erhalten werden könnten. Zwar können die Publisher noch eine abweichende Vereinbarung über einen einheitlichen Zeitpunkt der Bereitstellung des digitalen Spiels und des Supportbeginns seiner Online-Komponenten mit dem Verbraucher treffen. ${ }^{230}$ Allerdings hätte die vereinheitlichende Betrachtung zur Folge, dass es ihnen nicht mehr möglich wäre, allein für den Support der Online-Komponenten bestimmter digitaler Spiele einen separaten Bereitstellungszeitpunkt zu vereinbaren, geschweige denn hierfür eine gesonderte Vergütung zu verlangen, wie dies z.B. bei Konsolenspielen der Fall ist. ${ }^{231}$ Denn wenn das digitale Spiel und dessen OnlineKomponenten ein einheitlicher digitaler Inhalt sind, müssen sie auch als eine Einheit nach entsprechender Vergütung bereitgestellt werden. Eine Aufspaltung der Bestandteile digitaler Inhalte nimmt die DI-RL nicht vor und erst recht regelt sie für solche Bestandteile keine gesonderte Bereitstellungs- oder Vergütungsmöglichkeit.

Die Zusammenfassung vom digitalen Spiel und seinen Online-Komponenten zu einem digitalen Inhalt bzw. zu einer digitalen Dienstleistung würde damit zu einer nicht interessengemäßen Vereinheitlichung ausdifferenzierter Geschäftsmodelle führen. Die zusammenfassende Betrachtung ist daher abzulehnen.

\footnotetext{
229 Siehe dazu oben, S. 2.

${ }^{230}$ „Sofern die Parteien nichts anderes vereinbart haben [...]“, Art. 5 Abs. 1 S. 2.

231 Siehe dazu unten, S. 93 ff.
} 


\section{bb) Getrennte Betrachtung von Spiel und Online-Komponenten}

Vielmehr ist der getrennten Betrachtung des digitalen Spiels und des Supports seiner Online-Komponenten der Vorzug zu geben. Sowohl der Online-Mehrspielermodus als auch die Online-DRM-Systeme stellen eigenständige digitale Inhalte bzw. digitale Dienstleistungen i.S.d. Art. 2 der DI-RL dar.

Der Online-Mehrspielermodus ist ein eigenständiger digitaler Inhalt i.S.d. Art. $2 \mathrm{Nr}$. 1 DI-RL. Hier werden digitale Daten, nämlich eine virtuelle Spielumgebung, vermittelt durch den Einsatz von Master- bzw. Dedicated Game-Servern ${ }^{232}$, vom Publisher bereitgestellt.

Der Online-Mehrspielermodus weicht außerdem auch inhaltlich erheblich vom Rest des digitalen Spiels ab. Wie in Kapitel 1 ersichtlich geworden ist, ermöglicht der Online-Mehrspielermodus das Zusammenspiel mehrerer real existierender Personen in einer virtuellen Spielumgebung, wohningegen der Einzelspielermodus des restlichen Spiels nur das Spielen gegen eine künstliche Intelligenz erlaubt. ${ }^{233}$ Damit unterscheidet sich der Online-Mehrspielermodus in bedeutender Weise vom Rest des digitalen Spiels, auch wenn er - wie bei Inklusivspielen üblich - in dieses integriert ist.

Doch auch in wirtschaftlicher Hinsicht hebt sich der Online-Mehrspielermodus vom Rest des digitalen Spiels ab. Dies ergibt sich daraus, dass der Support dieser OnlineKomponente bei bestimmten Arten digitaler Spiele, wie z.B. bei Konsolenspielen, nur nach Abschluss eines zusätzlichen, entgeltpflichtigen Vertrages erbracht wird. Somit kommt dem Online-Mehrspielermodus durchaus ein eigenständiger wirtschaftlicher Wert zu, der es verbietet, diese Online-Komponente und das digitale Spiel als einen einheitlichen digitalen Inhalt $\mathrm{zu}$ betrachten.

Aber auch Online-DRM-Systeme werden vom Anwendungsbereich der DI-RL erfasst. Doch anders als der Online-Mehrspielermodus fallen sie nicht unter Art. $2 \mathrm{Nr}$. 1, sondern vielmehr unter Art. 2 Nr. 2 lit. a) DI-RL. Es handelt sich bei den OnlineDRM-Systemen zwar nicht um Dienstleistungen, welche die Erstellung, Verarbeitung oder Speicherung digitaler Daten ermöglichen. Allerdings kontrollieren und ermöglichen diese Systeme den Zugang zum digitalen Spiel. Sie dienen damit nicht der Verwirklichung des Spielerlebnisses, sondern vielmehr dem Rechtemanagement zugunsten der Publisher. ${ }^{234}$ Darüber hinaus können sie aber auch - jedenfalls in Fällen, in denen die Online-DRM-Systeme Account-basiert sind -, verhindern, dass Dritte unbefugt Zugriff auf die vom Spieler erworbenen Spielkopien nehmen, sodass sie somit auch den Interessen der Spieler dienen.

Wenn man die Online-Komponenten bzw. ihren Support als separate, vom digitalen Spiel zu unterscheidende digitale Inhalte bzw. digitale Dienstleistungen ansieht, ergibt sich nicht ohne weiteres eine Supportpflicht ab dem Zeitpunkt der Bereitstellung des digitalen Spiels aus Art. 5 Abs. 1 DI-RL. Vielmehr ist hier zu prüfen, ob überhaupt

\footnotetext{
232 Siehe dazu oben, S. $15 \mathrm{ff}$.

233 Siehe dazu oben, S. 15.

234 Siehe dazu oben, S. $19 \mathrm{ff}$.
} 
eine Vereinbarung zum Support der konkreten Online-Komponenten zustande gekommen ist. Dabei handelt es sich um eine Frage des Zustandekommens von Verträgen, welche die DI-RL, wie bereits erläutert, ausdrücklich ausklammert. Zwar muss - eine Supportpflicht unterstellt - der Support der Online-Komponenten den Anforderungen der Art. 7-9 der DI-RL entsprechen. Jedoch geht es in diesem Kapitel nicht darum, dass der Support nicht ordnungsgemäß erbracht wird, sondern vielmehr um die Frage, $o b$ eine Supportpflicht überhaupt besteht.

Insgesamt muss daher auch nach dem Inkrafttreten der DI-RL für jede Art digitaler Spiele gesondert geprüft werden, ob eine Supportpflicht hinsichtlich der Online-Komponenten besteht. In Fällen, in denen es an einer ausdrücklichen Regelung hierzu fehlt, kann die Supportpflicht vor dem Hintergrund des höchst ausdifferenzierten Marktes digitaler Spiele nur im Wege der Vertragsauslegung im Einzelfall ermittelt werden, worauf im Folgenden näher eingegangen wird.

\section{Ermittlung der Supportpflicht durch Auslegung}

Die Auslegung hat das Ziel, den rechtlich relevanten Sinn einer Erklärung festzustellen. ${ }^{235} \S \S 133$ und 157 BGB enthalten Vorschriften zur Auslegung von Willenserklärungen und Verträgen. Wenngleich ihrem Wortlaut nach die Regelung des $\S 133$ BGB nur auf Willenserklärungen und die des $§ 157$ BGB nur auf Verträge Anwendung zu finden scheinen, sind sich Literatur und Rechtsprechung darin einig, dass sich beide Vorschriften ergänzen und für alle Arten von Rechtsgeschäften gelten. ${ }^{236}$ Der in $\S 133$ BGB niedergelegte Grundsatz, dass man zur Sinnermittlung nicht beim Wortlaut stehen bleiben darf, gilt somit nicht nur für Willenserklärungen, sondern auch für Verträge - und umgekehrt sind nicht nur Verträge, sondern alle Rechtsgeschäfte unter Berücksichtigung von Treu und Glauben sowie der Verkehrssitte auszulegen. ${ }^{237}$

Hinsichtlich der Auslegungsmethode ist zwischen der sog. einfachen bzw. eigentlichen $^{238}$ und der dieser nachrangigen ${ }^{239}$ ergänzenden Auslegung zu unterscheiden. ${ }^{240}$ Die einfache Auslegung hat das Ziel, den rechtserheblichen Inhalt einer Erklärung zu ermitteln, während die ergänzende Auslegung Lücken in der rechtsgeschäftlichen Vereinbarung schließen will. ${ }^{241}$

Regelmäßig enthalten die auf den Abschluss des Überlassungsvertrages des Inklusivspiels gerichteten Willenserklärungen des Publishers keine Aussagen über eine

\footnotetext{
235 Vgl. Bork, BGB AT, Rn. 502; Walker, BGB AT, § 6, Rn. 2; Leipold, BGB AT, S. 226; Palandt/Ellenberger, $\S 133$ BGB, Rn. 1.

236 Vgl. statt vieler nur Bork, BGB AT, Rn. 499 f.; BGH, NJW-RR 2002, 1096, 1096.

237 Vgl. Bork, BGB AT, Rn. 499 ff.; Staudinger/Singer, § 133 BGB, Rn. 3; MüKo BGB/Busche, § 133 BGB, Rn. 18.

238 Vgl. zu den unterschiedlichen Bezeichnungen dieser Auslegung in Literatur und Rechtsprechung Staudinger/Roth, § 157 BGB, Rn. 3.

239 BGH, NJW-RR 2009, 593, 594 f.; Staudinger/Roth, § 157 BGB, Rn. 4, 5; Bork, BGB AT, Rn. 533; NK-BGB/Looschelders, § 157, Rn. 6; PWW/Brinkmann, § 157 BGB, Rn. 15.

240 Bork, BGB AT, Rn. 511.

241 Palandt/Ellenberger, § 157 BGB, Rn. 2; Soergel/Wolf, § 157 BGB, Rn. 29.
} 
Supportpflicht. Es fehlt in diesen Fällen sowohl an einer eindeutigen als auch an einer mehrdeutigen Willenserklärung des Publishers, welcher der normative Wille entnommen werden kann, eine Pflicht zum Support der Online-Komponenten zu übernehmen. Aus diesem Grunde führt die einfache Auslegung der Willenserklärung selbst nicht weiter.

Der Erwerber des Inklusivspiels muss aber regelmäßig zum Abschluss des Überlassungsvertrages über das Inklusivspiel besonderen Vertragsbedingungen des Publishers zustimmen, die in der Regel Allgemeine Geschäftsbedingungen (AGB) i. S. d. § 305 Abs. 1 BGB darstellen und sich als Auslegungsgrundlage anbieten.

Der ständigen Rechtsprechung des $\mathrm{BGH}^{242}$ und der herrschenden Literatur ${ }^{243} \mathrm{zu}-$ folge sind AGB nach einem objektiven Maßstab auszulegen. Dies bedeutet, dass die besonderen Umstände des Einzelfalles keine Berücksichtigung finden dürfen. ${ }^{244}$ Für die Auslegung ist vom Wortlaut der vorformulierten Klauseln auszugehen und auf den Verständnishorizont derjenigen Verkehrskreise abzustellen, die typischerweise an Geschäften dieser Art beteiligt sind. ${ }^{245}$

\section{a) Auslegung der AGB des Publishers}

Fraglich ist, ob sich den Vertragsbedingungen der Publisher durch Auslegung eine Pflicht zum Support der Online-Komponenten entnehmen lässt. Dies soll am Beispiel der „Verkaufsbedingungen“ ${ }^{246}$ des Publishers $E A$ untersucht werden. Diese regeln unter anderem den

„,Kauf von Software-Produkten, digitalen Inhalten, einschließlich zusätzlicher oder besonderer Funktionalitäten, Abonnements von Inhalten, virtueller Währungen und In-Game-Inhalte [...] “. ${ }^{247}$

Die soeben aufgezählten Gegenstände fasst der Publisher unter dem umfassenden Begriff der ,EA-Inhalte“ zusammen. Zwar werden Online-Komponenten nicht ausdrücklich aufgeführt. Jedoch lässt der sehr weite Begriff der zusätzlichen oder besonderen „Funktionalitäten“ den Schluss zu, dass darunter auch Online-Komponenten wie Online-DRM-Systeme und der Online-Mehrspielermodus fallen sollen. Jedenfalls lässt aber die allgemeine und vor allem nicht abschließende (,einschließlich“) Auflistung verschiedener digitaler Inhalte, die eine sehr große Palette an Produkten, Diensten und Services umfasst, darauf schließen, dass zu den $E A$-Inhalten auch die OnlineKomponenten digitaler Spiele gehören sollen.

242 BGH, NJW 2011, 2122, 2123; NJW-RR 2007, 1697, 1700; NJW 2005, 1183, 1184; vgl. NJW 1961, 212, 213; NJW 1953, 21, 21.

243 MüKo BGB/Basedow, §305c, Rn. 33 ff.; Ulmer/Brandner/Hensen/Ulmer/Schäfer, § 305c BGB, Rn. 73 ff.; Erman/Roloff, § 305c BGB, Rn. 20; Palandt/Grüneberg, § 305c BGB, Rn. 16; Jauernig/Stadler, § 305c BGB, Rn. 6; Bork, BGB AT, Rn. 1771.

244 BGH, NJW 1989, 3010, 3011; MüKo BGB/Basedow, § 305c, Rn. 39.

245 Ulmer/Brandner/Hensen/Ulmer/Schäfer, § 305c BGB, Rn. 80.

246 Abrufbar unter http://tos.ea.com/legalapp/termsofsale/US/de/PC/ (Stand vom 22. Juli 2019).

247 Vgl. die Einleitung der „Verkaufsbedingungen“ von $E A$. 
Der zweite Absatz von Ziff. 2 der „Verkaufsbedingungen“ enthält zu den $E A$-Inhalten die folgende Bestimmung:

„,Unsere Verpflichtung zur Bereitstellung der gekauften EA-Inhalte beginnt mit Abschluss der Bestellung und endet, sobald Sie die EA-Inhalte erhalten haben".

Der Publisher verspricht hier die „Bereitstellung der $E A$-Inhalte“ nach Abschluss des Bestellvorgangs. Auch diese Regelung verdeutlicht, dass der Publisher hier nicht nur die Lieferung einer Spielkopie übernimmt, sondern grundsätzlich auch für den Support ihrer Online-Komponenten einstehen will. Nur so erklärt sich die Verwendung des - weit zu verstehenden - Wortes „Bereitstellung“ anstelle von Begriffen wie „Lieferung“ oder „Übergabe“.

Nur ein solches Verständnis wird letztlich auch den Interessen der durchschnittlichen Erwerber eines Inklusivspiels gerecht. Diese gehen davon aus, dass sie das Spiel nach Erwerb im kompletten Umfang - samt Online-Komponenten - nutzen können. Diese Auslegung steht auch nicht im Widerspruch zum Interesse des Publishers, seine Verpflichtung zum Support von Online-Komponenten zu begrenzen. Er hat es schließlich selbst in der Hand, ob und mit wem er überhaupt einen Überlassungsvertrag abschließt.

\section{b) Ergänzende Auslegung}

Es ist möglich, dass nicht immer AGB vorhanden sind, aus welchen sich im Wege einer objektiven Auslegung eine Supportpflicht ergibt. Aus diesem Grunde ist zu untersuchen, ob auch durch eine ergänzende Auslegung des Überlassungsvertrages eine Pflicht zum Support der Online-Komponenten ermittelt werden kann.

Sowohl in der Rechtsprechung als auch in der Literatur ist anerkannt, dass die ergänzende Vertragsauslegung zur Ermittlung von Pflichten eines Vertrages genutzt werden kann, über welche die Parteien keine Regelung getroffen haben. ${ }^{248}$ So hat der BGH beispielsweise in einem Fall, in welchem zwei Ärzte ihre Arztpraxen auf Grundlage eines Vertrages getauscht hatten, im Wege der ergänzenden Vertragsauslegung eine Pflicht für die Vertragsparteien ermittelt, es zu unterlassen, jeweils in ihren alten geografischen Praxisbereich zurückzukehren und dort eine neue Praxis zu eröffnen. ${ }^{249}$

Die gesetzliche Grundlage der ergänzenden Vertragsauslegung sieht der BGH in $\S \S$ $133,157 \mathrm{BGB}^{250}$, die Literatur dagegen entweder in $\S \S 157,242 \mathrm{BGB}^{251}$ oder allein in $\S 157 \mathrm{BGB}^{252}$. Welche dieser Vorschriften als Ausgangspunkt für die ergänzende Vertragsauslegung herangezogen wird, macht jedoch im Ergebnis keinen Unterschied.

248 BGH, NJW 1955, 337, 337; Staudinger/Olzen, § 241 BGB, Rn. 166; MüKo BGB/Bachmann, § 241 BGB, Rn. 32; Hk-BGB/Schulze, § 242 BGB, Rn. 20.

BGH, NJW 1955, 337, 337.

BGH, NJW 2015, 955, 957; NJW 2013, 678, 679; NJW 2010, 1742, 1742.

Medicus/Petersen, BGB AT, Rn. 343.

252 Walker, BGB AT, § 6, Rn. 19; wohl auch Staudinger/Roth, § 157 BGB, Rn. 2; Finkenauer, AcP 2013, 619, $619 \mathrm{mwN}$. 
Die ergänzende Vertragsauslegung setzt eine Regelungslücke voraus, die gegeben ist, wenn im Vertrag eine zur Verwirklichung des Regelungsplans des Vertrages erforderliche Bestimmung fehlt. ${ }^{253}$ Ohne die Vervollständigung der Lücke darf eine angemessene, interessengerechte Lösung nicht zu erzielen sein. ${ }^{254}$ Zur Feststellung der Lücke sind neben den Interessen der Parteien auch Zweck und Ziel des Vertrages zu berücksichtigen. ${ }^{255}$ Demgegenüber ist das Vorliegen einer Regelungslücke zu verneinen, wenn die Parteien einen Punkt bewusst nicht geregelt haben, weil der Vertrag in dieser Hinsicht abschließend gemeint war. ${ }^{256}$ Dasselbe gilt auch dann, wenn es sich um einen schlicht unbilligen oder ungünstigen Vertrag handelt. ${ }^{257}$

Die Parteien des Inklusivspiel-Überlassungsvertrages haben eine Einigung über die dauerhafte Überlassung der Spielkopie des Inklusivspiels gegen die einmalige Entrichtung eines Entgelts getroffen. Sie haben jedoch die Frage offengelassen, ob der Publisher zum Support der Online-Komponenten auch rechtlich verpflichtet sein soll. Durch das Fehlen einer solchen Regelung wird der Regelungsplan des Rechtsgeschäfts - die Überlassung einer in vollem Umfang nutzbaren Spielkopie - gefährdet, da jederzeit der Support beendet und dadurch die Nutzungsmöglichkeit der Spielkopie ganz oder zum Teil wegfallen könnte.

Über die Frage, warum eine Regelung über den Support der Online-Komponenten im Vertrag nicht erfolgt ist, kann letztlich nur spekuliert werden; jedoch kommt es darauf nicht an. ${ }^{258}$ Zwar liegt es sicherlich im Interesse des Publishers, dass er nicht zum Support der Online-Komponenten des Inklusivspiels verpflichtet wird. Allerdings hat sich dieses Interesse in der Regel nicht zu einer diese Pflicht kategorisch ausschließenden „negative[n] Entscheidung“ verdichtet. ${ }^{259}$ So ergibt sich weder aus vorformulierten Vertragsbedingungen, etwaigen - in der Praxis ohnehin nicht stattfindenden - Vertragsverhandlungen ${ }^{260}$ noch aus einer anderen Regelung im Vertrag ${ }^{261}$, dass die Parteien darin übereingekommen sind, dass den Publisher keine Supportpflicht bzgl. des Inklusivspiels treffen soll.

253 BGH, NJW-RR 2007, 687, 690; NJW 2004, 1873, 1873; NJW 2013, 678, 679; vgl. NJW-RR 2005, 205, 206; Palandt/Ellenberger, § 157 BGB, Rn. 3; Finkenauer, AcP 2013, 619, 619 f.

BGH, NJW 2015, 1167, 1168; NJW 2015, 955, 957; NJW 2013, 678, 679; Staudinger/Roth, § 157 BGB, Rn. 15.

BGH, NJW 1990, 1723, 1724; NJW 1980, 2180, 2181; Staudinger/Roth, § 157 BGB, Rn. 17 mwN.

257 Zur Unerheblichkeit der Gründe für das Vorliegen einer Regelungslücke im Vertrag siehe Flume, BGB AT, S. 326; Staudinger/Roth, § 157 BGB, Rn. 19 mwN.

258 Siehe allgemein zur ergänzenden Vertragsauslegung BGH, NJW 1982, 2184, 2185; NJW 2004, 1590, 1591; BeckOK BGB/Wendtland, § 157 BGB, Rn. 36.

259 Vgl. hierzu BGH, NJW 1965, 1960, 1960.

260 Vgl. ebd.

261 Vgl. BGH, WM 1965, 1284, 1285. 
Zum Ausfüllen der Regelungslücke ist der sog. hypothetische Parteiwille zu ermitteln. Hierfür ist zu fragen, welche Regelung ,die Parteien bei angemessener Abwägung ihrer Interessen nach Treu und Glauben als redliche Vertragspartner getroffen hätten, wenn sie den von ihnen nicht geregelten Fall bedacht hätten““. ${ }^{262}$ Die Wertungen der Parteien sollen quasi ,,zu Ende gedacht““263 werden, weswegen die im Vertrag enthaltenen Grundentscheidungen und Wertungen der Parteien, ihre Interessenlage sowie der Sinn und Zweck des Vertrages eine zentrale Bedeutung für die Ermittlung des hypothetischen Parteiwillens haben. ${ }^{264}$

Die Rechtsprechung und Literatur ziehen zum Füllen der Regelungslücke auch objektive Kriterien wie die Verkehrssitte und Treu und Glauben heran. ${ }^{265}$ Die Verkehrssitte beschreibt „die im Verkehr tatsächlich herrschende Übung“. ${ }^{266}$ Einen Aspekt, welchen der BGH und Medicus unter dem Rechtsbegriff von Treu und Glauben im Rahmen der ergänzenden Vertragsauslegung diskutieren, ist die Unzumutbarkeit des Risikos, welches eine Partei für den Fall zu tragen hätte, dass die im Vertrag vorhandene Lücke nicht durch eine interessengerechte Regelung geschlossen wird. ${ }^{267}$ Grundsätzlich ist hierzu festzustellen, dass eine unbillige Risikoverteilung allein noch keinen Grund für eine Lückenfüllung darstellt und unter Umständen noch nicht einmal zu einer Regelungslücke im Vertrag führt. ${ }^{268}$ Anders kann der Fall jedoch liegen, wenn eine Partei in Folge der Regelungslücke mit einem unzumutbaren Risiko belastet wird. ${ }^{269}$

Um die dargestellten Grundsätze zum Ausfüllen der Regelungslücke näher zu konkretisieren, sollen im Folgenden Kriterien zur Feststellung des hypothetischen Parteiwillens des Publishers und des Erwerbers des Inklusivspiels ermittelt werden. Zu diesem Zweck sollen im Folgenden zwei Fallgruppen dargestellt werden, bei denen die Rechtsprechung und die Literatur in der Vergangenheit eine Pflicht zu fortdauernden Erhaltungsmaßnahmen des Veräußerers eines Produktes diskutiert haben. Dies betrifft

262 So im Wortlaut BGH, NJW 1981, 219, 220; NJW 1982, 2184, 2185; NJW 2004, 1590, 1591 f.; NJW 2013, 678, 679; vgl. außerdem NJW 1993, 3193, 3194; NJW 2004, 3413, 3416; Finkenauer, AcP 2013, 619, 621 f.; Staudinger/Roth, § 157 BGB, Rn. 30 mwN.

BGH, NJW 1993, 3193, 3194; Finkenauer, AcP 2013, 619, 623.

Vgl. BGH, NJW-RR 2013, 494, 495; NJW 2012, 526, 527; MüKo-BGB/Busche, § 157 BGB, Rn 47; Bork, BGB AT, Rn. 537; NK-BGB/Looschelders, § 157, Rn. 22.

BGH, NJW 1953, 937, 937; NJW 1984, 1177, 1178; Palandt/Ellenberger, § 157 BGB, Rn. 7; im Ergebnis auch Staudinger/Roth, § 157 BGB, Rn. 31; Medicus/Petersen, BGB AT, Rn. 343, welche die Verkehrssitte mit „Üblichkeit“ und Treu und Glauben mit „Billigkeit“ gleichsetzen.

Soergel/Wolf, § 157 BGB, Rn. 63; vgl. NK-BGB/Looschelders, § 157, Rn. 59.

Vgl. BGH, JZ 1977, 179, 180; Medicus/Petersen, BGB AT, Rn. 343.

So Jauernig/Mansel, § 157 BGB, Rn. 2; vgl. auch BGH, BB 1984, 694, 695, der jedoch nicht auf die Risikoverteilung, sondern allgemein auf die Unangemessenheit der Folgen eines Vertrages abstellt.

Vgl. BGH, JZ 1977, 179, 180, der entschied, dass eine Bindung eines Reisebüros an eine einmal getätigte Zimmerreservierung ohne Rücktrittsrecht als ein unangemessenes Risiko des Reisebüros anzusehen sei, da es häufig zu Stornierungen durch Reisegruppen komme. 
einerseits die Pflege von Software (dazu im Folgenden aa)) und andererseits die Lieferung von Ersatzteilen (dazu im Folgenden bb)).

\section{aa) Die Softwarepflege}

In der Literatur - und vereinzelt in der Rechtsprechung - wurde in der Vergangenheit die Frage diskutiert, ob der Veräußerer von Software neben der Überlassung des Programms auch zur Durchführung der Pflege der überlassenen Software verpflichtet ist.

Die Softwarepflege kann eine breite Palette ganz unterschiedlicher Leistungen umfassen. ${ }^{270}$ Ihnen allen ist jedoch gemein, dass sie die Erhaltung der Nutzungsmöglichkeit und die Beseitigung von Funktionsstörungen der Software bezwecken. ${ }^{271}$ Typische Leistungsgegenstände von Softwarepflegeverträgen sind dementsprechend die Behebung von Fehlern im Programm, die Aktualisierung und Weiterentwicklung der Software, aber auch Maßnahmen wie telefonische Hotlines und Schulungen, welche den Anwender des Programms unterstützen sollen. ${ }^{272}$

Üblicherweise wird die Softwarepflege bereits im Zusammenhang mit dem Erwerb der zu pflegenden Software vertraglich vereinbart. ${ }^{273}$ Die Literatur und vereinzelt auch die Rechtsprechung diskutieren für die Fälle, in denen keine derartige Vereinbarung getroffen wurde, ob und auf welcher Rechtsgrundlage der Veräußerer der Software dennoch die Pflege bzw. den Abschluss eines Pflegevertrages schuldet.

Im Zentrum dieser Diskussion steht die Frage, ob sich eine vertragliche Pflicht zur Pflege bzw. zum Abschluss eines Pflegevertrages aus dem Überlassungsvertrag selbst ergibt. Für eine entsprechende vertragliche Nebenpflicht sprechen sich das LG Köln ${ }^{274}$ sowie - wenn auch zum Teil zurückhaltend - verschiedene Literaturstimmen ${ }^{275}$ aus.

\section{(1) Das Urteil des LG Köln vom 16. 10. 1997}

In dem vom LG Köln entschiedenen Fall aus dem Jahr 1997 erwarb das klagende Unternehmen von der Beklagten die Rechte zur unbefristeten Nutzung verschiedener

270 Siehe für eine beispielhafte Aufzählung möglicher Leistungen Wieczorek, in Kilian/Heussen, Computerrechtshandbuch, Abschnitt 1, Teil 3, 32.5, Rn. 19 ff.

271 Ebd., Abschnitt 1, Teil 3, Rn. 191; NK-BGB/Schmidl, Anh. IV zu §§ 535-580a, Software-Vertragsrecht, Rn. 107; von dem Bussche/Schelinski, in Leupold/Glossner, Münchener Anwalts Handbuch IT-Recht, Teil 1, Rn. 407.

272 Vgl. dazu Wieczorek, in Kilian/Heussen, Computerrechtshandbuch, Abschnitt 1, Teil 3, 32.5, Rn. $19 \mathrm{ff}$.

273 Marly, Softwarerecht, Rn. 1033 f.; so für Individualsoftware, NK-BGB/Schmidl, Anh. IV zu $\S \S$ 535-580a, Software-Vertragsrecht, Rn. 115.

274 LG Köln, NJW-RR 1999, 1285 - Zeitliche Begrenzung von Software-Wartungsleistungen.

275 Zahrnt, CR 2000, 205, 206; ders., Computervertragsrecht, Kap. 14.2 (1); Kaufmann, CR 2005, 841, 845; nur bei Vorliegen besonderer Umstände: Fritzemeyer/Splittgerber, CR 2007, 209, 213; Gabriel/C. Cornels, ITRB 2008, 277, 279 f.; Redeker, IT-Recht, Rn. 675 f.; Bischof/Witzel, ITRB 2003, 31, 38; a. A. Moritz, CR 1999, 541, 542; Wieczorek, in Kilian/Heussen, Computerrechtshandbuch, Abschnitt 1, Teil 3, 32.5, Rn. 15; Bartsch, NJW 2002, 1526, 1530; differenzierend NK-BGB/Schmidl, Anh. IV zu §§ 535-580a, Software-Vertragsrecht, Rn. 120. 
Softwarepakete, welche zur Abwicklung der Kundenaufträge des Klägers eingesetzt werden sollten. ${ }^{276}$ Die Parteien stritten darüber, ob die Beklagte dazu berechtigt war, den zwischen ihr und der Klägerin zusätzlich abgeschlossenen „Wartungsvertrag“‘277 in Bezug auf die Softwarepakte zu kündigen.

In seiner Entscheidung ging das LG Köln zunächst auf die einem etwaigen Kündigungsrecht vorgelagerte Frage nach dem Bestehen einer Pflegepflicht ein. Es stellte hierzu fest, dass eine selbstständige leistungsbezogene Nebenpflicht zur ,Wartung für eine bestimmte Zeit" ${ }^{\text {278 }}$ Teil des Überlassungsvertrages sei. Das Gericht begründete dieses Ergebnis mit der Pflicht des Veräußerers zur Sicherung des vertraglichen Leistungserfolges. ${ }^{279}$ Dieser konnte nur gewährleistet werden, wenn der Hersteller der Software auch zur Wartung derselben verpflichtet war, da etwaige Störungen im Betriebsablauf, die ohne Wartung weder vermieden noch unverzüglich behoben worden wären, zu nicht unerheblichen Nachteilen für den Kläger geführt hätten. ${ }^{280}$ Zusätzlich vergleicht das Landgericht die Pflege von Software mit dem Vorhalten von Ersatzteilen für Industrieprodukte wie Kraftfahrzeuge. So seien Automobilhersteller verpflichtet, für einen bestimmten Zeitraum solche Ersatzteile vorrätig zu halten. ${ }^{281}$

\section{(2) Ansichten in der Literatur}

In der Literatur wird eine generelle Pflicht zur Pflege bzw. zum Abschluss eines Pflegevertrages zum Teil abgelehnt. ${ }^{282}$ Begründet wird dies damit, dass eine entsprechende Pflicht in unangemessener Weise in die Dispositionsfreiheit des Software-Herstellers eingreifen würde ${ }^{283}$ und der Erwerber der Software nicht schutzbedürftig sei, da er schließlich einen Pflegevertrag mit dem Hersteller aushandeln könnte ${ }^{284}$. Darüber hinaus wird der Vergleich, den das LG Köln zwischen der Bereithaltung von Ersatzteilen für Industrieprodukte und der Pflege von Software gezogen hat, kritisiert. Software verschleiße im Gegensatz zu Hardware nicht ${ }^{285}$ und die Softwarepflege erschöpfe

\footnotetext{
276 LG Köln, NJW-RR 1999, 1285, 1285.

277 Ebd.

278 Ebd., 1286.

279 Ebd.

280 Ebd.

281 Ebd.; siehe auch AG München, NJW 1970, 1852, 1852; Palandt/Grüneberg, § 242 BGB, Rn. 29; Palandt/Weidenkaff, § 433 BGB, Rn. 29.

282 Junker, NJW 2000, 1304, 1309; Bartsch, NJW 2002, 1526, 1530; Moritz, CR 1999, 541, 542; Wieczorek, in Kilian/Heussen, Computerrechtshandbuch, Abschnitt 1, Teil 3, 32.5, Rn. 15; NKBGB/Schmidl, Anh. IV zu $§ \S 535-580$ a, Software-Vertragsrecht, Rn. 118.

283 NK-BGB/Schmidl, Anh. IV zu $\S \S 535-580$ a, Software-Vertragsrecht, Rn. 118; vgl. Junker, NJW 2000, 1304, 1309.

284 NK-BGB/Schmidl, Anh. IV zu $§ \S 535-580$ a, Software-Vertragsrecht, Rn. 118; Bartsch, NJW $2002,1526,1530$.

285 Moritz, CR 1999, 541, 541f.
} 
sich auch nicht in einer bloßen Bereithaltung von Ersatzteilen, sondern in der Herbeiführung eines Wartungserfolges ${ }^{286}$.

Neuere Literaturstimmen sprechen sich im Gegensatz dazu dafür aus, dass im Falle des Fehlens einer vertraglichen Regelung eine Pflegepflicht im Einzelfall aufgrund einer entsprechenden Interessenabwägung bejaht werden könne. ${ }^{287}$ Abzuwägen seien die Interessen des Erwerbers an einer funktionstüchtigen Software mit den Interessen des Softwareherstellers, wobei hierbei vor allem seine personelle und sachliche Ausstattung sowie seine Dispositionsfreiheit von Bedeutung seien. ${ }^{288} \mathrm{Zu}$ berücksichtigen sei dabei, ob und inwiefern andere Marktteilnehmer zur gewünschten Softwarepflege in der Lage sind ${ }^{289}$ und in welchem Ausmaß die Nutzungsmöglichkeit der Software von der Pflege abhängt ${ }^{290}$. Eine Pflicht könne auch umso eher angenommen werden, je höher der Erwerbspreis für die Software ausfällt. ${ }^{291}$

Für die zuletzt genannte Ansicht spricht, dass sie aufgrund der anzuwendenden Interessenabwägung eher zu interessengerechten Ergebnissen gelangt als die erste Auffassung, welche eine vertraglich verankerte Pflege-Nebenpflicht kategorisch ausschließt.

$\mathrm{Zu}$ den Kriterien, die für die Interessenabwägung von Bedeutung sind, gehören somit die Dispositionsfreiheit der Parteien, der Grad der Abhängigkeit der Nutzungsmöglichkeit der Software von der jeweiligen - nicht geregelten - Leistung, die Höhe des Entgelts, welches der Erwerber als Gegenleistung für den Erwerb der Software erbracht hat, und die Möglichkeit des Erwerbers, die gewünschte Leistung auch von anderen Unternehmen am Markt zu erhalten.

\section{(3) Vergleich mit dem Support von Online-Komponenten}

Fraglich ist, ob die Kriterien der Literatur und Rechtsprechung zur Ermittlung einer nicht ausdrücklich geregelten Pflegepflicht auch für die Herleitung einer Pflicht zum Support der Online-Komponenten fruchtbar gemacht werden können. Dies setzt voraus, dass beide Sachverhalte - die Softwarepflege und der Support der Online-Komponenten - hinreichend ähnlich sind.

Auf den ersten Blick scheint es kaum Unterschiede zwischen der Softwarepflege und dem Support der Online-Komponenten zu geben. Beide Maßnahmen haben einen nicht unerheblichen Einfluss auf die Nutzungsmöglichkeit der Software.

Zwischen der - in durchaus vielfältigen Formen vorkommenden - Softwarepflege und dem Support der Online-Komponenten gibt es jedoch einen entscheidenden Unterschied. Die Softwarepflege dient der Sicherung des Leistungserfolges. Der Support

\footnotetext{
286 Junker, NJW 2000, 1304, 1309.

287 Gabriel/C. Cornels, ITRB 2008, 277, 279 f.; Grapentin/Ströbl, CR 2009, 137, 138; Fritzemeyer/Splittgerber, CR 2007, 209, 212 f.; Redeker, IT-Recht, Rn. 675 f. Grapentin/Ströbl, CR 2009, 137, 138.

289 Ebd., Fn. 3; Kaufmann, CR 2005, 841, 845; Fritzemeyer/Splittgerber, CR 2007, 209, 210.

290 Fritzemeyer/Splittgerber, CR 2007, 209, 210.

291 Vgl. Zahrnt, CR 2000, 205, 206; Kaufmann, CR 2005, 841, 845.
} 
der Online-Komponenten führt diesen dagegen erst herbei und ist damit Voraussetzung für diesen und dessen Absicherung. Der Support geht hinsichtlich seiner Tragweite und Auswirkungen für die Nutzungsmöglichkeit der Software somit weit über die bloße Pflege derselben hinaus. Während die Software grundsätzlich auch ohne Pflege zumindest für eine gewisse Zeit noch genutzt werden kann, entfällt jegliche oder zumindest die teilweise Nutzungsmöglichkeit derselben in dem Moment, in dem die Client-Server-Kommunikation unterbrochen wird. Die Auswirkungen des Supportendes treten also abrupt und umfassend ein, die des Pflegeendes dagegen schleichend.

Es ist daher folgerichtig, dass Literatur und Rechtsprechung eine Pflicht zur Pflege des Software-Herstellers über die Grundsätze des $§ 242$ BGB herleiten und nicht über die ergänzende Vertragsauslegung. Die Herleitung von vertraglichen Nebenpflichten über $§ 242$ BGB betrifft nämlich das Wie der Leistungserbringung. ${ }^{292}$ Leistungsbezogene Nebenpflichten haben den Sinn, die vertraglich geschuldete Hauptleistung abzusichern. ${ }^{293}$ Die ergänzende Vertragsauslegung dagegen betrifft das $O b$ der Leistung und damit die Frage, welcher Leistungserfolg überhaupt herbeigeführt werden soll. ${ }^{294}$

Damit wird deutlich, dass der Support der Online-Komponenten zwar Ähnlichkeiten mit der Softwarepflege aufweist, der Support den Leistungserfolg aber überhaupt erst herbeiführt, während die Pflege selbigen absichert.

Die Unterschiede zwischen Softwarepflege und Support der Online-Komponenten bedeuten jedoch nicht, dass die Kriterien, welche für die Herleitung einer vertraglichen Pflegepflicht herangezogen wurden, nicht auch für die Ermittlung einer Supportpflicht im Wege der ergänzenden Vertragsauslegung nutzbar gemacht werden können. Denn sowohl die Softwarepflege als auch der Support der Online-Komponenten sind auf die Nutzungsmöglichkeit der Software bezogen. Für eine Übertragbarkeit der Wertungen spricht auch ein Erst-Recht-Schluss. Denn wenn schon - bei einer fehlenden Vereinbarung - die Herleitung einer leistungssichernden (Pflege-)Nebenpflicht in Betracht kommt, muss dies erst recht für eine Pflicht gelten, die den Leistungserfolg überhaupt erst herbeiführt.

\section{bb) Die Lieferung von Ersatzteilen}

Eine weitere in der Literatur und vereinzelt auch in der Rechtsprechung diskutierte Frage ist, ob der Verkäufer bzw. Hersteller von Gegenständen dazu verpflichtet ist, dem Käufer Ersatzteile für diese Gegenstände zu liefern.

Die Frage wirft grundsätzlich keine rechtlichen Probleme auf, wenn sich die Vertragsparteien im Kauf- oder in einem separaten Vertrag auf eine solche Pflicht geeinigt haben. ${ }^{295}$ Sie wird jedoch in solchen Fällen relevant, in denen es an einer solchen Vereinbarung mangelt.

\footnotetext{
292 Vgl. Erman/Armbrüster, § 157 BGB, Rn. 3.

293 Medicus/Lorenz, SchR I AT, Rn. 109.

294 Erman/Armbrüster, § 157 BGB, Rn. 3.

295 Kühne, BB 1986, 1527, 1527.
} 
Dann könne nach der herrschenden Meinung - jedenfalls bei der Lieferung von langlebigen, teuren Kaufgegenständen, wie z. B. Kraftfahrzeugen - eine Ersatzteillieferungspflicht des Herstellers bzw. Verkäufers in Betracht kommen. ${ }^{296}$ Hierbei handle es sich entweder um eine nachvertragliche Pflicht aus dem Kaufvertrag ${ }^{297}$ oder um eine im Wege der ergänzenden Vertragsauslegung zu ermittelnden Pflicht ${ }^{298}$.

Die Ersatzteillieferungspflicht wird im Wesentlichen damit begründet, dass vor allem Erwerber komplexer Kaufsachen, die sich aus mehreren Einzelteilen zusammensetzen, darauf angewiesen seien, vom Verkäufer bzw. Hersteller Ersatzteile zu beziehen, weil sie diese weder selbst herstellen noch anderweitig beschaffen können. ${ }^{299}$ Dies gelte insbesondere dann, wenn der Hersteller in der Werbung oder anderweitig einen Vertrauenstatbestand dahingehend geschaffen hat, dass er Ersatzteile für das Produkt herstellen und liefern wird. ${ }^{300}$

Die Unterschiede zwischen der Lieferung von Ersatzteilen und dem Support der Online-Komponenten von Inklusivspielen liegen vor allem darin, dass die Ersatzteile nur eventuell und erst nach Verstreichen einiger Zeit benötigt werden, wohingegen der Erwerber des Inklusivspiels ohne Weiteres auf den Support der Online-Komponenten angewiesen ist.

Wie auch beim Erwerb der Ersatzteile gibt es für den Support der Online-Komponenten oftmals nur eine Quelle, welche diese Leistungen erbringen kann. In der Regel ist dies der Publisher oder ein von diesem beauftragtes Drittunternehmen. ${ }^{301}$ Die Abhängigkeit des Erwerbers vom Veräußerer ist damit ein Kriterium, das - wie auch bei der Frage nach einer Software-Pflegepflicht - für die Interessenabwägung im Rahmen der Ermittlung der Supportpflicht fruchtbar gemacht werden kann.

\section{cc) Ausfüllen der Regelungslücke}

Unter Anwendung der soeben ermittelten Kriterien soll im Folgenden geprüft werden, ob die im Inklusivspiel-Überlassungsvertrag festgestellte Lücke ${ }^{302}$ derart geschlossen werden kann, dass den Publisher eine Pflicht zum Support der Online-Komponenten des Inklusivspiels trifft.

296 AG München, NJW 1970, 1852, 1852; Soergel/Huber, Anh I § 433 BGB, Rn. 26; Palandt/Grüneberg, § 242 BGB, Rn. 29; Ramm, Fortwirkung, S. 66 ff.; Kühne, BB 1986, 1527, 1528;

Rodig, BB 1971, 854, 855; Finger, NJW 1970, 2049, 2050 ff.; Greulich, BB 1955, 208, 210 ; keine generelle Pflicht: Ullrich/Ulbrich, BB 1995, 371, 372; Staudinger/Beckmann, § 433 BGB, Rn. 165.

297 Staudinger/Beckmann, § 433 BGB, Rn. 165; Palandt/Weidenkaff, § 433 BGB, Rn. 29 f.; AG München, NJW 1970, 1852, 1852; Finger, NJW 1970, 2049, 2050; Greulich, BB 1955, 208, 209.

Vgl. Soergel/Huber, Anh I § 433 BGB, Rn. 26; Rodig, BB 1971, 854, 854; Welters, Obsoleszenz, S. 54 f.

299 Vgl. statt vieler nur Kühne, BB 1986, 1527, 1528; Ramm, Fortwirkung, S. 68 f.

300 Ramm, Fortwirkung, S. 68 f.

301 Siehe dazu oben, S. 3.

302 Siehe dazu oben, S. 44 f. 


\section{(1) Interessengerechte Auslegung}

Ausgangspunkt für das Ausfüllen der Regelungslücke ist der enge funktionelle Zusammenhang zwischen der Spielkopie und den Online-Komponenten, der darin besteht, dass im Falle des Fehlens des Supports das Inklusivspiel ganz oder teilweise nicht mehr genutzt werden kann. Es besteht damit eine sehr hohe Abhängigkeit der Nutzungsmöglichkeit der Spielkopie von der nicht geregelten Leistung (dem Support der Online-Komponenten). Dieser Aspekt spricht bereits für eine Regelungsbedürftigkeit des Supports der Online-Komponenten.

Hinzu kommt, dass aus Sicht des Erwerbers das von ihm zu entrichtende Entgelt die Gegenleistung sowohl für die Überlassung des Spielclients als auch für den Support der Online-Komponenten darstellt. Dies ergibt sich zum einen daraus, dass es bei Inklusivspielen üblich ist, das gesamte Spiel, einschließlich des Online-Mehrspielermodus nach Erwerb des Spielclients nutzen zu können. Es ist außerdem keine weitere Gegenleistung des Erwerbers für die Nutzung des Spiels oder für den Support seiner Online-Komponenten erforderlich. Der Erwerber des Inklusivspiels hat daher die berechtigte Leistungserwartung, dass ihm das Spiel samt Support der Online-Komponenten nach dem Erwerb zur Verfügung steht. Die Verneinung einer Supportpflicht bei Inklusivspielen stünde im Widerspruch zu dieser Leistungserwartung und gefährdete darüber hinaus das Äquivalenzinteresse des Erwerbers, da er ohne Support nur mit einer weitgehend wert- und funktionslosen Spielkopie zurückbliebe.

Hinzu kommt, dass der Publisher in aller Regel das einzige Unternehmen ist, welches dazu in der Lage ist, den Support der Online-Komponenten zu erbringen. Es ist nicht bekannt, dass Käufer eines Inklusivspiels ohne Einverständnis des Publishers Dritte mit dem Support der Online-Komponenten ${ }^{303}$ beauftragen könnten. Der Erwerber des Inklusivspiels ist also in besonderem Maße auf die Support-Leistung des Publishers des Inklusivspiels angewiesen. Die Aufbürdung des Risikos des vollständigen Funktions- und Wertverlustes ist für den Erwerber der Spielkopie somit mangels anderweitiger „Supportalternativen“ unzumutbar.

Gegen eine Supportpflicht könnte zwar sprechen, dass Inklusivspiele grundsätzlich und vor allem im Vergleich mit komplexer Firmen- und Industriesoftware im unteren Preissegment anzusiedeln ist. Die Literatur und Rechtsprechung hat eine Pflegepflicht schließlich eher bei hochpreisiger Software bejaht. ${ }^{304}$ Es ist aber nicht einzusehen, warum der Support der Online-Komponenten nur bei hochpreisiger Software verpflichtend sein soll. Es würde sich dann nämlich die Frage stellen, wo man die Grenze zwischen ,hochpreisiger“ und ,günstiger“ Software zieht. Im Vergleich zu komplexer Firmen- und Industriesoftware sind digitale Spiele immer weitaus günstiger. Dies hätte zur Folge, dass eine ganze Kategorie von Produkten per se von der Herleitung einer Supportpflicht im Wege der ergänzenden Vertragsauslegung ausgeschlossen wäre.

Darüber hinaus spielt die Dispositionsfreiheit für den Erwerber des Inklusivspiels nur eine sehr untergeordnete Rolle. Denn der Erwerber kann faktisch ohnehin keine

303 Ausgenommen von dieser Aussage sind Dedicated Games-Server, die durchaus von Drittfirmen betrieben werden und mit denen der Käufer eines Inklusivspiels - unabhängig vom Publisher bzw. Entwickler - ein vertragliches Verhältnis eingehen kann.

Siehe dazu oben, S. $48 \mathrm{f}$. 
Regelungen mit dem Publisher in Bezug auf den Support der Online-Komponenten aushandeln. Die Vertragsparteien daher darauf zu verweisen, eine ausdrückliche Regelung zum Support der Online-Komponenten selbstständig auszuhandeln und in den Überlassungsvertrag aufzunehmen, wäre realitätsfremd.

Trotz der nicht unwesentlichen Kosten, die mit dem Support der Online-Komponenten für den Publisher verbunden sind ${ }^{305}$, ist die Aufnahme einer Pflicht zur Etablierung und Aufrechterhaltung der Client-Server-Kommunikation im Überlassungsvertrag für den Publisher auch nicht unzumutbar. Er hat es schließlich selbst in der Hand, zu bestimmen, wie viele Vervielfältigungsstücke des Spiels in Verkehr gebracht werden bzw. mit wie vielen Erwerbern er einen Überlassungsvertrag abschließt.

Die hohe Abhängigkeit der Nutzungsmöglichkeit des Inklusivspielclients vom nicht geregelten Support der Online-Komponenten, die berechtigte Leistungserwartung des Käufers, die fehlenden „Supportalternativen“ und die praktische Unfähigkeit des Erwerbers, mit dem Publisher den Support vertraglich zu regeln, sprechen für die Herleitung einer Supportpflicht im Überlassungsvertrag.

\section{(2) Entgegenstehende Vereinbarungen}

In Rechtsprechung und Literatur findet sich die Einschränkung, dass die ergänzende Vertragsauslegung nicht zu einer Abänderung oder Erweiterung des Vertragsgegenstandes führen dürfe. ${ }^{306}$ Diese Schranke dient dem Schutz des Parteiwillens und der Privatautonomie der Parteien. ${ }^{307}$ Das Verbot der Erweiterung des Vertragsgegenstandes meint aber nicht, dass es unzulässig ist, eine neue Regelung oder eine neue Pflicht einer Partei im Wege der ergänzenden Auslegung zu ermitteln. Gemeint ist damit vielmehr, dass die ergänzende Vertragsauslegung nicht die Grenze des Regelungsplans des Vertrages der Parteien überschreiten darf. ${ }^{308}$ Diese Grenze ist überschritten, wenn die Auslegung zu einem Ergebnis führt, welches im Widerspruch zum Willen der Parteien steht. ${ }^{309}$ In Bezug auf Inklusivspiele ist es insofern denkbar, dass in den Überlassungsvertrag seitens des Publishers eine Regelung aufgenommen wird, nach der kein vertraglicher Anspruch auf den Support der Online-Komponenten des Spiels begründet werden soll.

Der generelle Ausschluss einer Pflicht zum Support der Online-Komponenten eines Inklusivspiels wird in der Regel aber gegen $\S 307$ Abs. 1 BGB verstoßen und damit unwirksam sein. Eine derartige Klausel benachteiligt den Erwerber des Inklusivspiels unangemessen, da sie sein Äquivalenzinteresse gefährdet und ihn dem Risiko aussetzt,

\footnotetext{
305 Siehe dazu oben, S. $18 \mathrm{f}$.

306 BGH, NJW-RR 2015, 183, 185; NJW 2009, 1482, 1484; NJW 1953, 937, 937; MüKo-BGB/Busche, § 157 BGB, Rn. 56; Staudinger/Roth, § 157 BGB, Rn. 39; Palandt/Ellenberger, § 157 BGB, Rn. 9.

307 Staudinger/Roth, § 157 BGB, Rn. 39; vgl. Soergel/Wolf, § 157 BGB, Rn. 125 ff.; MüKo$\mathrm{BGB} /$ Busche, $\S 157 \mathrm{BGB}, \mathrm{Rn} .55$.

308 Finkenauer, AcP 2013, 619, 629; Staudinger/Roth, § 157 BGB, Rn. 42; Ehricke, RabelsZ 1996, 661, 688.

309 Ehricke, RabelsZ 1996, 661, 688; vgl. Medicus/Petersen, BGB AT, Rn. 344.
} 
dass die einmal erworbene Spielkopie in Gänze nicht mehr genutzt werden kann und damit vollständig an Wert verliert. Das Gleiche gilt - jedenfalls für Inklusivspiele für etwaige Regelungen, nach denen eine Supportpflicht erst in einer später zu treffenden Vereinbarung entstehen soll.

\section{c) Verhältnis der Supportpflicht zu gesonderten Regeln}

Es ist bereits angesprochen worden, dass der Erwerber der Spielkopie nicht nur einen Überlassungsvertrag abschließt, sondern auch gesonderten Regeln und Bestimmungen des Publishers zustimmen muss, wie z. B. dem EULA. ${ }^{310}$ Darüber hinaus kann es erforderlich werden, dass der Erwerber einen Spieler-Account einrichtet, mit dem er sich jedes Mal neu einloggen muss, wenn er das Spiel nutzen möchte.

Oftmals kann der Spieler auf das Spiel bzw. bestimmte spielbezogene Online-Komponenten desselben gar nicht erst zugreifen, wenn er einen solchen Account nicht einrichtet bzw. den genannten Regelwerken nicht zustimmt. Andererseits hat der Spieler jedoch schon - wie soeben festgestellt - mit dem Erwerb des Inklusivspiels einen Anspruch auf den Support der Online-Komponenten und damit auf die Nutzung derselben erworben. Damit stellt sich die Frage, wie sich die bereits aus dem Überlassungsvertrag mit dem Direktverkäufer ergebende Supportpflicht zu diesen gesonderten Regelwerken verhält.

Hierfür ist zunächst zu beachten, dass sowohl der Spieler als auch der Publisher ein vitales Interesse daran haben, dass das Spiel von Störungen und Manipulationen, die durch Mitspieler verursacht werden, nicht beeinträchtigt wird. Es muss dem Publisher daher möglich sein, die Spieler an Spielregeln und Nutzungsbeschränkungen zu binden sowie die ordnungsgemäße Verwendung des Spiels samt seinen Online-Komponenten zu kontrollieren. Zu diesem Zweck dienen Vereinbarungen wie das EULA und andere Regelwerke, denen der Spieler unter Umständen zustimmen muss.

Sofern der Spieler diesen Regelwerken bereits zum Zeitpunkt des Abschlusses des Überlassungsvertrages zustimmen muss, ergeben sich - sofern die Voraussetzungen der $\S \S 305$ ff. BGB erfüllt sind - in rechtlicher Hinsicht grundsätzlich keine weiteren Probleme. Denn hier fällt die Entstehung der Supportpflicht mit der Zustimmung zu den genannten Regelwerken zusammen.

Problematisch kann jedoch der Fall sein, in welchem beide Ereignisse auseinanderfallen. Es ist vorstellbar, dass der Publisher die Nutzung bestimmter Online-Komponenten von der Zustimmung zu weiteren Regeln abhängig macht, wobei die Einsichtnahme in diese Regeln und die Zustimmung dazu erst nach der Installation des Spiels ermöglicht wird.

Fraglich ist, ob die Zustimmung zu den gesonderten Regelwerken bzw. die Einrichtung eines Accounts als eine aufschiebende Bedingung ( $\$ 158$ Abs. 1 BGB) angesehen werden kann mit der Folge, dass der im Überlassungsvertrag entstandene Anspruch auf den Support der Online-Komponenten erst ab dem Eintritt der Bedingung ${ }^{311}$ geltend gemacht werden kann.

\footnotetext{
310 Siehe dazu oben, S. 35.

311 Vgl. MüKo BGB/Westermann, § 158 BGB, Rn. 40.
} 
Die Pflicht zur Erbringung des Supports des Online-Mehrspielermodus kann durchaus unter der aufschiebenden Bedingung der Zustimmung zu gesonderten Regelwerken vereinbart werden. Hierfür spricht einerseits das Interesse sowohl des Publishers als auch des Spielers an einer kontrollierten sowie bestimmten Regeln unterworfenen Nutzung der spielbezogenen Online-Komponenten durch alle Nutzer. Zu beachten ist jedoch, dass der Erwerber des digitalen Spiels auf die Notwendigkeit der Zustimmung $\mathrm{zu}$ den gesonderten Regelwerken ausdrücklich hingewiesen werden und er diesem Erfordernis bei Erwerb des Spielclients - und damit beim Erwerb des aufschiebend bedingten Supportanspruchs - zugestimmt haben muss. Dies ergibt sich nunmehr aus Art. 8 Abs. 5 sowie aus Erwägungsgrund 53 der DI-RL. Hiernach kann das Erfordernis der Zustimmung zu gesonderten Regelwerken eine Beschränkung der Nutzung des digitalen Inhalts bedeuten, die nicht mehr vertragsgemäß ist und damit gegen Art. 8 DIRL verstößt. ${ }^{312}$

Ganz anders verhält es sich allerdings mit den Online-DRM-Systemen. Hierzu gehören die Software-Aktivierung, die bei jedem Spielstart erforderliche Anmeldung mit einem Spieler-Account und die in regelmäßigen Abständen erfolgende Authentifizierung der Spielkopie im Laufe des Spiels. ${ }^{313}$ Diese Online-Komponenten begegnen dem Spieler bereits bei der Installation und können darüber hinaus das gesamte Spielerlebnis beeinflussen, unabhängig davon, ob spielbezogene Online-Komponenten genutzt werden oder nicht. Es widerspräche den Interessen des Erwerbers des Inklusivspiels, wenn ein Anspruch auf Support dieser Art der Online-Komponenten aufschiebend bedingt wäre, da er von vornherein vom Support dieser Funktionen abhängig ist. Erfolgt der Support nicht, fällt die Nutzungsmöglichkeit des Spiels weg und der Erwerber gelangt unter Umständen nicht einmal mehr zu dem Punkt im Spiel, wo er gesonderten Regelungen zustimmen kann. Der Anspruch auf den Support der Online-DRM-Systeme ist damit bedingungsfeindlich und entsteht unbedingt.

\section{Der Händlervertrieb}

Der Vertrieb von Inklusivspielen wird nicht nur von Publishern vorgenommen. Es ist weit verbreitet, dass auch Händler digitale Spiele an Endabnehmer veräußern. ${ }^{314}$ Sie sind sowohl im Internet anzutreffen als auch in Form von spezialisierten Fachgeschäften oder allgemeinen Elektronikmärkten.

Fraglich ist hier, wer gegenüber dem Erwerber zum Support der Online-Komponenten des digitalen Spiels verpflichtet ist.

In eher seltenen Fällen kann der Händler zum Support verpflichtet sein (dazu 1.), häufiger wird jedoch den Publisher die Pflicht zum Support treffen (dazu 2.).

\footnotetext{
312 Vgl. Ehle/Kreß, CR 2019, 723, 724.

313 Siehe dazu auch oben, S. $19 \mathrm{ff}$.

314 Vgl. Moser, Browsergames, S. 70 f.
} 


\section{Supportpflicht des Händlers}

Es ist durchaus möglich, dass der Händler, welcher digitale Spiele an Endabnehmer veräußert, zum Support des Online-Mehrspielermodus bzw. der Online-DRM-Systeme dieser Spiele verpflichtet ist.

Da es sich bei den Online-Komponenten digitaler Spiele um separate, vom digitalen Spiel zu trennende digitale Inhalte bzw. digitale Dienstleistungen handelt ${ }^{315}$, ergibt sich eine Pflicht des Händlers zum Support der Online-Komponenten nicht ohne Weiteres aus Art. 5 DI-RL aufgrund der Tatsache, dass dieser das digitale Spiel dem Erwerber überlässt. Eine Pflicht des Händlers zum Support der Online-Komponenten ergibt sich nur dann, wenn die Umstände des Einzelfalles auch für eine solche Verpflichtung sprechen.

Um dies festzustellen, ist die zwischen dem Händler und dem Erwerber abgeschlossene Vereinbarung - wie auch der Vertrag im Direktvertrieb zwischen Publisher und Erwerber - (ergänzend) auszulegen. ${ }^{316}$

Eine Pflicht des Händlers zum Support der Online-Komponenten kommt aber grundsätzlich bereits dann nicht in Betracht, wenn er für den Support rein tatsächlich nicht zuständig ist bzw. zuständig sein kann. Die folgenden Kriterien können herangezogen werden, um eine Zuständigkeit des Händlers für den Support zu bejahen oder zu verneinen.

Für eine Support-Zuständigkeit des Händlers spricht es, wenn er eine spielspezifische Online-Vertriebsplattform betreibt und für die Nutzung der Spiele die Installation gesonderter Software und die Einrichtung eines Spieler-Accounts verlangt. ${ }^{317}$ Ein Beispiel hierfür stellt die Internet-Vertriebsplattform Steam dar, auf welcher digitale Spiele zum Download angeboten werden. Wie bereits oben erläutert ${ }^{318}$, übernimmt der Betreiber dieser Plattform zum Teil auch den Support für die Masterserver, die für die Verbindung des Spielclients zu den jeweiligen Dedicated Game-Servern erforderlich sind.

Gegen eine Zuständigkeit des Händlers zum Support der Online-Komponenten kann im Einzelfall angeführt werden, dass der Händler mit dem Erwerber des Spiels nur zum Zeitpunkt des Erwerbs und auch dann nur in anonymisierter Form in Kontakt kommt. Denn in solchen - insbesondere für Ladengeschäfte typischen - Fällen will der Ladenbetreiber lediglich das Spiel veräußern, jedoch nicht darüber hinausgehende Maßnahmen wie den Support der Online-Komponenten übernehmen, wozu er regelmäßig auch kaum in der Lage sein wird.

Diese Aspekte können jedoch allenfalls eine Richtschnur bieten für die Frage, ob im Einzelfall der Händler oder der Publisher des digitalen Spiels den Support der OnlineKomponenten übernimmt. Für eine abschließende Beurteilung kommt es auf die Umstände des Einzelfalles an.

315 Siehe dazu oben, S. $40 \mathrm{ff}$.

316 Siehe dazu oben, S. $42 \mathrm{ff}$.

317 Vgl. hierzu das Steam Subscriber Agreement, abrufbar unter http://store.steampowered.com/subscriber_agreement/.

318 Siehe dazu oben, S. 3. 


\section{Supportpflicht des Publishers}

Die Veräußerung des Spiels wird hier vom Händler vorgenommen, der Support der Online-Komponenten jedoch vom Publisher des Spiels. Zusammen mit dem Erwerber des Spielclients sind in dieser Konstellation also - im Gegensatz zum Direktvertrieb drei Personen beteiligt. Es stellt sich damit die Frage, ob und woraus der Erwerber der Spielkopie einen Anspruch auf den Support der Online-Komponenten gegen den Publisher erwirbt.

\section{a) Abtretung oder Vertrag zugunsten Dritter}

Es ist möglich, dass der Händler vom Publisher einen Anspruch auf den Support der Online-Komponenten erworben hat, den er an den Erwerber des Inklusivspiels gemäß $\S 398$ BGB abtritt. ${ }^{319}$ Als Kausalgeschäft für die Abtretung kommt dabei der zwischen dem Händler und dem Erwerber abgeschlossene Überlassungsvertrag über das Inklusivspiel in Betracht.

Wenngleich in Einzelfällen ein derartiger Erwerb des Anspruchs auf den Support der Online-Komponenten durch den Endabnehmer zumindest im Prinzip möglich ist, dürfte die Annahme einer Abtretung überwiegend zu verneinen sein.

Erstens ist es für den Endabnehmer nicht ersichtlich, ob er tatsächlich vom Händler einen solchen Anspruch im Zusammenhang mit dem Erwerb des Inklusivspiels bekommt. Der Händler trifft hierüber in der Regel keine Aussage und es sind grundsätzlich auch sonst keinerlei Anhaltspunkte dafür erkennbar, dass eine solche Abtretung tatsächlich stattfindet. Zweitens liefe der Erwerber Gefahr, den Anspruch nicht abgetreten zu bekommen, falls er überhaupt nicht vom Publisher an den Händler abgetreten wurde. Ein gutgläubiger Erwerb von Forderungen ist grundsätzlich nicht möglich. ${ }^{320}$ Drittens ist auch zu bezweifeln, ob sich der Händler bzw. seine Erfüllungsgehilfen bei jedem einzelnen digitalen Spiel darüber im Klaren sind, ob eine Abtretung von Support-Ansprüchen erforderlich ist.

Schließlich ist auch ein Erwerb des Anspruchs auf Support der Online-Komponenten auf Grundlage eines Vertrages zwischen dem Händler und dem Publisher zugunsten des Endabnehmers gemäß $§ 328$ Abs. 1 BGB möglich. Doch auch hier wird der Erwerber in der Regel keine Kenntnis darüber haben, ob zwischen Letzterem und dem Publisher ein solcher Vertrag tatsächlich abgeschlossen wurde. Hinzu kommt, dass bei einem Vertrag zugunsten des Endabnehmers stets die Gefahr besteht, dass dieser seine Drittberechtigung wieder verliert, ohne dafür verantwortlich zu sein. Denn im Falle einer Leistungsstörung aufseiten des Versprechensempfängers - in diesem Fall der Händler - ist es nicht ausgeschlossen, dass der Versprechende - also der Publisher den das Deckungsverhältnis bildenden Vertrag beendet, bspw. im Wege des Rücktritts. $^{321}$

\footnotetext{
319 So für einen Anspruch des Standard-Software-Erwerbers gegen den Hersteller auf Mitwirkung an der Software-Aktivierung Faust, K\&R 2002, 583, 586.

320 BeckOK BGB/Rohe, § 398 BGB, Rn. 30.

321 Vgl. MüKo BGB/Gottwald, § 334 BGB, Rn. 5.
} 
Diese Unsicherheiten der Begründung eines Anspruchs durch Abtretung oder Vertrag zugunsten Dritter verdeutlichen das Bedürfnis des Endabnehmers nach einem direkten Vertragsverhältnis mit dem Publisher des Spiels.

\section{b) Multipolar-mehrseitiger Austauschvertrag}

Im Gegensatz zum Direktvertrieb sind beim Händlervertrieb von Inklusivspielen drei Parteien zu berücksichtigen: der Händler, der Publisher und der Erwerber des Inklusivspiels. Würde man die Supportpflicht also als Teil des Überlassungsvertrages ansehen, hätte dies zur Folge, dass ein einziger Vertrag vorliegt, an dem drei Personen beteiligt sind, welche jede für sich unterschiedliche Interessen verfolgt.

Derartige Vereinbarungen werden auch multipolar-mehrseitige (Austausch-)Verträge genannt. ${ }^{322}$ Sie zeichnen sich im Gegensatz zu den weitaus verbreiteteren zweiseitigen Verträgen dadurch aus, dass an ihnen mindestens drei Personen beteiligt sind und jede dieser Personen eine eigenständige Rechtsposition bzw. ein eigenes „Lager“ einnimmt. ${ }^{323}$ Damit wird auch die Abgrenzung dieser Vereinbarungen zu Gesellschaftsverträgen klar: die Vertragsparteien multipolar-mehrseitiger Verträge erbringen ihre Leistungen nicht zur Verfolgung eines gemeinsamen Zwecks, sondern tauschen sie untereinander aus - wie auch bei herkömmlichen gegenseitigen Verträgen üblich. ${ }^{324}$ Grundsätzlich ist eine solche Multipolarität auch in der hiesigen Parteienkonstellation zu erkennen. Der Händler will dem Erwerber den Spielclient überlassen und im Gegenzug dafür ein Entgelt erhalten. Der Publisher will den Support der OnlineKomponenten als Gegenleistung für ein Entgelt erbringen. Der Erwerber wiederum entrichtet das Entgelt für beide Leistungen, also für den Erhalt des Spielclients sowie für den Support der Online-Komponenten. Dennoch ist aus den folgenden Gründen die Zusammenfassung der Überlassungs- und der Supportpflicht zu einem multipolarmehrseitigen Vertrag abzulehnen.

Mehrseitige Verträge kommen erst zustande, wenn zwischen allen Parteien Willenserklärungen ausgetauscht worden sind, da ansonsten ein Vertragsschluss bereits zu einem Zeitpunkt bejaht werden könnte, an dem mindestens noch einer Partei keine Willenserklärung einer anderen Partei zugegangen ist. ${ }^{325}$ Hier fehlt es aber an einem Austausch von Willenserklärungen zwischen dem Händler und dem Publisher. Zwar wird es zwischen diesen Personen vertragliche Beziehungen geben, jedoch sind diese verschieden von dem konkreten Überlassungs- bzw. Supportvertrag mit dem Kunden.

Hinzu kommt, dass mehrseitige Verträge auf längere Zeit abgeschlossen werden und sich eher für die Regelung von Sachverhalten eignen, die vom Vertrauen der beteiligten Parteien zueinander gekennzeichnet sind. ${ }^{326}$ Ein solches Vertrauensverhältnis erscheint jedoch zumindest im Hinblick auf die Beziehung zwischen dem Erwerber und

322 Zwanzger, Der mehrseitige Vertrag, S. 9 f.; vgl. Luber, Austauschvertrag, S. 10; Gernhuber, Hdb. SchR, S. 326.

323 Zwanzger, Der mehrseitige Vertrag, S. 9 f.

324 Larenz, LBS Band 1, AT, S. 209.

325 Ausführlich dazu Zwanzger, Der mehrseitige Vertrag, S. $143 \mathrm{f}$.

326 Ebd., S. 94. 
dem Händler fraglich. Der Händler ist darauf aus, den Vertrag mit seinem Kunden möglichst schnell abzuwickeln und keine längerfristige vertragliche Bindung mit diesem einzugehen. Bei der Veräußerung von Inklusivspielen handelt es sich um Massengeschäfte, bei denen der Händler die Identität des Kunden oft noch nicht einmal kennt und es ihm auf diese Kenntnis auch nicht ankommt.

Mithin liegen zwei getrennte Verträge vor, einerseits ein Überlassungsvertrag zwischen Kunde und Händler, andererseits ein Vertrag zwischen dem Publisher und dem Erwerber, welcher die Pflicht des Publishers zum Support der Online-Komponenten enthält (im Folgenden „Supportvertrag“).

\section{c) Zustandekommen des Supportvertrages}

Problematisch ist, dass im Falle des Händlervertriebs der Publisher - jedenfalls persönlich - nicht am Abschluss des Software-Überlassungsvertrages beteiligt ist und sich damit die Frage stellt, ob und auf welche Weise ein Vertrag zwischen dem Publisher und dem Erwerber der Software über den Supportvertrag zustande kommt.

Es ist zum einen denkbar, dass der Händler als Stellvertreter des Publishers fungiert und mit seiner Hilfe der Supportvertrag zustande kommt (dazu aa)). Alternativ ist es möglich, dass der Supportvertrag zwischen dem Publisher und dem Erwerber direkt abgeschlossen wird, ohne dass der Händler dabei als Stellvertreter in Erscheinung tritt (dazu bb)).

\section{aa) Der Händler als Stellvertreter oder Bote}

Die Frage, ob bei Verträgen, welche zwischen dem Hersteller einer Software und ihrem Erwerber zustande kommen sollen, der Händler als Stellvertreter tätig wird, kam in der Vergangenheit bei den sog. Shrinkwrap-, Click- bzw. Enter-Vereinbarungen auf. Hierbei handelt es sich um Vereinbarungen, welche die Nutzungsbefugnisse des Software-Erwerbers mit Blick auf die gekaufte Software beschränken sollen. ${ }^{327}$

Die Besonderheit dieser Verträge liegt darin, dass sie nach der Intention des Herstellers nach Vornahme bestimmter Handlungen des Erwerbers zustande kommen sollen, wie dem Aufreißen der Softwareverpackung, dem Mausklick auf einem „Akzeptieren"-Button oder dem Betätigen der Enter-Taste.

Diskutiert wird dabei, ob es überhaupt zu dem gewünschten Vertragsschluss kommt ${ }^{328}$ und ob die als AGB einzuordnenden Nutzungsbeschränkungen in den Überlassungsvertrag einbezogen werden und Wirkung entfalten ${ }^{329}$.

327 Schuhmacher, CR 2000, 641, 641; Lejeune, ITRB 2001, 263, 263; ausführlich dazu Schubert, Schutzhüllenverträge, S. 15 ff.; Söder, Schutzhüllenverträge, S. 37 ff.; Sickinger, Standardsoftware, S. 78.

328 Söder, Schutzhüllenverträge, S. 88 ff.; Schubert, Schutzhüllenverträge, S. 309 ff.; Sickinger, Standardsoftware, S. 81 ff.; Marly, Softwarerecht, Rn. 999 ff.; Schuhmacher, CR 2000, 641, $642 \mathrm{f}$.

329 Söder, Schutzhüllenverträge, S. 127 ff.; Schuhmacher, CR 2000, 641, 644 ff. 
Mit Blick auf das Zustandekommen des Vertrages lehnt die überwiegende Literatur das Tätigwerden des Händlers als Stellvertreter des Softwareherstellers ab. ${ }^{330}$ Begründet wird dies zum einen damit, dass aufgrund des Offenkundigkeitsprinzips die Stellvertretung des Händlers für den Erwerber eindeutig ersichtlich werden müsse - entweder ausdrücklich oder aus den Umständen. ${ }^{331}$ Ein ausdrücklicher Hinweis auf die Stellvertretung sei aber als AGB einzuordnen und überraschend im Sinne des $\S 305 \mathrm{c}$ Abs. 1 BGB. ${ }^{332}$

Darüber hinaus sprächen der äußere Anschein sowie die berechtigten Erwartungen des Erwerbers regelmäßig gegen eine Stellvertretung des Händlers. ${ }^{333}$ Der Händler selbst habe außerdem kein Interesse daran, für den Hersteller der Software als Stellvertreter zu fungieren, da er die Verträge mit den Endkunden zügig und ohne Komplikationen abwickeln wolle. ${ }^{334}$ Diesem Ziel widerspräche eine Stellvertreterstellung, welche nicht unerhebliche logistische Herausforderungen mit sich bringen würde, da der Händler für jedes einzelne Softwareprodukt mit Vertretungsmacht ausgestattet werden und auf den Abschluss inhaltlich vorgeschriebener Verträge achten müsste. ${ }^{335}$ Es bestünde für den Händler außerdem stets das Risiko, dass das Rechtsgeschäft als ein solches des Händlers gilt, wenn die Voraussetzungen des Offenkundigkeitsprinzips nicht eingehalten wurden, wobei dem Händler aufgrund der Regelung des § 164 Abs. 2 BGB auch keine Möglichkeit zur Anfechtung dieses Rechtsgeschäfts zusteht. ${ }^{336}$

Dieser Ansicht ist zu folgen. Die Interessen des Händlers und das äußere Erscheinungsbild des Auftretens desselben gegenüber dem Erwerber der Software sprechen gegen eine Einordnung des Händlers als Stellvertreter des Herstellers mit Blick auf den Shrinkwrap-, Click- bzw. Entervertrag.

Diese Wertungen lassen sich auch auf den Supportvertrag übertragen. Auch beim Supportvertrag fehlt es sowohl an ausdrücklichen Erklärungen als auch an Umständen, aus denen sich ergeben könnte, dass der Händler als Stellvertreter beim Abschluss dieser Vereinbarung fungiert. Es bestünde ebenfalls das Risiko, dass der Händler bei mangelnder Offenkundigkeit Gefahr laufen würde, den Supportvertrag als ein Eigengeschäft abzuschließen, woran der Händler kein Interesse haben wird, da er zum Support - wie bereits ausgeführt - regelmäßig nicht in der Lage ist.

Zwar ist es denkbar, dass der Händler als Bote des Herstellers bzw. des Erwerbers der Software auftritt, jedoch sprechen auch hier logistische Herausforderungen gegen

330 Söder, Schutzhüllenverträge, S. 90; Loewenheim, in FS Kitagawa, S. 953; Schuhmacher, CR 2000, 641, 642; Runte, CR 2001, 657, 660; Baus, Verwendungsbeschränkungen, S. 46; Sickinger, Standardsoftware, S. 79 f.; a. A. Marly, Softwarerecht, Rn. 1010, der nunmehr vom Vorliegen einer Anscheinsvollmacht des Händlers ausgeht.

331 Söder, Schutzhüllenverträge, S. 90; vgl. Baus, Verwendungsbeschränkungen, S. 46.

332 Baus, Verwendungsbeschränkungen, S. 46.

333 Söder, Schutzhüllenverträge, S. 90.

334 Ebd.

335 Vgl. ebd.

336 Baus, Verwendungsbeschränkungen, S. 46. 
eine solche Konstruktion, da der Händler jedes Mal die Willenserklärung des Erwerbers an den entsprechenden Hersteller übermitteln müsste. ${ }^{337}$

Daher scheidet im Regelfall eine Stellvertretung oder Botenschaft des Händlers aus.

\section{bb) Unmittelbarer Vertragsschluss zwischen Publisher und Erwer- ber}

Damit bleibt zu untersuchen, ob ein Supportvertrag unmittelbar zwischen dem Publisher und dem Erwerber des Inklusivspiels über den Support der Online-Komponenten zustande kommt. Hierfür ist erforderlich, dass der Publisher zusammen mit dem Inverkehrbringen der Spielkopie auch ein Angebot ad incertam personam auf $\mathrm{Ab}-$ schluss eines Supportvertrages entäußert. Ob ein solches Angebot vorliegt, wird durch Auslegung ermittelt. Denn nicht nur der Inhalt einer Willenserklärung, sondern auch die Tatsache, ob überhaupt eine Willenserklärung entäußert wurde, wird im Wege der Auslegung bestimmt ${ }^{338}$, wobei eine Trennung zwischen der Auslegung einer Willenserklärung und der Feststellung ihrer Existenz nicht immer trennscharf möglich ist ${ }^{339}$.

Es kommt für das Vorliegen einer Willenserklärung darauf an, ob der Leistende mit Rechtsbindungswillen gehandelt hat, auf den der Leistungsempfänger ,,aus dem Handeln des Leistenden unter den gegebenen Umständen nach Treu und Glauben mit

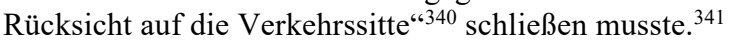

Der Nutzer des Inklusivspiels geht davon aus, dass er ebendieses nach dem Erwerb in vollem Umfang verwenden kann. Er weiß auch, dass er das Spiel und seine OnlineKomponenten nur mithilfe der Support-Leistungen des Publishers verwenden kann, er aber mit diesem direkt allenfalls nach dem Erwerb und der Installation des Spiels in Kontakt tritt. Da aber - wie bereits oben erläutert ${ }^{342}$ - ein zeitlich nachgelagerter $\mathrm{Ab}$ schluss des Supportvertrages die berechtigten Interessen des Erwerbers und den Zweck des Erwerbs des Inklusivspiels gefährden würde, kann der Erwerber das Inverkehrbringen der Spielkopie des Inklusivspiels so verstehen, dass dieses bereits das konkludente Angebot des Publishers auf Abschluss des Supportvertrages enthält. Damit liegt ein Angebot des Publishers auf Abschluss eines Supportvertrages vor.

Ein solches Angebot bedarf dann der Annahme des Erwerbers der Software. Die Annahme erfordert ein nach außen hin erkennbares Verhalten, welches eindeutig auf den Annahmewillen schließen lässt. ${ }^{343}$ Ein solches Verhalten kann in dem Erwerb der

337 Im Ergebnis ebenfalls gegen eine Botenstellung des Händlers Runte, CR 2001, 657, 660; a. A. Sickinger, Standardsoftware, S. 80.

338 Jauernig/Mansel, § 133 BGB, Rn. 1; Hk-BGB/Dörner, § 133 BGB, Rn. 2; MüKo BGB/Busche, $\S 133$ BGB, Rn. 51 .

339 Erman/Arnold, § 133 BGB, Rn. 11.

340 So zur Unterscheidung zwischen Gefälligkeiten mit und ohne rechtsgeschäftlichen Charakter der BGH, NJW 1956, 1313, 1313.

341 Vgl. Hk-BGB/Dörner, § 133 BGB, Rn. 2.

342 Siehe oben S. 52 f.

343 Palandt/Ellenberger, § 151 BGB, Rn. 2; BeckOK BGB/Eckert, § 151 BGB, Rn. 3. 
Spielkopie des Inklusivspiels erblickt werden. In dem Moment, in welchem der Erwerber das Spiel auf das Kassenband legt oder im Internet auf den Bestellen-Button klickt, gibt er unzweideutig zu erkennen, dass er das Inklusivspiel erwerben und alle seine Funktionen nutzen möchte. Er will damit auch alle rechtsgeschäftlichen Handlungen vornehmen, die erforderlich sind, um dieses Ziel zu erreichen.

Daher gibt er auch eine Annahmeerklärung ab, die sich auf den Abschluss des Supportvertrages bezieht. Dies stellt einen entscheidenden Unterschied zu den Shrinkwrap-, Click- bzw. Enter-Vereinbarungen dar, bei denen gerade eine vom Rechtsbindungswillen getragene Annahmehandlung zweifelhaft erscheint. ${ }^{344}$

Damit die Annahme wirksam wird, muss sie dem Publisher grundsätzlich auch zugehen, es sei denn, der Zugang ist gem. § 151 Satz 1 BGB kraft eines Verzichts des Anbietenden oder aufgrund der Verkehrssitte entbehrlich. Eine solche Verkehrssitte existiert bei rechtlich lediglich vorteilhaften Geschäften. ${ }^{345}$ Auf den ersten Blick könnte der Supportvertrag ohne weiteres als ein rechtlich lediglich vorteilhaftes Geschäft angesehen werden, da der Spieler für den Support kein gesondertes Entgelt erbringt. Es ist jedoch oben bereits erläutert worden, dass sich das für den Erwerb des Inklusivspiels zu entrichtende Entgelt aus Sicht des Spielers als Vergütung sowohl für die Überlassung des Spielclients als auch für den Support der Online-Komponenten darstellt. ${ }^{346}$ Diese Vergütung entrichtet der Erwerber an den Händler, welcher mit Blick auf die Support-Vergütung gemäß $§ 362$ Abs. 2 BGB i. V. m. $§ 185$ Abs. 1 BGB empfangsermächtigt ist.

Abgesehen von der Pflicht zur Vergütung treffen den Erwerber darüber hinaus allerdings keine weiteren Verpflichtungen in Bezug auf den Support der Online-Komponenten. Der Supportvertrag ist damit mit einem rechtlich lediglich vorteilhaften Rechtsgeschäft vergleichbar, sodass der Zugang der Annahme kraft Verkehrssitte entbehrlich ist.

\section{d) Zusammenfassung}

Für den Fall, dass der Veräußerer des Inklusivspiels nicht identisch ist mit dem Publisher, welcher den Support der Online-Komponenten erbringt, kommt zwischen dem Erwerber und dem Publisher zum Zeitpunkt des Erwerbs des Inklusivspiels ein separater Supportvertrag zustande, welcher die Pflicht des Publishers zum Support der Online-Komponenten enthält.

344 Vgl. dazu Loewenheim, in FS Kitagawa, S. 954; Redeker, IT-Recht, Rn. 579; Bischof/Witzel, in Redeker, Handbuch der IT-Verträge, Teil 2.3, Rn. 76; Schubert, Schutzhüllenverträge, S. 310; Hoeren, Softwareüberlassung als Sachkauf, Rn. 414; Wiesemann/Kast, in Auer-Reinsdorff/Conrad, Handbuch IT- und Datenschutzrecht, § 24, Rn. 134; von dem Bussche/Schelinski, in Leupold/Glossner, Münchener Anwalts Handbuch IT-Recht, Teil 1, Rn. 152; Jobke, Produktaktivierung, S. 112.

BGH, NJW 2000, 276, 277; NJW 2004, 287, 288; Palandt/Ellenberger, § 151 BGB, Rn. 4; MüKo BGB/Busche, § 151 BGB, Rn. 5.

346 Siehe dazu oben, S. 52. 


\section{Typologisierung der Supportpflicht}

Es konnte durch Auslegung ermittelt werden, dass im Falle des Direktvertriebs die Supportpflicht bereits Teil des Überlassungsvertrages des Inklusivspiels ist, wohingegen beim Händlervertrieb zwischen dem Verbraucher und dem Publisher ein vom Überlassungsvertrag zu unterscheidender Supportvertrag zustande kommt.

Damit ist als Nächstes die Frage zu klären, wie die Supportpflicht vertragsrechtlich zu typologisieren ist.

Die DI-RL legt nicht die Rechtsnatur der Verträge über die Bereitstellung digitaler Inhalte bzw. digitaler Dienstleistungen fest. ${ }^{347}$ Damit bleibt es nach wie vor Aufgabe der Mitgliedsstaaten, festzulegen, wie der Support von Online-Komponenten digitaler Spiele vertragsrechtlich zu typologisieren ist.

Es ist bereits dargestellt worden, dass sowohl die Literatur als auch die Rechtsprechung mit Blick auf Abo- und Inklusivspiele davon ausgeht, dass ein separater Vertrag zwischen dem Erwerber und dem „Anbieter“ des Spiels über den Zugang zur „virtuellen Welt" zustandekommt. ${ }^{348}$

Es besteht sowohl in der Literatur als auch in der Rechtsprechung weitgehend Einigkeit darüber, dass sich aus diesem Vertrag die Pflicht des Spielanbieters ergebe, die Nutzung der virtuellen Spielwelt für den Spieler zu ermöglichen und sie zu erhalten. ${ }^{349}$ Geschuldet sei somit „die Bereitstellung einer für den Teilnehmer online erreichbaren, funktionierenden virtuellen Spielumgebung ${ }^{\text {"350. }}$.

Zumeist konkretisieren Literatur und Rechtsprechung die zum Zwecke der Bereitstellung der virtuellen Spielwelt zu erbringenden Handlungen. So müsse der Vertragspartner des Spielers den Spielverlauf und die Nutzerprofile abspeichern ${ }^{351}$ sowie die erforderlichen Server bereitstellen, warten und den Zugang zu diesen eröffnen ${ }^{352}$.

Der Etablierung und Aufrechterhaltung der Client-Server-Kommunikation kommt für das Funktionieren der Online-Komponenten nach Ansicht der Literatur und Rechtsprechung damit aber allenfalls nur eine gleichrangige Rolle im Vergleich zu anderen

347 Erwägungsgrund 12 der DI-RL; vgl. Ehle/Kreß, CR 2019, 723, 724; Spindler/Sein, MMR 2019, 415,415 .

348 Siehe dazu oben, S. $36 \mathrm{ff}$.

349 Oehler/von Ribbeck, in Duisberg/Picot, Recht der Computer- und Videospiele, Kap. 6, Rn. 11; vgl. Psczolla, Onlinespielrecht, S. 89; Lober/Weber, MMR 2005, 653, 656; Creutz, Regeln virtueller Welten, S. 138; Völzmann-Stickelbrock, in FS Eisenhardt, S. 331; Wemmer/Bodensiek, K\&R 2004, 432, 433; Krasemann, MMR 2006, 351, 352; Weber, in Brandi-Dohrn/Lejeune, Recht 2.0, S. 207; AG Charlottenburg, MMR 2012, 598, 599; AG Karlsruhe, Urt. v. 19.05.2015 - Az. 8 C 377/14 - BeckRS 2015, 09351.

$350 \quad$ Psczolla, Onlinespielrecht, S. 89; vgl. auch Vetter, Virtuelle Welten, S. 119.

351 Vgl. Oehler/von Ribbeck, in Duisberg/Picot, Recht der Computer- und Videospiele, Kap. 6, Rn. 11; Vetter, Virtuelle Welten, S. 119, 131; Psczolla, Onlinespielrecht, S. 88; Schrader, in Leible/Sosnitza, Onlinerecht 2.0: Alte Fragen - neue Antworten?, S. 107.

352 Vgl. Psczolla, Onlinespielrecht, S. 88; Vetter, Virtuelle Welten, S. 119; Völzmann-Stickelbrock, in FS Eisenhardt, 331; Wemmer/Bodensiek, K\&R 2004, 432, 433; Krasemann, MMR 2006, 351, 352; siehe hierzu auch AG Charlottenburg, MMR 2012, 598, 599; Schneider, Virtuelle Werte, S. 83 . 
Prozessen wie der servergestützten Abspeicherung von Spielständen oder Nutzerprofilen zu.

Diese Auffassung ist jedoch unzutreffend, da sämtliche serverbasierten Prozesse und damit auch die Bereitstellung der ,virtuellen Welt“ - nur Erfolg haben können, wenn die Client-Server-Kommunikation etabliert und aufrechterhalten wird. Sie ist damit Voraussetzung für das Funktionieren aller Online-Komponenten, und ihre Unterbrechung führt dazu, dass - wie oben erläutert ${ }^{353}$ - nicht nur die Nutzungsmöglichkeit der Online-Spielwelt, sondern die des gesamten Spielclients wegfallen kann.

Gegenstand der folgenden Typologisierung ist damit der Support der Online-Komponenten, also konkret die Etablierung und Aufrechterhaltung der Client-Server-Kommunikation.

\section{Kaufvertragliche Pflicht}

Die rechtliche Einordnung eines schuldrechtlichen Vertrages orientiert sich an der Vereinbarung der Parteien und an dem in ihr zutage tretenden Parteiwillen. ${ }^{354}$ Die hieraus ermittelten Rechte und Pflichten der Vertragspartner sind sodann - unter Berücksichtigung ihrer Interessenlage und der von ihnen verfolgten wirtschaftlichen Ziele einem Vergleich mit den Merkmalen eines gesetzlich geregelten Vertragstypus zu unterziehen. ${ }^{355}$

Die Zuordnung einer Vereinbarung zu einem gesetzlich geregelten Vertragstyp setzt dabei nicht voraus, dass eine exakte Übereinstimmung des Vertrages mit dem geregelten Typus in allen Punkten vorliegt. ${ }^{356}$ Es genügt, wenn die Vereinbarung dem Leitbild der jeweiligen Vertragsart hinreichend ähnlich ist. ${ }^{357}$

Die Besonderheit von Inklusivspielen liegt darin, dass der Erwerber die Spielkopie als Gegenleistung für die einmalige Zahlung eines Entgelts erwirbt und daraufhin das Spiel verwenden darf, ohne ein weiteres Mal hierfür Geld entrichten zu müssen. ${ }^{358}$ Die Überlassung der Spielkopie erinnert daher an ein Austauschgeschäft wie den Kaufvertrag gemäß § 433 Abs. 1 BGB. Der Support dagegen stellt eine Leistung dar, welche sich nicht in einem einmaligen Erwerbsvorgang erschöpft, sondern fortlaufend zu erbringen ist, jedoch - wie bereits oben festgestellt - in einem engen funktionellen $\mathrm{Zu}$ sammenhang mit der Spielkopie steht. ${ }^{359}$

Es ist daher denkbar, dass die Pflicht zum Support der Online-Komponenten von der kaufvertraglichen Pflicht zur sach- und rechtsmängelfreien Überlassung der Kaufsache gem. $§ 433$ Abs. 1 Satz 2 BGB mit umfasst ist. Hierfür ist freilich Voraussetzung,

\footnotetext{
353 Siehe dazu die Einleitung.

354 Vgl. Martinek, Vertragstypen I, S. 21; Stoffels, Schuldverträge, S. 173.

355 Vgl. Leenen, Typus und Rechtsfindung, S. 183; Martinek, Vertragstypen I, S. 21.

356 Leenen, Typus und Rechtsfindung, S. 183.

357 Lutz, Softwarelizenzen, S. $29 \mathrm{f}$.

358 Siehe dazu die Einleitung.

359 Siehe dazu oben, S. 52.
} 
dass bereits auf die Verpflichtung zur Überlassung des Inklusivspiels die kaufvertraglichen Vorschriften Anwendung finden.

\section{a) Die Verpflichtung zur Überlassung des Inklusivspiels}

In seiner Compiler/Interpreter-Entscheidung von 1987 befasste sich der BGH erstmals mit der Frage, ob die kaufrechtlichen Sachmangel-Vorschriften der $\S \S 459$ ff. BGB a. F. auf eine Vereinbarung anzuwenden sind, welche die dauerhafte Überlassung von Software zum Gegenstand hat. ${ }^{360}$

Ohne den Softwareüberlassungsvertrag eindeutig als Kaufvertrag einzuordnen, wandte der BGH im Fall die Sachmangelvorschriften ,zumindest“ entsprechend an und meinte, dass die Einordnung als Kaufvertrag bei einer dauerhaften Überlassung von Software zur freien Verfügung gegen ein einmaliges Entgelt naheliege. ${ }^{361}$

In zwei späteren Urteilen, der EDV-Standardprogramm ${ }^{362}$ und der LohnprogrammEntscheidung ${ }^{363}$, ordnete das Gericht einen Vertrag über die dauerhafte Softwareüberlassung gegen ein einmaliges Entgelt ausdrücklich als Kaufvertrag gemäß $§ 433$ Abs. $1 \mathrm{BGB}$ ein.

Der bisherigen Rechtsprechung des BGH lässt sich entnehmen, dass bei der dauerhaften Softwareüberlassung gegen ein einmaliges Entgelt die Einordnung des Überlassungsvertrages als Kaufvertrag naheliegt. Vor allem digitale Spiele werden heutzutage aber nur noch selten auf einem Datenträger überlassen, sondern immer häufiger im Wege des Downloads erworben, was die Frage aufwirft, ob dann immer noch der Verkauf einer „Sache“ i. S. d. § 433 Abs. 1 Satz 1 BGB vorliegt.

Mit der Einführung des $\S 453$ Abs. 1 BGB im Zuge der Schuldrechtsreform, welcher die Anwendung der Vorschriften über den Kauf von Sachen auch auf den Kauf von Rechten sowie sonstigen Gegenständen erstreckt, hat die Einordnung von Software als Sache für das Kaufrecht allerdings kaum noch Relevanz. ${ }^{364}$ So hat schließlich auch der Gesetzgeber in der Gesetzesbegründung zu $§ 453$ Abs. 1 BGB Software ausdrücklich als ein Beispiel für „sonstige Gegenstände“ angeführt. ${ }^{365}$ Da Software somit jedenfalls als „,sonstiger Gegenstand“ von den kaufrechtlichen Vorschriften erfasst wird, kann dahinstehen, ob sie auch eine „Sache“ gemäß § 433 Abs. 1 Satz 1 BGB darstellt.

Darüber hinaus kann der Erwerber das digitale Spiel in der Regel - wie andere Software auch - nur unter einer Reihe von verschiedenen Nutzungsbeschränkungen verwenden, sodass sich die Frage stellt, ob die Überlassung des Inklusivspiels auch „zur freien Verfügung“ erfolgt. Ohne näher auf seinen Inhalt einzugehen, führte der BGH

360 BGH, NJW 1988, 406.

361 Ebd., 407, 408.

362 BGH, NJW 1990, 320, 321.

363 BGH, NJW 2000, 1415, 1415.

364 Heydn, CR 2010, 765, 772; Bartsch, CR 2010, 553, 558; Stichtenoth, K\&R 2003, 105, 107;

Bräutigam/Rücker, CR 2006, 361, 364; Hoeren, AGB Internet- und Softwareverträge, S. 63;

Schneider, CR 2005, 695, 697; Diedrich, CR 2002, 473, 476; Redeker, NJOZ 2008, 2917, 2922;

Staudinger/Jickeli/Stieper, § 90 BGB, Rn. 14; Palandt/Weidenkaff, § 433 BGB, Rn. 9. 
dieses Kriterium - wie soeben dargestellt - in seiner Compiler/Interpreter-Entscheidung anscheinend als Voraussetzung für die (entsprechende) Anwendung kaufvertraglicher Vorschriften an. ${ }^{366}$ In späteren Entscheidungen hat das Gericht dieses Kriterium allerdings nicht wieder aufgegriffen. ${ }^{367}$

Die Literatur bewertet dieses Kriterium uneinheitlich. Nach einer Ansicht muss dieses Merkmal für die Einordnung eines Softwareüberlassungsvertrages als Kaufvertrag erfüllt sein. ${ }^{368}$ Als Grund hierfür wird angeführt, dass die freie Verfügungsmacht über den Kaufgegenstand für den Kaufvertrag typisch sei, dem Erwerber der Software aber regelmäßig nur ein beschränktes Nutzungsrecht eingeräumt werde. ${ }^{369}$ Wenn Verfügungsbeschränkungen vorhanden sind, seien sie prägend für den Vertragstyp und schlössen daher die Anwendung von Kaufrecht aus. ${ }^{370}$

Die überwiegende Meinung in der Literatur ist demgegenüber der Ansicht, dass das Kriterium der freien Verfügung keine Relevanz für die kaufrechtliche Einordnung des Softwareüberlassungsvertrages habe. ${ }^{371}$ Begründet wird dies zum einen damit, dass die kaufrechtlichen Vorschriften nicht voraussetzen, dass der Erwerber über seine Kaufsache frei verfügen kann. ${ }^{372}$ Kritisiert wird außerdem, dass der Inhalt des Kriteriums nicht näher umrissen und damit unklar sei, wann es erfüllt ist und wann nicht. ${ }^{373}$ Schließlich wird auch eine Parallele zum Sacheigentum gezogen, welches letztlich auch nicht unbeschränkt ausgeübt werden kann, vor allem, wenn an der im Eigentum befindlichen Sache ein Urheberrecht besteht. ${ }^{374}$

Der zuletzt genannten Ansicht ist zu folgen. Würde man dem Kriterium der Nutzungseinschränkung Gewicht beimessen, würde man den Vertragstyp anhand von AGB-Klauseln bestimmen, was einen unzulässigen Zirkelschluss darstellt. ${ }^{375}$

Daher kommt es für die Frage, ob der Überlassungsvertrag als Kaufvertrag einzuordnen ist, nicht darauf an, ob die Software „,zur freien Verfügung“ überlassen wird.

366 BGH, NJW 1988, 406, 407.

367 Vgl. Redeker, IT-Recht, Rn. 524.

368 Engel, BB 1985, 1159, 1162; Moritz, CR 1989, 1049, 1054; zur Megede, NJW 1989, 2580, 2584; Moritz, CR 1994, 257, 260; Volle, CR 1996, 139, 140; Schneider, CR 2005, 695, 697; Kast, in Auer-Reinsdorff/Conrad, Handbuch IT- und Datenschutzrecht, § 12, Rn. 59. zur Megede, NJW 1989, 2580, 2584.

370 Vgl. Volle, CR 1996, 139, 140.

371 Hoeren, Softwareüberlassung als Sachkauf, S. 53; Koch, Computer-Vertragsrecht, Rn. 20; Beckmann/Köhler, in FS Rüßmann, S. 392 f.; Baus, Verwendungsbeschränkungen, S. 33; Michalski/Bösert, Computerprogramme, S. 22 f.; Dörner/Jersch, iur 1988, 137, 145; König, Computerprogramm, Rn. 667; Sickinger, Standardsoftware, S. 60 f.; Staudinger/Beckmann, § 453 BGB, Rn. 57; Bösert, Nießbrauch, S. 40 ff.

Dörner/Jersch, iur 1988, 137, 145.

Bösert, Nießbrauch, S. 40.

374 lassung als Sachkauf, S. 51; vgl. BGH, NJW 1995, 1556, $1556 \mathrm{f}$.

Baus, Verwendungsbeschränkungen, S. 33; vgl. Bösert, Nießbrauch, S. 43. 
Eine Minderansicht in der Literatur ist darüber hinaus der Auffassung, dass das Leitbild des Kaufvertrages nicht auf die Überlassung von Software auf Dauer gegen einmaliges Entgelt passe, und will den Überlassungsvertrag als Dauerschuldverhältnis in Form eines Lizenzvertrages einordnen. ${ }^{376}$ Begründet wird dies damit, dass bei der Softwareüberlassung die Einräumung eines Gebrauchsrechts im Vordergrund stehe und das vom Kunden gezahlte Entgelt die Vergütung hierfür darstelle. ${ }^{377}$ Da der Erwerber somit nur ein Nutzungsrecht an der Softwarekopie erhalte, gehöre sie nicht ihm, weshalb Kaufrecht keine Anwendung finden könne. ${ }^{378}$ Außerdem sei aus rechtlicher Sicht die Software als immaterielles Gut entscheidend und nicht der Träger, auf welchem sie verkörpert ist. ${ }^{379}$

Dieser Ansicht schließt sich auch ein Teil der Literatur mit Blick auf die Überlassung digitaler Spiele an. ${ }^{380}$ Der Erwerber des Spiels sei in erster Linie an der immateriellen Spielsoftware interessiert und nur nachrangig am Eigentum des Datenträgers, weshalb es ihm gerade auf die Einräumung einer Lizenz ankomme, welche ihm die Nutzung des Programms erlaube. ${ }^{381}$

Hiergegen ist jedoch einzuwenden, dass die Einordnung der Softwareüberlassung als Lizenzvertrag kaum weiterhilft, da dieser im Gesetz keine Regelung gefunden hat und daher gesetzliche Vertragstypen wie der Kaufvertrag doch wieder analog auf den Lizenzvertrag angewandt werden müssten. ${ }^{382}$

Auch wenn die Überlassung der Softwarekopie mit der Einräumung von urheberrechtlichen Nutzungsrechten einhergeht ${ }^{383}$, ist Letztere nur von untergeordneter Bedeutung und vermag nicht den gesamten Vertrag in einen Lizenzvertrag umzuwandeln. ${ }^{384}$ Darüber hinaus sind sowohl die urheberrechtliche Schutzfähigkeit als auch etwaige an den Erwerber einzuräumende urheberrechtliche Nutzungsrechte von der

376 Hilty, CR 2012, 625, 637; ders., MMR 2003, 3, 14 f.; ders., Lizenzvertragsrecht, S. 695;

Scholz/Haines, CR 2003, 393, 394; Ulmer, CR 2000, 493, 495; Moritz, CR 1994, 257, 262; Betten, GRUR 1991, 453, 454; für typengemischten Vertrag mit Elementen des Kauf- und Lizenzvertragsrechts Metzger, NJW 2003, 1994, 1995; ebenso Nordemann, CR 1996, 5, 6; für einen Know-how-Lizenzvertrag Kilian, CR 1986, 187, 195.

Hilty, MMR 2003, 3, 14 f.; ders., CR 2012, 625, 629.

Hilty, Lizenzvertragsrecht, S. 696.

379 Hilty, CR 2012, 625, 628.

380 Völzmann-Stickelbrock, in FS Eisenhardt, S. 331.

381 Ebd., S. $330 \mathrm{f}$.

Vgl. Koch, Computer-Vertragsrecht, Rn. 73; Köhler/Fritzsche, in Lehmann, Rechtsschutz und Verwertung von Computerprogrammen, 2. Teil, XIII, Rn. 16; Lejeune, in Ullrich/Lejeune, Der internationale Softwarevertrag, Teil I, Kap. 2, Rn. 277; Schuhmacher, CR 2000, 641, 641; Hoeren, CR 1988, 908, 913; Bartl, BB 1988, 2122, 2125.

Siehe dazu näher unten in Kapitel 4, S. 147.

384 Dörner/Jersch, iur 1988, 137, 140. 
Frage zu unterscheiden, wie der Vertrag schuldrechtlich einzuordnen ist. ${ }^{385}$ Dies ergibt sich dogmatisch schon aus der Tatsache, dass die Einräumung von Nutzungsrechten als Verfügungs- und nicht als Verpflichtungsgeschäft anzusehen ist. ${ }^{386}$ Darüber hinaus bestimmen die Nutzungsrechte nur, in welchem Umfang der Erwerber die Software bzw. das digitale Spiel verwenden darf. ${ }^{387}$ Der dem Erwerb zugrunde liegende schuldrechtliche Vertrag legt dagegen sowohl die Leistungspflichten des Veräußerers der Software als auch die Rechte fest, welche dem Erwerber im Falle einer mangelhaften oder ungenügenden Leistung zustehen. ${ }^{388}$

Damit ist der Ansicht des BGH und der ganz herrschenden Lehre ${ }^{389}$ zu folgen, wonach auf die Verpflichtung zur dauerhaften Überlassung von Software gegen die einmalige Zahlung von Entgelt Kaufrecht zumindest entsprechend anzuwenden ist.

Auch in Bezug auf die dauerhafte Überlassung digitaler Spiele gegen ein einmaliges Entgelt vertritt die Literatur überwiegend eine kaufvertragliche Einordnung ${ }^{390}$, wobei

385 Vgl. BGH, NJW 2007, 2394, 2395 - ASP-Vertrag; NJW 1988, 406, 407; OLG Nürnberg, CR 1993, 359, 360; Staudinger/Beckmann, § 453 BGB, Rn. 53; Heydn, CR 2010, 765, 774; Köhler/Fritzsche, in Lehmann, Rechtsschutz und Verwertung von Computerprogrammen, 2. Teil, XIII, Rn. 13; Krauß, Softwareverträge, S. 19 f.; Scholz/Haines, CR 2003, 393, 394.

386 Köhler/Fritzsche, in Lehmann, Rechtsschutz und Verwertung von Computerprogrammen, 2. Teil, XIII, Rn. 13; zur Einordnung der Nutzungsrechtseinräumung als Verfügungsgeschäft vgl. Dreier/Schulze/Schulze, § 31 UrhG, Rn. 15.

387 Heydn, CR 2010, 765, 774.

388 Vgl. BGH, NJW 1988, 406, 407.

389 Hoeren, IT-Vertragsrecht, S. 78; ders., Softwareüberlassung als Sachkauf, S. 57; ders., AGB Internet- und Softwareverträge, S. 63; Köhler/Fritzsche, in Lehmann, Rechtsschutz und Verwertung von Computerprogrammen, 2. Teil, XIII, Rn. 29; Koch, Computer-Vertragsrecht, Rn. 10; Redeker, IT-Recht, Rn. 528; Loewenheim, in FS Kitagawa, S. 959; Malzer, Softwarevertrag, S. 93; Eckert/Maifeld/Matthiesen, Kaufrecht, Rn. 320; Schröder, Softwareverträge, S. 3; Taeger, Computerprogramme, S. 146; Krau $\beta$, Softwareverträge, S. 22; Sickinger, Standardsoftware, S. 71; Oechsler, Schuldverhältnisse, Rn. 68; Intveen, ITRB 2012, 93, 93; ders., ITRB 2008, 237, 238; Lejeune, CR 2007, 75, 77 f.; Merveldt, CR 2006, 721, 722; Bräutigam/Rücker, CR 2006, 361, 368; Fischl, ITRB 2004, 286, 286; Mankowski, MDR 2003, 854, 857; Goldmann/Redecke, MMR 2002, 3, 3; von Westerholt/Berger, CR 2002, 81, 82; Gaul, CR 2000, 570, 570; ders., MDR 2000, 549, 549; Hoeren/Schuhmacher, CR 2000, 137, 137; Schuhmacher, CR 2000, 641, 644; Klimek/Sieber, ZUM 1998, 902, 904; Eickmeier/Eickmeier, CR 1993, 73, 73; Haberstumpf, GRUR Int. 1992, 715, 722; Junker, NJW 1990, 1575, 1576; Tellis, BB 1990, 500, 501 f.; König, NJW 1990, 1584, 1584; Bartl, BB 1988, 2122, 2124; Dörner/Jersch, iur 1988, 137, 142; Heussen, GRUR 1987, 779, 787; Köhler, CR 1987, 827, 830; Bartl, CR 1985, 13, 14; Schneider, Softwarenutzungsverträge, S. 77; a. A. Hilty, CR 2012, 625, 629; ders., MMR 2003, 3, 14 f.; Metzger, NJW 2003, 1994, 1995; Mincke, JurPC 1991, 932, 938; Lesshaft/Ulmer, CR $1988,813,815$.

390 Psczolla, Onlinespielrecht, S. 85; Creutz, Regeln virtueller Welten, S. 137; Vetter, Virtuelle Welten, S. 131; Klickermann, MMR 2007, 766, 768; Diegmann/Kuntz, NJW 2010, 561, 562. 
innerhalb dieser Meinungsgruppe strittig ist, ob es sich um einen Sach- ${ }^{391}$ oder Rechtskauf $\mathrm{f}^{392}$ oder um den Kauf eines sonstigen Gegenstandes ${ }^{393}$ im Sinne des $\S 453$ Abs. 1 Fall 2 BGB handelt. Da $\S 453$ Abs. 1 BGB die Vorschriften des Sachkaufs auf den Kauf von Rechten und sonstigen Gegenständen gleichermaßen erstreckt, hat diese Differenzierung im Ergebnis keine rechtlichen Auswirkungen.

\section{b) Die Verpflichtung zum Support der Online-Komponenten}

Wie bereits festgestellt, ist der Support der Online-Komponenten Voraussetzung für die gesamte oder teilweise Nutzungsmöglichkeit der Spielkopie. Diese enge Verknüpfung zwischen Support und Spielkopie wirft die Frage auf, ob nicht auch die Pflicht zum Support der Online-Komponenten kaufrechtlich zu typologisieren ist.

Die Folge dessen wäre, dass beide Pflichten demselben Vertragstypus unterfallen und damit auch einem einheitlichen Vertragstyp zuzuordnen wären. In Betracht kommt zunächst die Subsumtion des Supports unter die Hauptpflicht zur Übergabe der Sache und zur Verschaffung des Eigentums hieran gemäß § 433 Abs. 1 Satz 1 BGB (dazu aa)). Von Relevanz ist darüber hinaus die Hauptpflicht des Verkäufers, die Kaufsache gemäß $§ 433$ Abs. 1 Satz 2 BGB frei von Sach- und Rechtsmängeln zu verschaffen (dazu bb)).

\section{aa) Pflicht zur Überlassung der Kaufsache}

Beim Kaufvertrag handelt es sich um einen schuldrechtlichen gegenseitigen Vertrag im Sinne der $\S \S 320 \mathrm{ff}$. BGB, welcher auf den Austausch von Gegenständen gegen Geld abzielt, jedoch vom Erfüllungsgeschäft streng zu unterscheiden ist. ${ }^{394}$

$\S 433$ Abs. 1 Satz 1 BGB regelt die erste Hauptpflicht ${ }^{395}$ des Verkäufers, nämlich die Kaufsache zu übergeben und das Eigentum hieran zu übertragen ${ }^{396}$. Eine Subsumtion des Supports unter diese Hauptpflicht erscheint aber schon deswegen problematisch, weil es sich beim Support um eine fortdauernde, auf die Aufrechterhaltung der Client-Server-Kommunikation gerichtete Tätigkeit handelt, die Pflicht zur Übergabe der Kaufsache und zur Eigentumsverschaffung daran mit einem Akt erfüllt ist.

Hinzu kommt, dass für die Subsumtion des Supports unter $\S 433$ Abs. 1 Satz 1 BGB kein tauglicher Anknüpfungspunkt ersichtlich ist. Wie in Kapitel 1 ausgeführt, erfolgt

391 Krasemann, MMR 2006, 351, 352; Lober/Weber, MMR 2005, 653, 656; Weber, in BrandiDohrn/Lejeune, Recht 2.0, S. 207.

392 Sofern die Spielkopie im Wege des Downloads erworben wird, Trump/Wedemeyer, K\&R 2006, $398,398$.

393 Oehler/von Ribbeck, in Duisberg/Picot, Recht der Computer- und Videospiele, Kap. 6, Rn. 3; allgemein auf $\S 453$ Abs. 1 BGB abstellend Striezel, Virtuelle Gegenstände, S. 200.

394 Siehe statt vieler nur Palandt/Weidenkaff, Einf v $\S 433$, Rn. $1 \mathrm{ff}$.

395 Staudinger/Beckmann, § 433 BGB, Rn. 1; Medicus/Lorenz, SchR II BT, § 3, Rn. 2.

396 Vgl. Medicus/Lorenz, SchR II BT, § 3, Rn. 2 ff.; Looschelders, SchR BT, Rn. $22 \mathrm{ff}$. 
die Kommunikation zwischen Server und Spielkopie durch einen permanenten Austausch von kleinen Informationspaketen, den Packets. ${ }^{397}$ Diese Packets als Sachen einzuordnen und der Übergabe- und Eigentumsverschaffungspflicht zu unterwerfen, wäre lebensfremd, da sie nur eine Trägerfunktion übernehmen und ihre Existenz in dem Moment endet, in welchem sie auf dem Endgerät des Inhabers der Spielkopie ankommen. Außerdem findet der Austausch in beide Richtungen zwischen Spielkopie und Server statt, sodass sich konsequenterweise auch der Käufer letztlich zu einer Übergabe und Eigentumsverschaffung an diesen Packets gegenüber dem Verkäufer verpflichten müsste.

Aus diesem Grunde ist die Pflicht zum Support der Online-Komponenten nicht von der kaufvertraglichen Hauptpflicht zur Übergabe der Kaufsache und zur Verschaffung des Eigentums hieran erfasst.

\section{bb) Pflicht gemäß $§ 433$ Abs. 1 Satz 2 BGB}

Weiter ist zu untersuchen, ob der Support der Online-Komponenten Teil der zweiten Hauptpflicht ${ }^{398}$ des Verkäufers ist, welche darin besteht, dem Käufer die Kaufsache „frei von Sach- und Rechtsmängeln zu verschaffen“, § 433 Abs. 1 Satz 2 BGB.

$\S 434$ BGB regelt den Begriff des Sachmangels im Kaufrecht und untergliedert ihn in verschiedene Fallgruppen. ${ }^{399} \S 434$ Abs. 1 Satz 1 sowie Satz 2 Nr. 1 BGB enthalten mit der Beschaffenheitsvereinbarung und der Eignung für die nach dem Vertrag vorausgesetzten Verwendung die zwei Arten des sog. subjektiven Fehlerbegriffs ${ }^{400}$. $\S$ 434 Abs. 1 Satz 2 Nr. 2 BGB regelt darüber hinaus die Fallgruppe des sog. objektiven Sachmangelbegriffs ${ }^{401}$.

Dem Sachmangel gleichgestellt sind ferner der Montagefehler (§ 434 Abs. 2 Satz 1 BGB) sowie die Falsch- und Minderlieferung ( $\$ 434$ Abs. 3 BGB). ${ }^{402}$

Es herrscht weitgehend Einigkeit darüber, dass der subjektive Fehlerbegriff dem objektiven in $\S 434$ Abs. 1 BGB vorgeht, mit der Folge, dass $\S 434$ Abs. 1 Satz 2 Nr. 2 BGB subsidiär ist zu einer Beschaffenheitsvereinbarung gem. § 434 Abs. 1 Satz 1 und der Eignung für die nach dem Vertrag vorausgesetzte Verwendung gem. § 434 Abs. 1 Satz 2 Nr. 1 BGB. ${ }^{403}$

Tatbestandsmerkmal des Sachmangels ist weiterhin, dass dieser zum Zeitpunkt des Gefahrübergangs vorliegt ( $\$ 434$ Abs. 1 Satz 1 BGB). ${ }^{404}$

\footnotetext{
397 Siehe dazu oben, S. 28 f.

398 Siehe dazu Staudinger/Beckmann, § 433 BGB, Rn. 1, 132; Looschelders, SchR BT, Rn. 22 ff.

399 Palandt/Weidenkaff, § 434 BGB, Rn. 7.

400 Zum Begriff Grigoleit/Herresthal, JZ 2003, 233, 233.

401 Eckert/Maifeld/Matthiesen, Kaufrecht, Rn. 359; Medicus/Lorenz, SchR II BT, § 6, Rn. 18 $\mathrm{mwN}$.

402 Vgl. Jauernig/Berger, § 434 BGB, Rn. 2.

403 Palandt/Weidenkaff, § 434 BGB, Rn. 7, 20; Eckert/Maifeld/Matthiesen, Kaufrecht, Rn. 330; Medicus/Lorenz, SchR II BT, § 6, Rn. 6; vgl. Looschelders, SchR BT, Rn. 44; Hk-BGB/Saenger, § 434 BGB, Rn. 7.

404 Vgl. statt vieler nur Looschelders, SchR BT, Rn. 55.
} 


\section{(1) § 434 Abs. 1 Satz 1 BGB}

Gemäß $§ 434$ Abs. 1 Satz 1 BGB ist die Sache frei von Sachmängeln, wenn sie bei Gefahrübergang die vereinbarte „Beschaffenheit“ hat. Fraglich ist, wie der Begriff der Beschaffenheit auszulegen ist und ob der Support der Online-Komponenten des Inklusivspiels darunter gefasst werden kann.

Der Beschaffenheitsbegriff soll zunächst nicht solche Umstände erfassen, die in der Zukunft liegen. ${ }^{405}$ Dies ergibt sich aus dem Erfordernis, dass der Sachmangel im Zeitpunkt des Gefahrübergangs vorliegen muss, vgl. $§ 434$ Abs. 1 S. 1 BGB ${ }^{406}$. Zwar kann eine Beschaffenheitsvereinbarung auch zukünftige Umstände in Bezug nehmen, jedoch ist dann Teil der Beschaffenheit nur das Potential ${ }^{407}$ der Kaufsache mit Blick auf diesen zukünftigen Umstand, nicht jedoch der Umstand selbst. Dies gilt insbesondere dann, wenn die spätere, besondere Eigenschaft der Kaufsache erst noch durch ein gesondertes Verhalten entweder des Verkäufers oder einer dritten Person bewirkt werden soll. ${ }^{408}$

In diesem Sinne hatte auch das OLG Koblenz in einem Fall, in welchem der Kläger eine Digitalkamera von dem beklagten Unternehmen erworben hatte, die erst nach Erwerb der Kamera erfolgende Aktualisierung derselben durch Updates nicht als Teil ihrer Beschaffenheit angesehen. ${ }^{409}$

Im Entwurf des Gesetzes zur Modernisierung des Schuldrechts ${ }^{410}$ ließ der Gesetzgeber außerdem die Frage ausdrücklich offen, ob der Beschaffenheitsbegriff ,nur Eigenschaften umfasst, die der Kaufsache unmittelbar physisch anhaften oder ob auch Umstände heranzuziehen sind, die außerhalb der Sache selbst liegen“"411. Die alte Gesetzeslage unterschied demgegenüber zwischen „Fehlern“412 (§ 459 Abs. 1 BGB a. F.) und „Eigenschaften“ ( $\$ 459$ Abs. 2 BGB a. F.) einer Kaufsache.

Nach der Rechtsprechung des BGH konnten zu „Fehlern“ nur solche Umstände gerechnet werden, welche der Kaufsache ,unmittelbar innewohn[en] und von [ihr] ausgeh[en] “413. Weiter wurde demgegenüber der Begriff der „Eigenschaften“ verstanden, welcher auch Beziehungen der Kaufsache zur Umwelt erfasst, die ,nach der Verkehrsanschauung für die Brauchbarkeit und den Wert der Sache von Bedeutung sind“ und

405 Staudinger/Matusche-Beckmann, § 434 BGB, Rn. 56; Reinicke/Tiedtke, Kaufrecht, Rn. 312; BeckOK BGB/Faust, § 434 BGB, Rn. 26; Schröcker, ZGR 2005, 63, 78; MüKo BGB/Westermann, § 434, Rn. 11; Erman/Grunewald, § 434, Rn. 6, 10, 66 mwN.

Vgl. MüKo BGB/Westermann, § 434, Rn. 11, 50; Erman/Grunewald, § 434, Rn. 66.

407 Vgl. dazu Schmidt, BB 2005, 2763, 2767.

$408 \mathrm{Vgl}$. PWW/Schmidt, § 434 BGB, Rn. 19.

409 OLG Koblenz, Urt. v. 20. April 2009, Az. 6 U 268/08 - zit. nach juris, Tz. 16.

410 Vom 26. November 2001, BGBl., Teil 1, S. 3138.

411 BT-Drs. 14/6040, S. 213, linke Spalte.

412 Ob ein „Fehler“ i. S. d. § 459 Abs. 1 BGB vorlag, wurde danach bestimmt, ob der Kaufsache ein „Beschaffenheitsmerkmal“ fehlte, vgl. BGH, NJW 1992, 2564, 2565.

413 Ebd.; Singer, in Canaris, 50 Jahre Bundesgerichtshof, S. 388. 
,,in der Beschaffenheit der Sache selbst ihren Grund haben, von ihr ausgehen, ihr auch für eine gewisse Dauer anhaften und nicht lediglich durch Heranziehung von Umständen in Erscheinung treten, die außerhalb der Sache liegen ". ${ }^{414}$

Die Umweltbeziehungen konnten dabei tatsächlicher, sozialer, wirtschaftlicher oder rechtlicher Natur sein. ${ }^{415}$

Es besteht weitgehend Einigkeit darüber, dass der Beschaffenheitsbegriff des neuen $\S 434$ Abs. 1 S. 1 BGB sowohl die Beschaffenheitsmerkmale gem. § 459 Abs. 1 BGB a. F. als auch die zusicherungsfähigen Eigenschaften i. S. d. § 459 Abs. 2 BGB a. F. umfasst. $^{416}$

Umstritten ist nach neuer Rechtslage jedoch, welche äußeren Umstände einen noch ausreichenden Bezug zur Kaufsache aufweisen, sodass sie noch zur Beschaffenheit der Kaufsache gerechnet werden können.

Nach einer Ansicht werden nur solche äußeren Umstände vom Beschaffenheitsbegriff erfasst, die an die physischen Merkmale der Kaufsache anknüpfen (im Folgenden: enger Beschaffenheitsbegriff). ${ }^{417}$ Zum Teil wird für diese Anknüpfung verlangt, dass die äußeren Umstände unmittelbar auf den Zustand der Kaufsache einwirken müssen. ${ }^{418}$ Nach diesem Verständnis gehören z. B. über die Luft oder das Wasser auf ein Grundstück übertragene Umwelteinwirkungen zur Beschaffenheit desselben. ${ }^{419}$ So ist ein kontaminierter Grundwasserstrom, der den Erdkörper eines Grundstücks durchfließt, Teil der Beschaffenheit dieses Grundstücks, auch wenn der Boden desselben als solcher nicht von Giftstoffen belastet ist. ${ }^{420}$ Die Unmittelbarkeit ist dagegen nach dem engen Beschaffenheitsbegriff nicht mehr gegeben, wenn die Kaufsache beispielsweise nicht in die vom Käufer vorgesehenen Räumlichkeiten passt ${ }^{421}$ oder mit anderen Sachen inkompatibel ist ${ }^{422}$. Denn der physische Zustand der Sache ist in solchen Fällen - trotz evtl. unpassender Umweltverhältnisse - einwandfrei und die Umweltverhältnisse wirken in diesem Fall nicht auf die Kaufsache ein.

414 BGH, NJW 1985, 2472, $2473 \mathrm{mwN}$.

415 BGH, NJW 1992, 2564, 2565; NJW 1991, 2556, 2556; NJW 1978, 370, 370.

416 BGH, NJW 2011, 1217, 1218; BeckOK BGB/Faust, § 434 BGB, Rn. 21; Staudinger/MatuscheBeckmann, § 434 BGB, Rn. 51; Eckert/Maifeld/Matthiesen, Kaufrecht, Rn. 338; Canaris, in Lorenz, Karlsruher Forum 2002, S. 61; Wolf/Kaiser, DB 2002, 411, 412; Schröcker, ZGR 2005, 63, $76 \mathrm{mwN}$.

417 BGH, NJW 2013, 1671, 1672; OLG Hamm, NJW-RR 2003, 1360, 1360; Grigoleit/Herresthal, JZ 2003, 118, 124; dies., JZ 2003, 233, 233; Erman/Grunewald, § 434, Rn. 4; Huber, AcP 2002, 179, 228; Ostendorf, JZ 2011, 822, 824 ff.; MüKo BGB/Westermann, § 434, Rn. 9; BeckOK BGB/Faust, § 434 BGB, Rn. 22 f. mwN.

418 Vgl. Canaris, in Lorenz, Karlsruher Forum 2002, S. 63 f.; wohl auch OLG Hamm, NJW-RR 2003, 1360, 1360 .

419 BGH, NJW 2013, 1671, 1672; BeckOK BGB/Faust, § 434 BGB, Rn. 22.

420 BGH, NJW 2013, 1671, 1672.

421 Canaris, in Lorenz, Karlsruher Forum 2002, S. 64.

422 BGH, NJW 1985, 2472, 2473. 
Die Gegenansicht spricht sich für einen weiten Beschaffenheitsbegriff aus und möchte außerhalb der Kaufsache liegende Umstände auch dann berücksichtigen, wenn sie nicht an physische Merkmale der Kaufsache anknüpfen. ${ }^{423}$ Zur Beschaffenheit soll demnach im Grundsatz jede von den Parteien vereinbarte Anforderung an die Kaufsache gehören, solange ihr irgendein Bezug zur Kaufsache gegeben ist. ${ }^{424}$ Dieser Auffassung zur Folge sollen beispielsweise zur Beschaffenheit der Kaufsache auch Umstände zählen wie die Zahlungsfähigkeit der Mieter eines verkauften Hauses, das Erstzulassungsdatum eines Wagens oder das Vorliegen eines Gutachtens über die Echtheit eines Kunstwerks. ${ }^{425}$

In Kapitel 1 dieser Arbeit ist deutlich geworden, dass es sich beim Support der Online-Komponenten nicht um einen Umstand handelt, der allein dem digitalen Spiel innewohnt oder ausschließlich von diesem ausgeht. Der Support verlangt vielmehr den Einsatz externer Server, welche mit der Spielkopie eine Verbindung eingehen und mit ihr Informationen austauschen.

Für diese Kommunikation kommt es aber nicht allein auf den Serverbetrieb an; entscheidend ist auch, dass die Spielkopie entsprechend programmiert ist, damit überhaupt eine Kommunikation mit dem jeweiligen Server zustande kommen kann. Die Eignung der Spielkopie, die Online-Komponenten umzusetzen, ist Teil ihrer Beschaffenheit. ${ }^{426}$ Es geht in dieser Arbeit aber nicht darum, dass der Support der OnlineKomponenten deshalb nicht erfolgt, weil ein Programmierfehler der Spielkopie vorliegt. Gegenstand dieser Arbeit sind vielmehr Fälle, in denen die für den Support der Online-Komponenten notwendigen Server nicht mehr betrieben werden, also ein externer Umstand dazu führt, dass die Nutzungsmöglichkeit der Spielkopie ganz oder teilweise wegfällt.

Unter Berücksichtigung dieser Umstände kommt eine Einordnung des Supports der Online-Komponenten unter den engen Beschaffenheitsbegriff nicht in Betracht.

Der Support knüpft nämlich nicht an den physischen Zustand des Inklusivspiels an. Ob der Support erbracht wird oder nicht, ist nämlich für das grundlegende Potenzial der Spielkopie, die Online- und alle sonstigen Funktionen zu erbringen, unerheblich. Der Support hat damit nur Einfluss auf die tatsächliche Realisierung dieser Funktionen und ist somit funktions- und nicht zustandsbezogen.

Anders verhält es sich mit dem weiten Beschaffenheitsbegriff. Dieser erfasst auch den Support der Online-Komponenten, da hiernach zur Beschaffenheit einer Sache alle

423 Singer, in Canaris, 50 Jahre Bundesgerichtshof, S. 394 f.; Schmidt-Räntsch, AnwB1. 2003, 529, 531; Staudinger/Matusche-Beckmann, § 434 BGB, Rn. 54; Redeker, Beschaffenheitsbegriff, S. 227; ders., NJW 2012, 2471, 2474; Reinicke/Tiedtke, Kaufrecht, Rn. 307; Eckert/Maifeld/Matthiesen, Kaufrecht, Rn. 341; Schröcker, ZGR 2005, 63, 77; Berger, JZ 2004, 276, 278 ff.; Wolf/Kaiser, DB 2002, 411, 412; Schulze/Ebers, JuS 2004, 462, 463.

Schmidt, BB 2005, 2763, 2765 f.; Reinicke/Tiedtke, Kaufrecht, Rn. 307; Schröcker, ZGR 2005, $63,76 \mathrm{f}$.

Reinicke/Tiedtke, Kaufrecht, Rn. 306.

426 Vgl. zur Einordnung von abredewidrig nicht realisierten Funktionen eines Computerprogramms als Sachmangel Marly, Softwarerecht, Rn. 1487; Hoeren, IT-Vertragsrecht, S. 103; zum Werkvertragsrecht ferner BGH, NJW 2007, 2761, 2761. 
Umweltbeziehungen gehören, die irgendeinen Bezug zur Kaufsache haben. Der Support der Online-Komponenten hängt eng mit der Nutzungsmöglichkeit der Spielkopie zusammen, denn ohne ihn ist das Spiel ganz oder zum Teil nicht nutzbar. Damit ist ein sehr enger Bezug zwischen dem Support und der Spielkopie gegeben.

Doch wie bereits oben erläutert, unterliegt der Beschaffenheitsbegriff den Beschränkungen des Erfordernisses, dass der Sachmangel zum Zeitpunkt des Gefahrübergangs vorliegen muss.

Der Support, also die Kommunikation zwischen Server und Spielkopie, stellt einen Umstand dar, welcher nicht bereits beim Abschluss des Kaufvertrages oder bei der Übergabe der Spielkopie realisiert werden kann. Damit die Spielkopie als solche mit all ihren Funktionen nutzbar ist, muss sie erst auf einem Endgerät installiert werden und ablaufen können. Die Client-Server-Kommunikation kann damit frühestens zu dem Zeitpunkt beginnen, in dem die Spielkopie auf dem Endgerät des Käufers installiert wird. Es handelt sich damit beim Support um einen Umstand, welcher erst in der Zukunft, also nach Abschluss des Kaufvertrages und erst nach dem Gefahrübergang, eintritt.

Hinzu kommt, dass es sich beim Support um eine zusätzliche Leistung handelt, die ein anderes tatsächliches Gepräge aufweist. Der Support der Online-Komponenten ist nämlich eine Leistung, welche über einen längeren Zeitraum zu erbringen ist und sich nicht nur in einem einmaligen Leistungsaustausch erschöpft. Der Kaufvertrag stellt dagegen ein Austauschgeschäft dar, welches auf eine einmalig-punktuelle Erbringung von Leistung und Gegenleistung gerichtet ist. ${ }^{427}$ Das Entstehen zusätzlicher Eigenschaften der Kaufsache kann dieser Vertragstypus daher aus dogmatischen Gründen nicht berücksichtigen. ${ }^{428}$

Die Zurechnung des Supports der Online-Komponenten zur Beschaffenheit des Inklusivspiels würde auch dem gesetzgeberischen Gedanken zuwiderlaufen, dass der Mangel der Kaufsache auch im Wege der Nacherfüllung gem. § 439 Abs. 1 BGB vom Verkäufer wieder behoben werden kann. ${ }^{429}$ Bei gänzlich außerhalb der Kaufsache liegenden Umständen ist dies aber nicht immer der Fall. ${ }^{430}$ So ist es auch beim Support der Online-Komponenten möglich, dass dieser von einer Person erbracht wird, die vom Verkäufer gänzlich verschieden ist und der Verkäufer auf diesen Support keinen Einfluss hat. Ihn auch in solchen Fällen für den Support haftbar zu machen, würde dazu führen, dass eine Nacherfüllung wegen subjektiver Unmöglichkeit gem. § 275 Abs. 1 BGB stets ausscheidet, was wiederum den Käufer des digitalen Spiels immer benachteiligen würde.

Schließlich ist zu berücksichtigen, dass eine Erfassung des Supports der OnlineKomponenten von der Pflicht zur sachmangelfreien Überlassung der Spielkopie eine bedenkliche Einschränkung der Vertragsautonomie der Parteien zur Folge hätte. Es

\footnotetext{
427 Vgl. Mankowski, MDR 2003, 854, 859.

428 Vgl. ebd.

429 Vgl. hierzu Ostendorf, JZ 2011, 822, 825.

430 Ebd.
} 
wäre ihnen die Möglichkeit genommen, den Support der Online-Komponenten abschließend in einem separaten Vertrag zu regeln.

Der Support der Online-Komponenten - egal ob es sich dabei um Online-DRMSysteme oder spielbezogene Funktionen wie den Online-Mehrspielermodus handelt ist damit nicht Teil der Beschaffenheit des Inklusivspiels gem. § 434 Abs. 1 Satz 1 BGB.

\section{(2) §434 Abs. 1 Satz 2 Nr. 1 BGB}

Dieser Fall des subjektiven Sachmangels ist auf diejenigen Kaufverträge zugeschnitten, in welchen die Parteien darin übereinkommen, dass der Käufer die Sache zu einem bestimmten Zweck benutzen kann. ${ }^{431}$ Regelmäßig haben die Vertragspartner hier keine ausdrückliche Vereinbarung über die Beschaffenheit der Kaufsache getroffen. ${ }^{432}$

Umstritten ist dabei, wie sich die „Verwendung“ i. S. d. § 434 Abs. 1 Satz 2 Nr. 1 BGB zur Beschaffenheit gemäß $§ 434$ Abs. 1 Satz 1 BGB verhält und ob hiervon auch Umstände umfasst werden, welche nicht Teil der Beschaffenheit der Kaufsache sein können.

Nach einer Ansicht sei die nach dem Vertrag vorausgesetzte Verwendung von der Beschaffenheit zu trennen, wofür insbesondere $\S 434$ Abs. 1 Satz 2 Nr. 2 BGB spreche, welcher beide Begriffe getrennt als kumulativ zu erfüllende Tatbestandsmerkmale aufführe. ${ }^{433}$ Auch lasse es der Text des Art. 2 Abs. 2 lit. b. und c. der Verbrauchsgüterkaufrichtlinie ${ }^{434}$ nicht zu, dass die Verwendung mit der Beschaffenheit gleichgesetzt werde. ${ }^{435}$ Diese Auffassung will den Begriff der Verwendung daher weiter als den der Beschaffenheit verstehen, sodass ein Gewährleistungsfall auch dann gegeben sein soll, wenn einer Verwendung z. B. bloß rechtliche Gründe entgegenstehen. ${ }^{436}$

Die Gegenansicht will die nach dem Vertrag vorausgesetzte Verwendung mit der Beschaffenheit der Kaufsache gleichsetzen ${ }^{437}$, wobei überwiegend angenommen wird, dass die nach dem Vertrag vorausgesetzte Verwendung stets eine konkludente Beschaffenheitsvereinbarung enthalte. ${ }^{438}$ In der Konsequenz sprechen sich Vertreter der zuletzt genannten Ansicht auch dafür aus, die Reichweite der Verwendung innerhalb

431 Grigoleit/Herresthal, JZ 2003, 233, 234 f.; vgl. Erman/Grunewald, § 434, Rn. 18.

432 Grigoleit/Herresthal, JZ 2003, 233, 235.

433 BeckOK BGB/Faust, $\S 434$ BGB, Rn. 30; Reinicke/Tiedtke, Kaufrecht, Rn. 320; Leible, in Gebauer/Wiedmann, Zivilrecht unter europäischem Einfluss, Kap. 10, Rn. 44.

434 RL 1999/44/EG vom 25. Mai 1999 zu bestimmten Aspekten des Verbrauchgüterkaufs und der Garantien für Verbrauchsgüter.

435 BeckOK BGB/Faust, § 434 BGB, Rn. 30.

436 Ebd., Rn. 31.

437 NK-BGB/Büdenbender, § 434 BGB, Rn. 11; vgl. Staudinger/Matusche-Beckmann, § 434 BGB, Rn. 74.

438 Ostendorf, JZ 2011, 822, 826; Grigoleit/Herresthal, JZ 2003, 233, 235; ähnlich auch Canaris, in Lorenz, Karlsruher Forum 2002, S. 57, der meint, dass ohnehin nur über die Beschaffenheit eine Vereinbarung getroffen werden könne und der im Vertrag zum Ausdruck gekommene Verwendungszweck nur Mittel zur Auslegung der Beschaffenheitsvereinbarung sei. 
der gleichen Grenzen zu halten wie den Begriff der Beschaffenheit der Kaufsache. ${ }^{439}$ Würde der Begriff der Verwendung nicht an die Beschaffenheit anknüpfen, wäre eine Abgrenzung zu Rechtsmängeln und kaufrechtlichen Nebenpflichten wie Aufklärungspflichten nicht mehr möglich. ${ }^{440}$

Dieser Ansicht ist zu folgen, da eine Loslösung des Begriffs der Verwendung von der Beschaffenheit zu einer ,uferlose[n] Ausdehnung des Fehlerbegriffs“" ${ }^{441}$ führen würde und Umstände eine Sachmangelhaftung des Verkäufers auslösen könnten, der er unter Umständen nicht im Wege der Nacherfüllung abhelfen könnte.

Da somit für $\S 434$ Abs. 1 Satz 2 Nr. 1 BGB die gleichen Umstände und Umweltbeziehungen zu berücksichtigen sind wie für $\S 434 \mathrm{Abs}$. $1 \mathrm{Satz} 1 \mathrm{BGB}$, kann aus dieser Vorschrift keine Pflicht zum Support der Online-Komponenten hergeleitet werden.

\section{(3) § 434 Abs. 1 Satz 2 Nr. 2 BGB}

Gemäß $§ 434$ Abs. 1 Satz 2 Nr. 2 BGB ist der Kaufgegenstand frei von Sachmängeln, wenn er sich (1) für die gewöhnliche Verwendung eignet und (2) eine Beschaffenheit aufweist, die bei Sachen der gleichen Art üblich ist, und (3) welche der Käufer nach der Art der Sache erwarten kann. Die Norm listet damit drei Tatbestandsmerkmale auf. ${ }^{442}$ In Rechtsprechung und Literatur besteht weitgehend Einigkeit darüber, dass die Tatbestandsmerkmale des $\S 434$ Abs. 1 Satz 2 Nr. 2 BGB kumulativ erfüllt sein müssen. ${ }^{443}$

Die Eignung zur gewöhnlichen Verwendung setzt voraus, dass in der Beschaffenheit der Kaufsache keine Defekte vorhanden sind, die es ausschließen oder erschweren, dass die Kaufsache für die gewöhnliche Verwendung gebraucht werden kann. ${ }^{444}$ Somit knüpft der Begriff der Eignung an die Beschaffenheit der Kaufsache i. S. d. § 434 Abs. 1 Satz 1 BGB an. ${ }^{445}$ Unter Berücksichtigung des oben entwickelten Verständnisses von der Beschaffenheit ${ }^{446}$ verlangt das Kriterium der Eignung somit hier nur, dass die

439 Oetker/Maultzsch, Schuldverhältnisse, Kap. 2, Rn. 67; Staudinger/Matusche-Beckmann, § 434 BGB, Rn. 74; Erman/Grunewald, § 434, Rn. 17; vgl. auch Ostendorf, JZ 2011, 822, 826, der die vertraglich vereinbarte Beschaffenheit und die vertraglich vorausgesetzten Verwendungszwecke als ,Äquivalente“" ansieht.

Oetker/Maultzsch, Schuldverhältnisse, Kap. 2, Rn. 67.

Erman/Grunewald, § 434, Rn. 17.

Oetker/Maultzsch, Schuldverhältnisse, Kap. 2, Rn. 68; Staudinger/Matusche-Beckmann, $\S 434$

BGB, Rn. 81; Eckert/Maifeld/Matthiesen, Kaufrecht, Rn. 359; vgl. Erman/Grunewald, § 434, Rn. $20 \mathrm{ff}$.

443 BGH, NJW 2013, 1671, 1672; Staudinger/Matusche-Beckmann, § 434 BGB, Rn. 81; Oetker/Maultzsch, Schuldverhältnisse, Kap. 2, Rn. 68; MüKo BGB/Westermann, § 434, Rn. 24; BeckOK BGB/Faust, § 434 BGB, Rn. 55; Eckert/Maifeld/Matthiesen, Kaufrecht, Rn. 359; a. A. juris PK/Pammler, § 434 BGB, Rn. 82, der einerseits in der Eignung zur gewöhnlichen Verwendung und andererseits in der üblichen Beschaffenheit, die der Käufer nach Art der Sache erwarten kann, zwei alternative Fallgruppen erblickt.

444 Vgl. Palandt/Weidenkaff, § 434 BGB, Rn. 23, 28; juris PK/Pammler, § 434 BGB, Rn. 70.

445 Palandt/Weidenkaff, § 434 BGB, Rn. 23, 28.

446 Siehe dazu oben, S. $71 \mathrm{ff}$. 
Kaufsache selbst das Potenzial zur Realisierung der gewöhnlichen Verwendung innehaben muss. Die Folge davon ist, dass der Support der Online-Komponenten keinen Umstand darstellt, der Voraussetzung für die Eignung des digitalen Spiels zur gewöhnlichen Verwendung ist. Denn auch wenn ohne den Support das digitale Spiel ganz oder zum Teil nicht gespielt werden kann, hat dieser - außerhalb der Kaufsache liegende Umstand nichts mit dem Potenzial der Spielkopie zu tun, den Support der OnlineKomponenten aufgrund ihrer Programmierung zu ermöglichen. Nur darauf kommt es hier aber an. Kurz gesagt heißt das, dass nach dem ersten Tatbestandsmerkmal des $\S$ 434 Abs. 1 Satz 2 Nr. 2 BGB nicht der Support für die Spielkopie geeignet sein muss, sondern umgekehrt die Spielkopie für den Support.

Die weiteren beiden Tatbestandsmerkmale dieser Vorschrift stellen ausdrücklich auf die - hier allerdings nach objektiven Kriterien zu bestimmende ${ }^{447}$ - Beschaffenheit der Kaufsache ab. Aber auch wenn der Beschaffenheitsbegriff hier nach objektiven Kriterien bestimmt wird, ist er inhaltlich mit dem Beschaffenheitsbegriff des $\S 434$ Abs. 1 Satz 1 BGB identisch. ${ }^{488}$ Es wäre auch nicht einzusehen, warum ein objektiv zu bestimmender Beschaffenheitsbegriff inhaltlich weitergehen sollte als die grundsätzlich der Parteivereinbarung unterliegende Beschaffenheit der Kaufsache gemäß § 434 Abs. 1 Satz 1 BGB. Die übliche bzw. zu erwartende Beschaffenheit des $\S 434$ Abs. 1 Satz 2 Nr. 2 BGB erfasst somit genauso wenig wie die vereinbarte Beschaffenheit des $\S$ 434 Abs. 1 Satz 1 BGB zukünftige Umstände der Kaufsache, die in Form einer gesondert zu erbringenden Leistung erst nach dem Gefahrübergang eintreten sollen. Das bedeutet, dass der Support der Online-Komponenten auch im Rahmen des $\S 434$ Abs. 1 Satz 2 Nr. 2 BGB nicht zur Beschaffenheit gehört, die üblich ist bzw. die der Käufer erwarten kann.

Das ändert sich auch nicht dadurch, dass der Verkäufer bzw. Hersteller des Spiels durch öffentliche Äußerungen auf den Support der Online-Komponenten Bezug nimmt, vgl. § 434 Abs. 1 Satz 3 BGB. Nach dieser Vorschrift kann die Beschaffenheit gem. § 434 Abs. 1 Satz 2 Nr. 2 BGB auch durch entsprechende Äußerungen mitbestimmt werden. ${ }^{449}$ Da der Wortlaut des $\S 434$ Abs. 1 Satz 3 BGB aber ausdrücklich auf die Beschaffenheit nach $\S 434$ Abs. 1 Satz 2 Nr. 2 BGB Bezug nimmt, wird deutlich, dass der Begriff nicht anders oder gar weiter verstanden werden soll als gem. $§ 434$ Abs. 1 Satz 1 oder Satz 2 BGB.

\section{(4) Zwischenergebnis}

$\S 434$ Abs. 1 BGB erfasst keine zukünftigen, wenn auch sehr eng mit der Kaufsache zusammenhängenden Umstände, deren Realisierung von einer zusätzlichen Leistung des Verkäufers oder eines Dritten abhängig ist, die noch dazu ein anderes Gepräge aufweist als die durch den Kaufvertrag begründeten Hauptleistungspflichten. Damit ist auch der Support der Online-Komponenten nicht Teil der Hauptleistungspflicht des

\footnotetext{
447 Vgl. BeckOK BGB/Faust, § 434 BGB, Rn. 66, 76.

448 juris PK/Pammler, § 434 BGB, Rn. 76; NK-BGB/Büdenbender, § 434 BGB, Rn. 11; wohl auch Palandt/Weidenkaff, § 434 BGB, Rn. 28.

449 BeckOK BGB/Faust, § 434 BGB, Rn. 77.
} 
Verkäufers, die Sache frei von Sachmängeln zu verschaffen. Das bedeutet im Umkehrschluss auch, dass die Nichterbringung des Supports keinen Sachmangel des digitalen Spiels gemäß § 434 Abs. 1 BGB darstellen kann.

Zwar kommt darüber hinaus noch in Betracht, den Support der Online-Komponenten als kaufvertragliche Nebenpflicht einzuordnen. Hiergegen spricht allerdings, dass es sich bei den Online-Komponenten nicht nur um einen untergeordneten Bestandteil des Inklusivspiels handelt. Wie bereits in Kapitel 1 erläutert, ist der Support sowohl der serverbasierten Online-DRM-Systeme als auch der spielbezogenen Online-Komponenten maßgeblich für die Nutzungsmöglichkeit der gesamten Spielkopie.

\section{c) Zusammenfassung}

Die Untersuchung hat ergeben, dass die Verpflichtung zur dauerhaften Überlassung der Inklusivspiel-Kopie gegen die einmalige Entrichtung eines Entgelts zwar als Kaufvertrag einzuordnen ist. Auf die Verpflichtung zum Support der Online-Komponenten hingegen finden die kaufrechtlichen Vorschriften keine Anwendung.

\section{Mietvertragliche Pflicht}

Wie bereits dargestellt, besteht nach Ansicht der Literatur für den „Anbieter“ eines digitalen Spiels die Pflicht, „zur Bereitstellung der virtuellen Spielumgebung ${ }^{\star 450}$ des digitalen Spiels, wobei dieser Begriff vom hier verwendeten Terminus des „Supports der Online-Komponenten “ abweicht. Trotz dieses unterschiedlichen Begriffsverständnisses soll die in der Literatur geführte Diskussion über die Typologisierung der Pflicht zur „Bereitstellung der virtuellen Spielumgebung“ im Folgenden als Ausgangspunkt für die vertragsrechtliche Einordnung der Pflicht zum Support der Online-Komponenten dienen.

Eine Literaturansicht vertritt, dass der Vertrag über die „Bereitstellung der virtuellen Spielumgebung “451 insgesamt den mietrechtlichen Regelungen gem. $\S 5535$ ff. BGB zu unterwerfen sei, sofern der Spieler im Gegenzug ein Entgelt an seinen Vertragspartner entrichtet. ${ }^{452}$ Vertragsgegenstand seien dabei die Software sowie die Serverkapazitäten, durch welche die virtuelle Spielumgebung realisiert wird, und auf die der Nutzer über sein Client-Programm zugreifen kann. ${ }^{453}$

Diese Ansicht überzeugt nicht. Dem Nutzer wird die serverseitig ablaufende Software nicht bereitgestellt oder zum Gebrauch überlassen. ${ }^{454}$ Mit der Software allein wäre dem Nutzer auch nicht geholfen, da die Bereitstellung der virtuellen Spielwelt bzw. der Support der Online-Komponenten - nur erfolgen könnte, wenn die Software

\footnotetext{
450 Siehe dazu oben, S. 63.

451 Siehe zum Begriffsverständnis oben, S. 63.

452 Psczolla, Onlinespielrecht, S. 89 ff.; Oehler/von Ribbeck, in Duisberg/Picot, Recht der Computer- und Videospiele, Kap. 6, Rn. 11; Creutz, Regeln virtueller Welten, S. 153; Diegmann/Kuntz, NJW 2010, 561, 562; wohl auch Berberich, Virtuelles Eigentum, S. 402 f.

453 Psczolla, Onlinespielrecht, S. 90.

${ }^{454}$ Vgl. dazu auch Schneider, Virtuelle Werte, S. 67.
} 
mit dem Spielclient auch kommuniziert. ${ }^{455}$ Der Nutzer hat mitunter noch nicht einmal Kenntnis davon, dass bestimmte Funktionen seines Spiels serverbasiert realisiert werden. Aus diesem Grund ist eine mietvertragliche Einordnung sowohl der Bereitstellung der virtuellen Spielumgebung als auch des Supports der Online-Komponenten abzulehnen.

\section{Typengemischte Pflicht}

Eine andere Auffassung in der Literatur meint, dass sich die Bereitstellung der virtuellen Spielumgebung aus mehreren verschiedenen Leistungen zusammensetze, sodass von einer typengemischten Leistungspflicht auszugehen sei. ${ }^{456}$

Rauda spricht sich dafür aus, auf die Erbringung von Support-Leistungen das Dienstvertragsrecht, auf die Gewährung des Zugangs zur ,virtuellen Welt“ Werkvertragsrecht und auf die eigentliche Gewährleistung des Betriebs der Spielwelt Mietvertragsrecht anzuwenden ${ }^{457}$ Krasemann differenziert nicht weiter und meint, dass der Bereitstellung der Spielwelt allgemein werk-, dienst- bzw. mietvertragliche Elemente innewohnen. ${ }^{458}$

Es fragt sich dabei aber, wann die Zugangsgewährung aufhört und die Gewährleistung des Betriebs der ,virtuellen Welt“ beginnt. Diese Abgrenzungsschwierigkeit führt zu Unsicherheiten bei der Auswahl des anwendbaren vertragsrechtlichen Regimes.

Wenn man davon ausgeht, dass sowohl die Zugangsgewährung als auch die Gewährleistung des Betriebs der ,,virtuellen Welt" ihre Grundlage in der Etablierung und Aufrechterhaltung der Client-Server-Kommunikation haben, liefe eine Unterbrechung dieser Kommunikation darauf hinaus, dass der Nutzer mit entsprechender Argumentation wahlweise Ansprüche des für ihn günstigeren miet- bzw. werkvertraglichen Gewährleistungsrechts geltend machen könnte, obgleich in beiden Fällen ein- und dieselbe Leistungshandlung nicht erbracht wird: die Etablierung und Aufrechterhaltung der Client-Server-Kommunikation.

Nichts anderes gilt für den Support des Online-Mehrspielermodus und der OnlineDRM-Systeme.

Aus diesem Grunde ist eine Aufspaltung des Supports der Online-Komponenten in Zugangsgewährung und Gewährleistung ihres Betriebs und eine entsprechend unterschiedliche Typologisierung abzulehnen.

455 Aus einem ähnlichen Grund hat der BGH auch die Einordnung eines Access-Provider-Vertrages als Mietvertrag abgelehnt BGH, NJW 2005, 2076, 2076.

456 Rauda, Computerspiele, Rn. 688; Preuß, Virtuelle Güter, S. 130 f.; Völzmann-Stickelbrock, in FS Eisenhardt, S. 332; Krasemann, MMR 2006, 351, 352; Klickermann, MMR 2007, 766, 768; Lober/Weber, CR 2006, 837, 839; Weber, in Brandi-Dohrn/Lejeune, Recht 2.0, S. 207; einen werkvertraglichen Schwerpunkt erkennend Schrader, in Leible/Sosnitza, Onlinerecht 2.0: Alte Fragen - neue Antworten?, S. 107.

457 Rauda, Computerspiele, Rn. 688; ähnlich auch Weber, in Brandi-Dohrn/Lejeune, Recht 2.0, S. $207 \mathrm{f}$.

458 Krasemann, MMR 2006, 351, 352; vgl. auch Klickermann, MMR 2007, 766, 768; Lober/Weber, CR 2006, 837, 839. 


\section{Dienstvertragliche Pflicht}

Eine dritte Ansicht will die Verschaffung des Zugangs zur Online-Spielwelt als Dienstvertrag einordnen.

Sie begründet ihre Auffassung damit, dass üblicherweise solche Verträge, welche den entgeltlichen Zugang zu Servern oder Datenbanken zum Gegenstand haben, als Dienstverträge eingeordnet werden, weil bezüglich der Erreichbarkeit der Server kein Erfolgsversprechen abgegeben werde. ${ }^{459}$ Ein solches Erfolgsversprechen sei auch gar nicht möglich, da der Anbieter dann auch die Verfügbarkeit der Übertragungsleitungen garantieren müsste, was jedoch unrealistisch sei. ${ }^{460}$

Die Einordnung des Supports der Online-Komponenten als dienstvertragliche Pflicht kommt dann in Betracht, wenn der Publisher des Spiels mit der Etablierung und Aufrechterhaltung der Client-Server-Kommunikation die Erbringung einer Tätigkeit gegen Entgelt verspricht und es sich hierbei um ein Dauerschuldverhältnis handelt. ${ }^{461} \mathrm{Im}$ Gegensatz zum Werkvertrag wird aufgrund eines Dienstvertrages kein Erfolg geschuldet. ${ }^{462}$

Dafür, dass ein Erfolg geschuldet ist, könnte sprechen, dass der Spieler erwartet, dass das Spiel samt seinen Online-Komponenten genutzt werden kann und ihm ein bloßes Bemühen des Publishers dahingehend nicht ausreicht.

Dagegen spricht jedoch die Art und Weise, wie die Online-Komponenten durch den Publisher realisiert werden. Der Support der Online-Komponenten wird mithilfe von zentralen Servern als Bestandteil einer Client-Server-Architektur erbracht, die sich über das Internet mit den Client-Programmen des Spielers verbinden.

Gegen die Annahme einer Erfolgshaftung und damit gegen die Anwendung des Werkvertragsrechts spricht insoweit erstens, dass die Serverkapazitäten des Publishers begrenzt sind und daher nicht durchweg garantiert werden kann, dass eine Client-Server-Kommunikation etabliert oder aufrechterhalten werden kann. Es kommt nämlich durchaus vor, dass infolge zahlreicher Nutzerzugriffe keineswegs jedem Spieler zu jeder Zeit die Nutzung der Online-Komponenten eröffnet werden kann. ${ }^{463}$

Zweitens kommt hinzu, dass die Client-Server-Kommunikation über das Internet stattfindet. Der Publisher ist in gleicher Weise wie der Spieler auf das Internet angewiesen und im selben Umfang wie er von möglichen Netzausfällen betroffen, die auBerhalb seiner Kontrolle liegen. Insofern weist der Support der Online-Komponenten digitaler Spiele Ähnlichkeiten mit dem Access-Provider-Vertrag auf. Diesen Vertrag ordnen der BGH und die überwiegende Literatur als Dienstvertrag ein mit ähnlichen

\footnotetext{
459 Wemmer/Bodensiek, K\&R 2004, 432, 434.

460 Ebd.

461 Palandt/Weidenkaff, § 611 BGB, Rn. 1 f.

462 MüKo BGB/Müller-Glöge, § 611 BGB, Rn. 22.

463 So wurde berichtet, dass kurz nach der Veröffentlichung des Spiels SimCity (EA) aufgrund des hoher Zugriffszahlen auf die Server zahlreiche Spieler mit Verbindungsproblemen zu kämpfen hatten, Feith, SimCity (2013), abrufbar unter http://www.gamestar.de/spiele/simcity/news/simcity,47958,3010078.html.
} 
Argumenten wie den soeben angeführten. ${ }^{464}$ Denn auch die Leistungskapazitäten des Access-Providers, welcher den Zugang zum Internet schuldet, sind begrenzt, sodass dieser nur ein ,sachgerechte[s] Bemühen um die Herstellung der Verbindung in das Internet ${ }^{\star 465}$ schulden könne. Für einen Dienstvertrag spricht hier gerade die Tatsache, dass der Eintritt des Erfolges vom Schuldner nicht beherrscht werden kann. ${ }^{466}$

Gegen die Anwendung des Werkvertragsrechts ist drittens anzuführen, dass die werkvertragsrechtlichen Vorschriften insgesamt nicht passen ${ }^{467}$, denn schon jede noch so kleine Unterbrechung der Client-Server-Kommunikation würde die Mängelgewährleistungsrechte des $\S 634$ BGB auslösen. Dies würde jedoch für den Publisher ein erhebliches und kaum überschaubares Haftungsrisiko darstellen.

Schließlich ist der Support der Online-Komponenten über einen längeren Zeitraum zu erbringen, was für das Vorliegen eines Dauerschuldverhältnisses ${ }^{468}$ spricht und nicht für die Erbringung eines punktuellen Erfolges. Zwar hat sich der BGH in einem obiter dictum für die Anwendung des Werkvertragsrechts auf den Web-Hosting-Vertrag ausgesprochen, sofern bei diesem die Gewährleistung der Abrufbarkeit der Webseite des Kunden im Vordergrund steht. ${ }^{469} \mathrm{Im}$ vorliegenden Fall steht jedoch nicht die Abrufbarkeit von Online-Inhalten im Vordergrund, sondern die Nutzungsmöglichkeit der Kopie eines clientbasierten digitalen Spiels samt ihrer Online-Komponenten. Hierfür ist die Etablierung und Aufrechterhaltung der Client-Server-Kommunikation Voraussetzung. Auf der Gewährleistung dieser Client-Server-Kommunikation liegt der Schwerpunkt, die nicht den werk-, sondern nur den dienstvertraglichen Vorschriften zugeordnet werden kann.

Zwar werden die Dienste aufgrund eines Dienstvertrages gem. § 611 Abs. 1 BGB nur gegen Vergütung erbracht, woran es beim Support der Online-Komponenten von Inklusivspielen auf den ersten Blick fehlen könnte - für diese wird schließlich kein gesondertes Entgelt an den Supportverpflichteten gezahlt. Jedoch ist das Entgelt für den Support der Online-Komponenten bereits im Kaufpreis des Spiels enthalten. ${ }^{470}$ Es spricht nichts dagegen, dass auch bei einem Dienstvertrag die Vergütung einmalig und nicht in wiederkehrender Form erbracht wird. ${ }^{471}$

464 BGH, NJW 2010, 1449, 1450; NJW 2005, 2076, 2076; Spindler, CR 2004, 203, 207; Petri/Göckel, CR 2002, 329, 331; Härting, CR 2001, 37, 38; Schneider, EDV-Recht, Teil M, Rn. 508; a. A. Redeker, in Hoeren/Sieber/Holznagel, Handbuch Multimedia-Recht, Teil 12, Rn. 160.

BGH, NJW 2005, 2076, 2076.

Hk-BGB/Schreiber, § 611 BGB, Rn. 3; Oetker/Maultzsch, Schuldverhältnisse, Kap. 7 Rn. 11.

470 Siehe dazu oben, S. 52.

471 Vgl. Erman/Edenfeld, § 611 BGB, Rn. 387. 


\section{Einordnung als Hauptleistungspflicht}

Fraglich ist, ob die Pflicht zum Support der Online-Komponenten bei Überlassung eines Inklusivspiels als Hauptleistungs- oder als Nebenpflicht einzuordnen ist.

Vertragliche Schuldverhältnisse begründen in der Regel mehrere Pflichten für die am Vertrag beteiligten Parteien, wobei sie in Haupt- und Nebenleistungspflichten untergliedert werden können. ${ }^{472}$

Die Hauptleistungspflichten stellen die essentialia des vertraglichen Schuldverhältnisses dar und bestimmen den Typus des Vertrages. ${ }^{473}$ Demgegenüber bezwecken die Nebenleistungspflichten die „Vorbereitung, Durchführung und Sicherung““474 der Hauptleistung und haben damit eine dienende Funktion ${ }^{475}$. Davon zu unterscheiden sind nicht-leistungsbezogene Neben- bzw. Rücksichtspflichten, welche das Integritätsinteresse der Parteien schützen sollen. ${ }^{476}$

Wie Hauptleistungspflichten sind auch die Nebenleistungspflichten selbstständig einklagbar. ${ }^{477}$ Ferner finden auf die Verletzung sowohl von Haupt- als auch von Nebenleistungspflichten die $\S \S 281,323$ BGB Anwendung. ${ }^{478} \mathrm{Zu}$ beachten ist jedoch, dass sich das Schuldverhältnis aufgrund einer weiteren Hauptleistungspflicht in einen zusammengesetzten oder einen gemischten Vertrag verwandeln kann. ${ }^{479}$

Eine Einordnung einer Pflicht als Hauptleistungspflicht kommt in Betracht, wenn ein besonderes Interesse des Gläubigers an der Erfüllung der Pflicht durch den Schuldner besteht ${ }^{480}$. So ist anerkannt, dass bei besonderem Interesse des Verkäufers an der Abnahme der Kaufsache die Abnahme durch die Parteien von einer Nebenleistungszu einer Hauptleistungspflicht gekoren werden kann. ${ }^{481}$ So hat auch der Erwerber des Inklusivspiels - wie bereits ausgeführt - ein besonderes Interesse daran, dass der Direktverkäufer für den Support der Online-Komponenten einsteht, da nur auf diesem Wege die gesamte oder teilweise Nutzungsmöglichkeit der Spielkopie gewährleistet werden kann. Darüber hinaus entrichtet der Erwerber auch ein Entgelt für diesen Support ${ }^{482}$, was ebenfalls für die Einordnung des Supports der Online-Komponenten als Hauptleistungspflicht spricht.

\footnotetext{
472 Vgl. zum Ganzen Palandt/Grüneberg, § 241 BGB, Rn. 5 ff.

473 Ebd., Rn. 5; Larenz, LBS Band 1, AT, S. 11; Medicus/Lorenz, SchR I AT, Rn. 108; vgl. NKBGB/Krebs, § 241 BGB, Rn. 17.

474 Palandt/Grüneberg, § 241 BGB, Rn. 5.

475 Staudinger/Olzen, § 241 BGB, Rn. 151; Medicus/Lorenz, SchR I AT, Rn. 109.

476 Palandt/Grüneberg, § 241 BGB, Rn. 6.

477 MüKo BGB/Bachmann, § 241 BGB, Rn. 30; Medicus/Lorenz, SchR I AT, Rn. 109.

478 MüKo BGB/Bachmann, § 241 BGB, Rn. 30.

479 Roth-Neuschild, in Auer-Reinsdorff/Conrad, Handbuch IT- und Datenschutzrecht, $\S 13$, Rn. 43.

480 Vgl. Fikentscher/Heinemann, SchR, Rn. 36; Medicus/Lorenz, SchR I AT, Rn. 109.

481 Fikentscher/Heinemann, SchR, Rn. 36.

482 Siehe dazu oben, S. 52.
} 
Damit handelt es sich bei der Pflicht zum Support der Online-Komponenten eines Inklusivspiels um eine Hauptleistungspflicht.

\section{Der Überlassungsvertrag mit Support-Verpflichtung als gemischter Vertrag}

Der gemischte Vertrag stellt eine Vereinbarung dar, die Leistungspflichten enthält, welche sich nicht alle ein und demselben Vertragstyp zuordnen lassen. ${ }^{483}$ Die Leistungspflichten sind jedoch untrennbar miteinander verbunden und bilden nur gemeinsam ein ,sinnvolles Ganzes“484. Für die Einordnung einer Vereinbarung als gemischter Vertrag ist auf den Willen der Vertragsparteien abzustellen, wobei es darauf ankommt, ob das von den Parteien mit der Vereinbarung erstrebte wirtschaftliche Ergebnis mit einem gemischten Vertrag oder eher mit mehreren Verträgen zu erreichen ist. ${ }^{485}$

Wie bereits herausgearbeitet wurde, lassen sich die beiden Hauptleistungspflichten des Direktveräußerers des Inklusivspiels nicht demselben Vertragstyp zuordnen. Während es sich bei der Überlassung der Software um eine kaufvertragliche Verpflichtung handelt ${ }^{486}$, ist der Support der Online-Komponenten als dienstvertragliche Pflicht einzuordnen. ${ }^{487}$

Der Support der Online-Komponenten ist darüber hinaus wirtschaftlich sehr eng mit der Spielkopie verbunden. Dies ergibt sich zum einen daraus, dass ohne den Support die Spielkopie teilweise oder als Ganzes nicht mehr genutzt werden kann. Hinzu kommt, dass der Erwerber das Entgelt nicht nur als Gegenleistung für die Überlassung der Spielkopie, sondern auch für den Support der Online-Komponenten entrichtet. ${ }^{48}$ Damit besteht auch eine sehr enge wirtschaftliche Verbundenheit von Leistung und Gegenleistung der Parteien.

Der vorliegende Vertrag weist damit die Merkmale eines Typenkombinationsvertrages auf, welcher eine Unterart der gemischten Verträge darstellt. Hierbei handelt es sich um einen Vertrag, bei dem die vertragstypischen Leistungen einer Partei verschiedenen Vertragsarten angehören, die Gegenleistung der anderen Partei allerdings einheitlich in Geld erbracht wird. ${ }^{489}$

\section{Zusammenfassung}

Es konnte festgestellt werden, dass der zwischen dem Direktverkäufer und dem Erwerber des Inklusivspiels abgeschlossene Überlassungsvertrag, aufgrund dessen der

483 Esser/Schmidt, SchR I, S. 215; Gernhuber, Hdb. SchR, S. 157 f.; vgl. BeckOK/Gehrlein, § 311 BGB, Rn. 20.

484 Roth-Neuschild, in Auer-Reinsdorff/Conrad, Handbuch IT- und Datenschutzrecht, § 13 Rn. 45.

485 Gernhuber, Hdb. SchR, S. 160.

486 Siehe dazu oben, S. 65 ff.

487 Siehe dazu oben, S. $80 \mathrm{ff}$.

488 Siehe dazu oben, S. 52.

$489 \mathrm{Erman} / \mathrm{Kindl}$, vor. $\S 311 \mathrm{BGB}, \mathrm{Rn} .18$. 
Erwerber die Entrichtung eines einmalig zu zahlenden Entgelts schuldet, als gemischter Vertrag einzuordnen ist.

Neben der Pflicht des Publishers, die Spielkopie zu überlassen, tritt seine Pflicht zum Support der Online-Komponenten des digitalen Spiels, welche den dienstvertragsrechtlichen Vorschriften unterfällt. Dabei ist zu beachten, dass die Pflicht zum Support der spielbezogenen Online-Komponenten aufschiebend bedingt sein kann, die Pflicht zum Support der serverbasierten Online-DRM-Systeme allerdings unbedingt entsteht.

\section{B. Free-to-Play-Spiele}

Eine weitere Kategorie client-basierter Spiele mit Online-Komponenten stellen die Free-to-Play-Spiele dar. ${ }^{490} \mathrm{Sie}$ sind dadurch gekennzeichnet, dass der Spielclient kostenlos heruntergeladen und zeitlich unbegrenzt gespielt werden darf.

\section{I. Überlassung des Spielclients}

\section{Einordnung als Gefälligkeitsverhältnis}

Da der Erwerb des Free-to-Play-Spielclients unentgeltlich erfolgt, ist zunächst die Frage zu klären, ob diesem nur ein Gefälligkeitsverhältnis zugrunde liegt.

Gefälligkeitsverhältnisse stellen Sonderbeziehungen zwischen einem Gefälligen und einem Begünstigten dar, die kein Vertragsverhältnis und damit auch keine einklagbaren Leistungsansprüche begründen. ${ }^{491}$ Rechtsprechung und herrschende Lehre stellen zur Unterscheidung zwischen Gefälligkeits- und vertraglichen Schuldverhältnissen auf den Willen der Parteien ab, sich rechtlich zu binden. ${ }^{492}$ Ein solcher Rechtsbindungswille gilt als gegeben, wenn der Leistungsempfänger aufgrund objektiver Gesichtspunkte auf einen solchen Willen schließen musste. ${ }^{493}$ Zur Feststellung des Rechtsbindungswillens werden Indizien wie die Art und Umstände der Leistung, ihr Grund und Zweck, ihre wirtschaftliche und rechtliche Bedeutung für den Empfänger, die Interessenlage der Parteien und etwaige dem Leistenden erkennbare Gefahren, in welche der Empfänger durch eine fehlerhafte Leistung geraten kann, herangezogen. ${ }^{494}$

Die Umstände der Überlassung des Free-to-Play-Spielclients sprechen regelmäßig für das Vorliegen eines vertraglichen Schuldverhältnisses. Der kostenlose Erwerb des

\footnotetext{
490 Zum Begriff siehe oben, unter S. $31 \mathrm{f}$.

491 Palandt/Grüneberg, Einl. v. § 241 BGB, Rn. 7.

492 Ständige Rechtsprechung, BGH, NJW 1956, 1313, 1313; NJW 1971, 1404, 1405; NJW-RR 2006, 117, 120; NJW 2009, 1141, 1142; NJW 2012, 3366, 3367; vgl. auch Palandt/Grüneberg, Einl. v. § 241 BGB, Rn. 7; Staudinger/Bork, Vorbem. zu §§ 145-156, Rn. 80; Erman/Westermann, Einl. zu $\S$ 241ff. BGB, Rn. 14; BeckOK BGB/Sutschet, $§ 241$ BGB, Rn. 18; Looschelders, SchR AT, § 5, Rn. 6.

493 Vgl. BGH, NJW 1956, 1313, 1313.

494 Vgl. Staudinger/Olzen, § 241 BGB, Rn. 85.
} 
Free-to-Play-Spielclients ist nämlich oftmals nur nach Erstellung eines Benutzer-Accounts oder zumindest erst nach der Zustimmung zu bestimmten Nutzungsbedingungen möglich. ${ }^{495}$ In der Literatur wird ein Rechtsbindungswille der die Software überlassenden Partei bejaht, wenn die Nutzung der Software die Zustimmung zu Nutzungsbedingungen oder die Registrierung des Nutzers voraussetzt. ${ }^{496}$

Es ist außerdem davon auszugehen, dass der kostenlose Spielclient vom Publisher mit dem Ziel zur Verfügung gestellt wird, den Nutzer zum Erwerb virtueller Gegenstände zu bewegen. Free-to-Play-Spiele sind so aufgebaut, dass der Spieler zwar unbegrenzt spielen kann, jedoch geschieht das nur langsam und ohne bedeutende Fortschritte ${ }^{497}$ Dadurch erhält der Spieler einen Anreiz, virtuelle Gegenstände zu erwerben, um so im Spiel schneller bzw. leichter voranzukommen. ${ }^{498}$ So wird auch in der Literatur ein Rechtsbindungswille der die Software überlassenden Partei bejaht, wenn sie den Empfänger mit der Überlassung zu einem späteren Vertragsschluss bewegen möchte. ${ }^{499}$ Das für Gefälligkeitsverhältnisse typische einseitige wirtschaftliche Interesse des Empfängers ${ }^{500}$ und die rein altruistische Motivation des Leistenden sind damit bei Free-to-Play-Spielen in der Regel nicht gegeben. Die Veräußerung virtueller Gegenstände stellt für Publisher vielmehr eine bedeutende Einnahmequelle dar: So belief sich der Umsatz, den Publisher bzw. Entwickler von digitalen Spielen mit der Veräußerung solcher virtuellen Gegenstände allein in Deutschland im Jahr 2016 erwirtschafteten, nach Angaben des Verbandes der deutschen Games-Branche e. V. auf $€ 659$ Mio. $^{501}$

Nicht zu vernachlässigen ist darüber hinaus auch die Gefahr, in die sich der Empfänger durch eine fehlerhafte Leistung des Veräußerers begeben kann. Es ist allgemein bekannt, dass fehlerhafte - z. B. von Viren befallene - Software nicht unerhebliche Schäden am Endgerät des Nutzers auslösen kann. Das Interesse des Erwerbers, keine Programme zu erhalten, welche auf seinem Endgerät Schaden anrichten können, spricht daher ebenfalls für das Vorliegen eines vertraglichen Schuldverhältnisses. ${ }^{502}$

495 So z. B. bei den auf der Steam-Plattform erhältlichen Free-to-Play-Spielen, siehe beispielhaft hierfür das Spiel Black Squad (Neowiz, Neobricks), abrufbar unter

http://store.steampowered.com/app/550650/Black_Squad/sowie das Spiel Yu-Gi-Oh! Duel Links (Konami), abrufbar unter

http://store.steampowered.com/app/601510/YuGiOh_Duel_Links/.

496 Vgl. Holzbach/Süßenberger, in Moritz/Dreier, Rechts-Handbuch zum E-Commerce, Teil C, Rn. 342; vgl. auch Meyer, Freie Software, S. 86.

${ }^{497}$ Adams, Game Design, S. 119.

498 Ebd.

499 Vgl. Roth-Neuschild, in Auer-Reinsdorff/Conrad, Handbuch IT- und Datenschutzrecht, $§ 13$, Rn. 29.

500 Vgl. dazu Klünder, Gefälligkeitsleistungen, S. 12.

501 game - Verband der deutschen Games-Branche, Starke Nachfrage nach Computer- und Videospielen: Umsatz wächst um 7 Prozent (2017), abrufbar unter https://www.game.de/starkenachfrage-nach-computer-und-videospielen-umsatz-waechst-um-7-prozent/.

Vgl. dazu Marly, Softwarerecht, Rn. 808. 
Insgesamt spricht die Indizienlage daher für ein vertragliches Schuldverhältnis zwischen dem Leistenden und dem Empfänger des kostenlosen Free-to-Play-Spielclients.

\section{Einordnung als Schenkung}

Fraglich ist, wie die Überlassung des Free-to-Play-Spielclients vertragsrechtlich zu typologisieren ist. In Betracht kommt eine Schenkung gemäß § 516 Abs. 1 BGB.

Die Schenkung bezeichnet ein unentgeltliches Rechtsgeschäft, welches auf die Bereicherung des Beschenkten durch eine Zuwendung aus dem Vermögen eines anderen gerichtet ist und das in subjektiver Hinsicht die Einigung der Vertragsparteien über die Unentgeltlichkeit der Zuwendung voraussetzt. ${ }^{503}$ Der zu schenkende Gegenstand soll dabei dauerhaft in das Vermögen des Beschenkten übergehen. ${ }^{504}$

\section{a) Zuwendung}

Problematisch ist zunächst das Tatbestandsmerkmal der Zuwendung, welche die Hingabe eines Vermögensgegenstandes voraussetzt, die zu einer Entreicherung des Schenkers und einer Bereicherung des Empfängers führen muss. ${ }^{505}$ Software, die zum Download angeboten wird, kann jedoch ohne Verluste und in unbegrenzter Zahl vervielfältigt und verbreitet werden, weshalb man daran zweifeln könnte, dass das Vermögen des Schenkers durch die Zuwendung auch verringert wird. ${ }^{506}$ Aus diesem Grund lehnt ein Teil der Literatur das Vorliegen einer Entreicherung des Schenkers ganz ab. ${ }^{507}$

Damit würde man aber die per Download erfolgende Verbreitung kostenloser Software anders behandeln als die verkörperte Überlassung von Software, bei welcher man relativ unproblematisch eine Entreicherung aufgrund der Entäußerung des Datenträgers annehmen kann. Eine derartige Differenzierung zwischen körperlicher und unkörperlicher Übertragung von Software soll im Schenkungsrecht aber nicht stattfinden. ${ }^{508}$ Dies macht der Verweis in $\S 523$ Abs. 2 S. 2 BGB deutlich, wonach für die Haftung des Schenkers für Rechtsmängel die Vorschrift des $\S 453$ BGB entsprechende Anwendung findet. ${ }^{509}$ Tatsächlich dient das Tatbestandsmerkmal der Entreicherung

503 Vgl. Palandt/Weidenkaff, § 516 BGB, Rn. 1.

504 MüKo BGB/Koch, § 516 BGB, Rn. 1.

505 Ebd., Rn. 5 f., 11; BeckOK BGB/Gehrlein, § 516 BGB, Rn. 2; Jauernig/Mansel, § 516 BGB, Rn. 5 ff.; Hk-BGB/Saenger, § 516 BGB, Rn. 3.

506 Jaeger/Metzger, Open Source Software, Rn. 207; Spindler, in Spindler, Rechtsfragen bei Open Source, S. 155; Hoeren, in FS Kollhosser, S. 235; Baumgartner/Ewald, Apps und Recht, Rn. 32.

507 Hoeren, in FS Kollhosser, S. 236; Sester, CR 2000, 797, 799 f.

508 Vgl. Deike, CR 2003, 9, 15.

509 Spindler, in Spindler, Rechtsfragen bei Open Source, S. 154; so auch in Bezug auf kostenlose Apps allgemein Baumgartner/Ewald, Apps und Recht, Rn. 32. 
auch eher dazu, diejenigen Fälle auszuschließen, in denen es lediglich zu einer vorübergehenden Gebrauchsüberlassung kommt ${ }^{510}$, was jedoch bei der dauerhaften Überlassung des Free-to-Play-Spielclients nicht der Fall ist. Damit ist auch eine „Entreicherung" des Schenkers im hier verstandenen Sinn gegeben.

\section{b) Unentgeltlichkeit}

Erforderlich ist weiterhin, dass sich die Parteien über die Unentgeltlichkeit des Geschäfts geeinigt haben, was zu bejahen ist, wenn die Leistung des Schenkers unabhängig von einer Gegenleistung erbracht werden soll. ${ }^{511}$

\section{aa) Anlegung eines Nutzer-Accounts und Zustimmung zu Nutzungs- bedingungen}

Eine solche Gegenleistung könnte zunächst darin zu erblicken sein, dass der Nutzer - wie bereits dargestellt - einen Nutzer-Account anlegen und Nutzungsbedingungen zustimmen muss, bevor er das Spiel verwenden kann. Insofern wird auch mit Blick auf Open-Source-Software zum Teil die Ansicht geäußert, dass die in den sog. CopyLeft-Lizenzen enthaltene Verpflichtung des Nutzers, bei der Weitergabe der Software die von ihm erstellten Modifikationen freizugeben, eine Gegenleistungspflicht des Nutzers darstelle. ${ }^{512}$ Diese Ansicht ist jedoch abzulehnen, da die genannte Verpflichtung nur verhindern soll, dass aus der Open-Source-Software proprietäre Software wird. ${ }^{513}$ Diese Verpflichtung ist außerdem weder konditional noch kausal mit der Überlassung der Software verknüpft. ${ }^{514}$ Der Nutzer erhält vielmehr von vornherein einen Gegenstand, welchen er nur in eingeschränkter Weise benutzen darf. ${ }^{515}$ So verhält es sich auch mit dem kostenlos überlassenen Free-to-Play-Spielclient. Die Nutzungsbedingungen, welchen der Spieler unter Umständen zustimmen muss, und der Account, welchen er einzurichten hat, stellen von vornherein bestehende Beschränkungen der Nutzungsmöglichkeit des Spiels dar. Sie stehen der Einordnung des Erwerbs des Free-to-Play-Spielclients als unentgeltlich nicht entgegen.

\section{bb) Bereitstellung personenbezogener Daten}

Nach dem Inkrafttreten der DI-RL hat für die Bestimmung der Unentgeltlichkeit des Erwerbs eines Free-to-Play-Spielclients die Frage erheblich an Bedeutung gewonnen, ob der Verbraucher dem Unternehmer personenbezogene Daten bereitstellen muss.

510 Jaeger/Metzger, Open Source Software, Rn. 207; vgl. BeckOK BGB/Gehrlein, § 516 BGB, Rn. 4.

511 Palandt/Weidenkaff, § 516 BGB, Rn. 8.

512 Hoeren, in FS Kollhosser, S. 237.

513 Jaeger/Metzger, Open Source Software, Rn. 215.

514 Ebd.; Metzger/Jaeger, GRUR Int. 1999, 839, 847.

515 Spindler, in Spindler, Rechtsfragen bei Open Source, S. 157; Jaeger/Metzger, Open Source Software, Rn. 215; Metzger/Jaeger, GRUR Int. 1999, 839, 847; a. A. Sester, CR 2000, 797, 800 . 
Die DI-RL ist ausweislich ihres Art. 3 Abs. 1 S. 1 zwar nicht auf unentgeltliche Verträge zwischen Verbrauchern und Unternehmern anwendbar. ${ }^{516}$ Allerdings erfasst die Richtlinie gemäß Art. 3 Abs. 1 S. 2 auch solche Verträge, bei denen der Verbraucher kein Geld zahlt, anstelle dessen aber ,dem Unternehmer personenbezogene Daten bereitstellt oder deren Bereitstellung zusagt“.

Die Regelung des Art. 3 Abs. 1 S. 2 beseitigt damit die Illusion einer „Kostenloskultur im Internet“" 517 , indem sie in bestimmten Fällen personenbezogene Daten als Gegenleistung für die Bereitstellung digitaler Inhalte ansieht. Zwar bezeichnet die verabschiedete Fassung der DI-RL im Gegensatz zum ursprünglichen Kommissionsentwurf die Überlassung personenenbezogener Daten nicht mehr ausdrücklich als „Gegenleistung““ ${ }^{518}$ Dies kann jedoch nicht darüber hinwegtäuschen, dass in der wirtschaftlichen Praxis die Überlassung personenbezogener Daten sehr oft Voraussetzung für die Inanspruchnahme von Angeboten ist und damit als Entgelt für diese angesehen werden muss. ${ }^{519}$

Es wäre aber nicht gerechtfertigt, sämtliche Verträge über die Bereitstellung digitaler Inhalte nur deshalb als entgeltlich anzusehen, weil der Verbraucher im Zusammenhang mit diesen Verträgen auch personenbezogene Daten zur Verfügung stellt. Es sind schließlich kaum Fälle denkbar, in denen die Bereitstellung digitaler Inhalte nicht mit der Zurverfügungstellung von personenbezogenen Daten einhergeht. Gemäß Art. 3 Abs. 1 S. 2 a.E. werden daher solche Fälle der Zurverfügungstellung personenbezogener Daten als unentgeltlich angesehen, in denen die Bereitstellung nur zu dem Zweck der Vertragserfüllung oder der Einhaltung rechtlicher Anforderungen erfolgt. ${ }^{520}$

Eine einheitliche Einordnung des Erwerbs des Free-to-Play-Spielclients als entgeltlich oder unentgeltlich ist angesichts der Vielzahl und Unterschiedlichkeit der am Markt erhältlichen Free-to-Play-Spiele nicht möglich. Es sind aber durchaus Fälle denkbar, in denen der Verbraucher dem Publisher bestimmte personenbezogene Daten als Gegenleistung bereitstellen muss, um den Free-to-Play-Spielclient zu erwerben.

Die Einordnung als Schenkung gemäß $§ 516$ Abs. 1 BGB scheidet in einem solchen Fall aus, da der Erwerb hier von einer Gegenleistung abhängig und damit nicht mehr entgeltlich ist. ${ }^{521}$ Ebenfalls liegt die Einordnung des Vertrages als Tausch gemäß $§ 480$ BGB oder als Kauf gemäß $§ 433$ Abs. 1 BGB fern, da die Einwilligung zur Verarbeitung personenbezogener Daten gemäß Art. 7 Abs. 3 DS-GVO ${ }^{522}$ für den Verbraucher jederzeit widerruflich ist und somit die Daten nicht zwingend dauerhaft beim Publisher

516 Ehle/Kreß, CR 2019, 723, 724.

517 So zum Kommissionsentwurf Metzger, AcP 2016, 817, 818.

518 Art. 3 Nr. 1 des Kommissionsvorschlages (COM(2015) 634 final) sah ausdrücklich die Überlassung personenbezogener Daten als ,eine andere Gegenleistung als Geld“ an, vgl. hierzu Metzger, JZ 2019, 577, 579.

519 Vgl. Staudenmayer, ZEuP 2019, 663, 669; Metzger, JZ 2019, 577, 579.

${ }^{520}$ Metzger, JZ 2019, 577, 579; Staudenmayer, ZEuP 2019, 663, 669 f.

521 Vgl. zum Kommissionsentwurf Metzger, AcP 2016, 817, 833 f.

522 Datenschutzgrundverordnung, (EU) 2016/679, v. 27. April 2016. 
verbleiben ${ }^{523}$ Es bietet sich vielmehr an, mietvertragliche Vorschriften auf diesen Vertrag anzuwenden ${ }^{524}$ und entgeltliche Free-to-Play-Spiele damit wie die noch unten darzustellenden Zeitspiele ${ }^{525}$ zu behandeln.

Es ist aber auch möglich, dass eine Reihe von Free-to-Play-Spielen nicht unter die Regelung des Art. 3 Abs. 1 S. 2 DI-RL fällt, weil der Erwerb der Spielclients nicht von der Bereitstellung personenbezogener Daten abhängig ist und damit unentgeltlich erfolgt. $\mathrm{Zu}$ beachten ist in diesem Zusammenhang, dass bei Free-to-Play-Spielen in der Regel nicht die Verarbeitung von personenbezogenen Daten im Vordergrund steht, sondern vielmehr die Veräußerung virtueller Gegenstände innerhalb dieser Spiele. Dies wird durch die starke Zunahme von Käufen virtueller Gegenstände in Deutschland nahegelegt, welche sich zwischen 2017 und 2018 auf $40 \%$ belief. ${ }^{526}$ Die dauerhafte, unentgeltliche Überlassung des Free-to-Play-Spielclients ist dann als Schenkung einzuordnen.${ }^{527}$ Es handelt sich dabei um eine Handschenkung, da das herunterzuladende Programm in der Regel sofort zur Verfügung gestellt und somit die Zuwendung unmittelbar vollzogen wird.

Im weiteren Verlauf werden ausschließlich solche Free-to-Play-Spiele behandelt, deren Spielclient im soeben beschriebenen Sinn unentgeltlich erworben werden kann.

\section{Support der Online-Komponenten}

\section{Nutzung des Spiels ohne Erwerb virtueller Gegenstände}

Free-to-Play-Spiele können durchaus einen Online-Mehrspielermodus enthalten. ${ }^{528}$ Es ist darüber hinaus nicht auszuschließen, dass auch Online-DRM-Systeme zum Einsatz kommen. Das Spiel samt seinen Online-Komponenten kann der Erwerber dabei grundsätzlich auch ohne den Erwerb virtueller Gegenstände nutzen. ${ }^{529}$ Wie auch bei Inklusivspielen fehlt es bei den kostenlos zu erwerbenden Spielen aber oftmals an einer vertraglichen Regelung über eine etwaige Pflicht zum Support der Online-Komponenten.

Für die Herleitung einer Supportpflicht im Wege der ergänzenden Vertragsauslegung spricht zunächst - wie auch bei Inklusivspielen - die hohe Abhängigkeit der

523 Vgl. Metzger, AcP 2016, 817, 835.

524 Ebd., 838.

525 Siehe dazu unten, S. 97.

526 game-Verband der deutschen Games-Branche, Deutscher Markt für Spiele-Apps im ersten Halbjahr 2018 (2018), abrufbar unter https://www.game.de/marktdaten/deutscher-markt-fuerspiele-apps-im-ersten-halbjahr-2018/.

527 So auch Moser, Browsergames, S. 74; Striezel, Virtuelle Gegenstände, S. 202; Rauda, Computerspiele, Rn. 685; Baumgartner/Ewald, Apps und Recht, Rn. 38; so für Software im Allgemeinen von dem Bussche/Schelinski, in Leupold/Glossner, Münchener Anwalts Handbuch ITRecht, Teil 1, Rn. 71; Koch, Computer-Vertragsrecht, S. 423.

528 Siehe dazu oben, S. 31.

529 Vgl. dazu oben, S. 31. 
Nutzungsmöglichkeit des digitalen Spiels von der nicht geregelten Leistung. ${ }^{530} \mathrm{Wie}$ das Inklusivspiel kann auch das Free-to-Play-Spiel ganz oder teilweise nicht mehr genutzt werden, wenn der Support der Online-Komponenten beendet wird. Hinzu kommt, dass es keine alternativen Supportdienstleister gibt, an die sich der Nutzer im Falle der Beendigung des Supports wenden könnte, sodass er auf den Support der Online-Komponenten durch den jeweiligen Publisher angewiesen ist. Außerdem ist der Nutzer faktisch nicht in der Lage, mit dem Publisher eine vertragliche Supportpflicht auszuhandeln.

Problematisch ist allerdings, dass der Erwerber des Free-to-Play-Spiels - im Gegensatz zum Erwerber eines Inklusivspiels - keinerlei Gegenleistung erbringt. Darüber hinaus erwirbt er auch keine virtuellen Gegenstände. Er tätigt also keine Investition, welche im Falle der Beendigung des Supports der Online-Komponenten frustriert sein könnte. Falls der Support beendet wird, steht der Erwerber damit nicht schlechter da als in dem Fall, in welchem er den Spielclient gar nicht erst erworben hätte. Abhängig von der Art der Online-Komponente, deren Support beendet wurde, steht ihm dann immer noch ein zumindest teilweise nutzbarer Spielclient zur Verfügung. Da der Erwerber des Free-to-Play-Spielclients somit in wirtschaftlicher Hinsicht kaum vom Support betroffen ist, erscheint es nicht gerechtfertigt, den Publisher zum Support der Online-Komponenten zu verpflichten. Dafür spricht auch die generelle Ausrichtung des Free-to-Play-Spiels auf den Erwerb virtueller Gegenstände. Hierauf kommt es dem Publisher maßgeblich an. Falls der Spieler daran jedoch kein Interesse hat, sollte der Publisher nicht zum Support nicht lukrativer Online-Komponenten des Spiels verpflichtet sein.

Damit kann eine Pflicht des Publishers zum Support der Online-Komponenten des Free-to-Play-Spiels in Fällen, in denen der Erwerber keine virtuellen Gegenstände erwirbt, nicht im Wege einer ergänzenden Vertragsauslegung hergeleitet werden. Somit hat der Erwerber des Free-to-Play-Spiels keinen Anspruch auf Support der OnlineKomponenten des Spiels gegen den Publisher oder eine andere für den Support zuständige Person.

\section{Nutzung des Spiels mit Erwerb virtueller Gegenstände}

Fraglich ist jedoch, ob bei Free-to-Play-Spielen eine Supportpflicht im Wege der ergänzenden Vertragsauslegung hergeleitet werden kann, falls der Nutzer virtuelle Gegenstände erwirbt.

\section{a) Typologisierung des dauerhaften Erwerbs virtueller Gegenstände}

Es existieren unterschiedliche Arten virtueller Gegenstände, wie z. B. Waffen, Spielfiguren oder auch Einrichtungsgegenstände. ${ }^{531}$ Die virtuellen Gegenstände haben außerdem ganz unterschiedliche Funktionen, wozu beispielsweise die Verbesserung der

\footnotetext{
$530 \mathrm{Zu}$ den Kriterien für die Herleitung einer Supportpflicht siehe oben, S. 52 ff.

531 Psczolla, Onlinespielrecht, S. 53.
} 
Kampfkraft oder die Erhöhung der Lebensdauer einer Spielfigur gehört. ${ }^{532}$ Sie können innerhalb eines Spiels entweder aufgrund von spielerischen Leistungen oder im Gegenzug für die Zahlung von realem oder von „Spielgeld“ erworben werden. ${ }^{53}$

Die herrschende Literatur wendet auf den Vertrag über den dauerhaften Erwerb des virtuellen Gegenstands gegen die einmalige Entrichtung eines Entgelts die kaufvertragsrechtlichen Vorschriften entweder direkt oder analog an. ${ }^{534}$ Zwar handle es sich bei virtuellen Gegenständen nicht um Sachen im Sinne des $\S 90$ BGB $^{535}$, jedoch komme eine Einordnung entweder als Kauf eines sonstigen Gegenstandes ${ }^{536}$ oder als Rechtskauf ${ }^{537}$ gemäß $\S 453$ Abs. 1 BGB in Betracht.

Eine Minderansicht ist dagegen für eine Einordnung als Miet- ${ }^{538}$ oder als Werkvertrag ${ }^{539}$. Nach dieser Auffassung spreche gegen die kaufvertragliche Einordnung, dass es sich bei der Überlassung des virtuellen Gegenstands letztlich nur um eine Umgestaltung der beim Spieler gespeicherten Daten der Spielkopie handle. ${ }^{540}$ Darüber hinaus sei die Annahme eines Kaufvertrages realitätsfern, da die virtuellen Gegenstände dem Erwerber nicht zeitlich unbegrenzt zur Verfügung stehen sollen, sondern nur so lange, wie auch das digitale Spiel fortbesteht. ${ }^{541}$ Eine kaufvertragliche Einordnung hätte jedoch zur Folge, dass der „Betreiber“ des Spiels auch dazu verpflichtet wäre, die zeitlich unbegrenzte Nutzung der virtuellen Welt zu ermöglichen. ${ }^{542}$

Gegen die zuletzt genannte Ansicht spricht jedoch, dass es für den Spieler in der Regel nicht ersichtlich ist, ob der Erwerb eines virtuellen Gegenstandes durch Umgestaltung des auf seinem Endgerät installierten Spiels erfolgt oder etwa durch eine

532 Vgl. Oehler/von Ribbeck, in Duisberg/Picot, Recht der Computer- und Videospiele, Kap. 6, Rn. 17; Völzmann-Stickelbrock, in FS Eisenhardt, S. 334.

533 Vgl. Psczolla, Onlinespielrecht, S. 53; Oehler/von Ribbeck, in Duisberg/Picot, Recht der Computer- und Videospiele, Kap. 6, Rn. 18; Diegmann/Kuntz, NJW 2010, 561, 561.

534 Lober/Weber, MMR 2005, 653, 656; Klickermann, MMR 2007, 766, 768; Diegmann/Kuntz, NJW 2010, 561, 562; Lutzi, NJW 2012, 2070, 2071; Kannowski/Till, NJOZ 2017, 522, 523; BeckOK BGB/Fritzsche, § 90 BGB, Rn. 27; Geis/Geis, CR 2007, 721, 721; Psczolla, Onlinespielrecht, S. 79; Schneider, Virtuelle Werte, S. 190; Rippert/Weimer, ZUM 2007, 272, 278; Striezel, Virtuelle Gegenstände, S. 220 ff.; Preuß, Virtuelle Güter, S. 115; Schapiro, in Bräutigam/Rücker, E-Commerce, 6. Teil, F., Rn. 22; Redeker, IT-Recht, Rn. 1165.

535 Dazu Geis/Geis, CR 2007, 721, 721; Schapiro, in Bräutigam/Rücker, E-Commerce, 6. Teil, F. Rn. 21.

536 So Lutzi, NJW 2012, 2070, 2071; Diegmann/Kuntz, NJW 2010, 561, 562; BeckOK BGB/Fritzsche, § 90 BGB, Rn. 27; Geis/Geis, CR 2007, 721, 721; Psczolla, Onlinespielrecht, S. 79.

537 So Lober/Weber, MMR 2005, 653, 656; Klickermann, MMR 2007, 766, 768; Schneider, Virtuelle Werte, S. 190; Rippert/Weimer, ZUM 2007, 272, 278; Schapiro, in Bräutigam/Rücker, ECommerce, 6. Teil, F. Rn. 21; Redeker, IT-Recht, Rn. 1165.

538 Creutz, Regeln virtueller Welten, S. 168.

539 Völzmann-Stickelbrock, in FS Eisenhardt, S. 344; für einen gemischten Vertrag mit werk- und dienstvertraglichen Elementen plädiert Gräber, virtuelle Güter, S. 83 f.

Völzmann-Stickelbrock, in FS Eisenhardt, S. 344.

${ }^{541}$ Gräber, virtuelle Güter, S. 69; dem folgend Creutz, Regeln virtueller Welten, S. 166.

${ }^{542}$ Creutz, Regeln virtueller Welten, S. 166. 
Übertragung von zusätzlichen Daten vonstattengeht. Das Ergebnis stellt sich für ihn außerdem in beiden Fällen gleich dar: Er verfügt über einen virtuellen Gegenstand innerhalb des digitalen Spiels. Aus diesen Gründen kann es nicht darauf ankommen, wie der Erwerb des virtuellen Gegenstands technologisch abläuft.

Es ist zwar einzusehen, dass die Anwendung des Kaufrechts auf den dauerhaften, entgeltlichen Erwerb virtueller Gegenstände nicht dazu führen darf, dass der „Betreiber“ des Spiels die Nutzungsmöglichkeit desselben für immer aufrechterhalten muss. Es ist aber nicht nachvollziehbar, warum dieses Ziel nur durch einen kategorischen Ausschluss der Anwendung des Kaufvertragsrechts erreicht werden könnte.

Damit ist der herrschenden Meinung zu folgen, nach der auf den dauerhaften, entgeltlichen Erwerb eines virtuellen Gegenstands Kaufrecht Anwendung findet.

\section{b) Zusammenhang zwischen Support und virtuellen Gegenständen}

Es ist möglich, dass sich die Beendigung des Supports der Online-Komponenten des Free-to-Play-Spiels negativ auf die Nutzungsmöglichkeit der erworbenen virtuellen Gegenstände auswirkt. Dies ist einerseits in Fällen denkbar, in welchen die Speicherung der virtuellen Gegenstände nicht lokal auf dem Endgerät des Spielers, sondern auf zentralen Servern des Publishers erfolgt. ${ }^{543}$ Andererseits kann die Beendigung des Supports der Online-Komponenten auch unabhängig vom Speicherort der virtuellen Gegenstände Einfluss auf ihre Nutzungsmöglichkeit haben, etwa wenn sie nur innerhalb eines Teils des Spiels genutzt werden können, dessen Nutzungsmöglichkeit wiederum vom Support der Online-Komponenten abhängt.

In diesen Fällen entsteht im Vertrag über die Überlassung des virtuellen Gegenstandes eine im Wege der ergänzenden Vertragsauslegung herzuleitende Supportpflicht. ${ }^{544}$ Für den Fall, dass die Person, welche den virtuellen Gegenstand überlässt, nicht identisch ist mit demjenigen, welcher den Support der Online-Komponenten erbringt, entsteht die Supportpflicht in einem separaten Supportvertrag. ${ }^{545}$ Für das Entstehen einer Supportpflicht spricht, dass der Erwerber des virtuellen Gegenstands eine Investition getätigt hat und erwartet, den virtuellen Gegenstand - zumindest für einen bestimmten Zeitraum - nutzen zu können. Diese berechtigte Leistungserwartung und das Äquivalenzinteresse des Erwerbers würden enttäuscht, wenn man eine Pflicht zum Support der für die Nutzungsmöglichkeit des virtuellen Gegenstandes notwendigen OnlineKomponenten verneinen würde und der Support daher jederzeit beendet werden könnte.

Die Pflicht ist dabei - wie auch beim Support von Inklusivspielen - als dienstvertragsrechtliche Leistungspflicht gemäß $§ 611$ Abs. 1 BGB einzuordnen. Die gemäß 611 Abs. 1 BGB erforderliche Vergütung des Supportverpflichteten ist Teil des Kaufpreises, welchen der Käufer des virtuellen Gegenstandes entrichtet.

543 Vgl. dazu Frieling, MedienWirtschaft 2/2011, 14, 17 f.; Wissenschaftliche Dienste des Deutschen Bundestages, Virtuelle Güter bei Computerspielen (2011), S. 6, abrufbar unter https://www.bundestag.de/blob/412052/a2ff34407556f84c8b5a31e90db0df8c/wd-10-085-11pdf-data.pdf; Preu $\beta$, Virtuelle Güter, S. 37 f.

544 Siehe dazu oben, S. 52 ff.

545 Siehe dazu oben, S. $61 \mathrm{ff}$. 


\section{Abospiele}

Die Gruppe der Abospiele kann untergliedert werden in die Konsolenspiele, die Zeitspiele und die MMOG. ${ }^{546}$ Charakteristisch für Abospiele ist, dass entweder die Nutzung des gesamten Spiels oder nur des Online-Mehrspielermodus lediglich im Gegenzug für die Entrichtung einer wiederkehrenden Gebühr möglich ist.

\section{Konsolenspiele}

Wie bereits in Kapitel 1 dieser Arbeit erläutert ${ }^{547}$, gehören zu den Konsolenspielen solche digitalen Spiele, deren Spielclient gegen ein einmal zu zahlendes Entgelt erworben und dessen Einzelspielermodus ohne zeitliche Begrenzung genutzt werden kann.

Die Pflicht zur Überlassung des Konsolenspielclients unterscheidet sich nicht von der Verpflichtung zur Überlassung des Inklusivspielclients. ${ }^{548}$ Aus diesem Grunde finden auf die Überlassungsverpflichtung die kaufrechtlichen Vorschriften direkte Anwendung, unabhängig davon, ob das Konsolenspiel auf einem Datenträger oder per Download erworben wird.

Es ist jedoch möglich, dass im Einzelspielermodus die Nutzung des Konsolenspiels von Online-DRM-Systemen kontrolliert wird. Wie bei Inklusivspielen entsteht dann ein Anspruch des Erwerbers des Konsolenspiels auf Support der Online-DRM-Systeme bereits im Überlassungsvertrag oder - bei Personenverschiedenheit des Veräußerers und des Support-Verpflichteten - in einem separaten Supportvertrag, der zeitgleich mit dem Überlassungsvertrag abgeschlossen wird. Im Falle des Fehlens einer Regelung über den Support der Online-Komponenten kann eine entsprechende Pflicht im Wege der ergänzenden Vertragsauslegung hergeleitet werden. ${ }^{549}$

Der Online-Mehrspielermodus dieses Spiels erhält jedoch erst dann Support, nachdem der Erwerber des Spielclients einen Abonnementvertrag abgeschlossen hat, welcher ihn zur Entrichtung einer wiederkehrenden Gebühr verpflichtet. ${ }^{550}$ Eine Pflicht zum Support des Online-Mehrspielermodus entsteht damit nicht schon im Überlassungs- bzw. Supportvertrag, sondern erst auf Grundlage dieses gesonderten Abonnementvertrages.

Diese Vereinbarung kommt mit dem Konsolenhersteller bzw. einem seiner Tochterunternehmen zustande ${ }^{551}$.

\footnotetext{
546 Siehe dazu oben, S. $31 \mathrm{ff}$.

547 Siehe dazu oben, S. $31 \mathrm{ff}$.

548 Siehe dazu oben, S. 65 f.

549 Siehe dazu oben, S. $52 \mathrm{ff}$.

550 Siehe hierzu die Produktbeschreibung des Xbox Live Gold-Abonnements sowie der PlayStation Plus-Mitgliedschaft, abrufbar unter http://www.xbox.com/de-DE/live/gold bzw. https://www.playstation.com/de-de/explore/playstation-plus/.

551 Vgl. die Einleitung der Nutzungsbedingungen für das PlayStation Network, abrufbar unter http://legaldoc.dl.playstation.net/ps3-eula/psn/e/de_tosua_de.html.
} 
Die Situation mit Blick auf die Supportpflicht stellt sich damit bei Konsolenspielen anders dar als bei Inklusiv- und Free-to-Play-Spielen. Es existieren hier ausdrückliche Regelungen, die bestimmen, wer auf welcher Grundlage den Support des OnlineMehrspielermodus erbringt. Damit fehlt es an einer Regelungslücke, die durch eine ergänzende Vertragsauslegung geschlossen werden könnte, sodass sich auch eine Auslegung verbietet, die eine (umfassende) Supportpflicht bereits im Überlassungsvertrag entstehen lässt. Ausgenommen hiervon sind - wie bereits erläutert - nur die OnlineDRM-Systeme, welche die Nutzung des Spiels schon im Einzelspielermodus kontrollieren.

$\mathrm{Zu}$ beachten ist dabei, dass aufgrund des Abonnementvertrages neben dem Support der Online-Komponenten auch noch weitere Leistungen vom Konsolenhersteller erbracht werden können. So erhält der Nutzer beispielsweise im Rahmen des PlayStation Plus-Abonnements auch Zugriff auf digitale Spiele, welcher er zusätzlich zu seinem vorher käuflich erworbenen Konsolenspiel spielen kann. ${ }^{552}$ Aufgrund der verschiedenen im Vertrag inkludierten Leistungen des Konsolenherstellers wird es sich beim Abonnementvertrag in der Regel um einen typengemischten Vertrag handeln. Teil dieses Vertrages ist aber jedenfalls die Pflicht zum Support des Online-Mehrspielermodus des zuvor käuflich erworbenen Konsolenspielclients. Diese Pflicht ist - wie auch die Supportpflicht bei Inklusivspielen - dem Dienstvertragsrecht gemäß §§ 611 ff. BGB zu unterstellen. ${ }^{553}$

\section{Zeitspiele}

Zeitspiele unterscheiden sich von den anderen Arten der Abospiele darin, dass sie im Ganzen, also inklusive ihres Spielclients, nur für die Dauer des Überlassungsvertrages gespielt werden können. Der Vertrag wird nicht auf Dauer abgeschlossen und verpflichtet den Erwerber des Spiels zur Entrichtung einer wiederkehrenden Gebühr.

Zunächst soll untersucht werden, wie die Pflicht zur Überlassung dieser Spiele vertragsrechtlich typologisiert werden kann (dazu 1.). Im Anschluss daran wird der Frage nachgegangen, welche Rechtsgrundlage für den Support der Online-Komponenten dieser Spiele in Betracht kommt (dazu 2.).

\section{Typologisierung der Überlassungspflicht}

Zeitspiele kann der Nutzer herunterladen und für eine begrenzte Zeit gegen die wiederkehrende Entrichtung einer Gebühr nutzen. Diese Nutzungsmöglichkeit verliert der Erwerber allerdings wieder nach der Kündigung des Überlassungsvertrages. Typologisch kommen zwei Vertragsarten in Betracht: der Pachtvertrag gemäß § 581 Abs. 1 BGB und der Mietvertrag gemäß $§ 535$ Abs. 1 BGB.

\footnotetext{
552 Siehe die Informationsseite zur PlayStation Plus-Mitgliedschaft, abrufbar unter https://www.playstation.com/de-de/explore/playstation-plus/.

553 Siehe dazu oben, S. 80 ff.
} 


\section{a) Pachtvertragliche Einordnung}

Gegenstände des Pachtvertrages können sowohl Sachen, Rechte als auch unkörperliche Gegenstände wie z. B. Unternehmen sein. ${ }^{554}$

Mehrere Literaturstimmen ordnen die Pflicht zur Überlassung von Software auf Zeit als Pacht- oder zumindest pachtähnlichen Vertrag gemäß $§ 581$ Abs. 1 BGB ein. ${ }^{555} \mathrm{Als}$ Grund dafür wird die Tatsache angeführt, dass sowohl körperliche als auch unkörperliche Gegenstände verpachtet werden können und dass Software einen unkörperlichen Gegenstand darstelle ${ }^{556}$ oder man diese Frage vor dem Hintergrund des weiten Pachtgegenstandsbegriffs ohnehin nicht entscheiden müsse ${ }^{557}$. Auch darüber hinaus sei aufgrund der im Wesentlichen gleichen Rechtsfolgen keine Abgrenzung zwischen Mietund Pachtvertrag mit Blick auf die Pflicht zur Überlassung von Software auf Zeit vonnöten. ${ }^{558}$ Aufgrund der Verweisungsvorschrift in $\S 581$ Abs. 2 BGB finden die Mietrechtsvorschriften auch auf den Pachtvertrag weitgehend Anwendung.

Die bisherigen Aussagen des BGH zur Frage der Einordnung der zeitlich begrenzten Softwareüberlassung als Pachtvertrag sind nicht eindeutig. In den Entscheidungen Programmsperre I sowie Programmsperre II diskutierte das Gericht knapp die Einordnung der Überlassungsvereinbarungen als Pachtvertrag, ohne jedoch abschließend hierzu Stellung zu nehmen. ${ }^{559}$ In einem jüngeren Urteil ordnet der BGH den zwischen zwei Unternehmen geschlossenen Lizenzvertrag, welcher dem Beklagten das Recht zur Nutzung, Weiterentwicklung sowie zum Vertrieb von Software einräumte, ,entsprechend der Rechtspacht als Dauernutzungsvertrag i. S. d. $\S \S 108,112$ InsO“ ein. ${ }^{560}$ Gegenstand dieser Untersuchung sind jedoch ausschließlich Verträge zwischen Unternehmern und Verbrauchern, sodass die Rechtsprechung des BGH zu dieser Frage hier nicht weiterhilft.

Trotz der soeben erwähnten Vorteile ist an einer pachtrechtlichen Typologisierung des Zeitspielüberlassungsvertrages problematisch, dass gemäß $§ 581$ Abs. 1 BGB dem Pächter nicht nur der Gebrauch des verpachteten Gegenstands, sondern auch der Genuss der Früchte zu gewähren ist, soweit sie nach den Regeln einer ordnungsgemäßen Wirtschaft als Ertrag anzusehen sind.

554 BeckOK BGB/Wagner, § 581 BGB, Rn. 2; vgl. Heydn, CR 2010, 765, 773; Lenhard, Vertragstypologie, S. 221.

555 Lenhard, Vertragstypologie, S. 221; Heydn, CR 2010, 765, 773; Brandi-Dohrn, CR 1986, 63, 67; zur Megede, NJW 1989, 2580, 2583; zumindest denkbar, aber in der Praxis unüblich: Kilian, CR 1986, 187, 194; für die unkörperliche Softwareüberlassung: Dörner/Jersch, iur 1988, 137, 146; für den ASP-Vertrag: Alpert, CR 2000, 345, 349.

556 Brandi-Dohrn, CR 1986, 63, 67; vgl. Dörner/Jersch, iur 1988, 137, 146.

557 Heydn, CR 2010, 765, 773.

558 Dörner/Jersch, iur 1988, 137, 146; Heydn, CR 2010, 765, 773; vgl. Roth-Neuschild, in AuerReinsdorff/Conrad, Handbuch IT- und Datenschutzrecht, § 13, Rn. 23.

559 BGH, NJW 1981, 2684, 2684 - Programmsperre I; NJW 1987, 2004, 2006 - Programmsperre II. 
Bei dieser Pflicht des Verpächters handelt es sich um eine typenprägende Hauptleistungspflicht, die nicht abbedungen werden kann, ohne dass der Vertrag den Charakter eines Pachtvertrages verlöre. ${ }^{561}$

Es ist zweifelhaft, ob der Nutzer eines digitalen Spiels tatsächlich „Früchte“ aus diesem ziehen kann. Zu den Früchten gemäß § 99 Abs. 1 BGB gehören die „Erzeugnisse der Sache" und ,die sonstige Ausbeute, welche aus der Sache ihrer Bestimmung gemäß gewonnen wird“. Die Ziehung von „Erzeugnissen“ scheidet bei Software schon von vornherein aus, da hierunter natürliche Tier- und Bodenprodukte verstanden werden. ${ }^{562}$

Die „sonstige Ausbeute“ wird im Gegensatz zu den Erzeugnissen aus der Substanz der Muttersache gewonnen. ${ }^{563}$ Als Gegenstand einer Ausbeute von digitalen Spielen kommen allenfalls virtuelle Güter wie Avatare oder allgemein die mit dem Spiel gespeicherten Daten in Betracht. Hierbei ist jedoch zu berücksichtigen, dass die Ausbeute selbst Sachqualität haben muss ${ }^{564}$, sodass bereits aus diesem Grund die genannten Gegenstände nicht als Ausbeute angesehen werden können ${ }^{565}$.

Eine Vielzahl von Vorschriften des BGB setzt außerdem voraus, dass die Früchte von der Muttersache getrennt werden können. ${ }^{566}$ Dies ist jedoch bei virtuellen Gegenständen und allen anderen im Zusammenhang mit einem digitalen Spiel anfallenden Daten grundsätzlich nicht der Fall. ${ }^{567}$ Sie können nur zusammen mit der jeweiligen Spielsoftware genutzt werden, welche daher nicht geeignet ist, Früchte abzuwerfen. ${ }^{568}$

Darüber hinaus heben mehrere Vertreter in der Literatur hervor, dass die Hersteller von Software im Allgemeinen kein Interesse daran hätten, dass der Erwerber der Software ein Fruchtziehungsrecht bekommt. ${ }^{59}$ Der Privatnutzer einer Software erhalte

561 MüKo BGB/Harke, § 581 BGB, Rn. 3.

562 BGH, NJW-RR 1989, 673, 674; Sedlmeier/Kolk, MMR 2002, 75, 79; MüKo BGB/Stresemann, $\S 99$ BGB, Rn. 2 mwN; so auch für digitale Online-Spiele Striezel, Virtuelle Gegenstände, S. 211.

BeckOK BGB/Fritzsche, § 99 BGB, Rn. 6; MüKo BGB/Stresemann, § 99 BGB, Rn. 4.

Erman/Schmidt, § 99 BGB, Rn. 3; BeckOK BGB/Fritzsche, § 99 BGB, Rn. 6; Striezel, Virtuelle Gegenstände, S. 211.

565 Striezel, Virtuelle Gegenstände, S. 211.

566 So z. B. § 596a BGB, vgl. näher hierzu MüKo BGB/Stresemann, § 99 BGB, Rn. 16.

567 So auch Moser, Browsergames, S. 68; Psczolla, Onlinespielrecht, S. 92.

568 So auch für andere Software als digitale Spiele, Karger, in Redeker, Handbuch der IT-Verträge, Teil 1.9, Rn. 14; Fritzsche, JuS 1995, 497, 503; Meyer, Software, S. 240.

569 Hoeren, in von Westphalen/Thüsing, Vertragsrecht und AGB-Klauselwerke, IT-Verträge, Rn. 161; ders., IT-Vertragsrecht, S. 251; Karger, in Redeker, Handbuch der IT-Verträge, Teil 1.9, Rn. 14; Röhrborn/Sinhart, CR 2001, 69, 71; Fritzsche, JuS 1995, 497, 503; Köhler/Fritzsche, in Lehmann, Rechtsschutz und Verwertung von Computerprogrammen, 2. Teil, XIII, Rn. 28; Henssler, MDR 1993, 489, 491; Bartsch, CR 1992, 393, 397; siehe dazu auch LG Köln, CR 1996, 154, 155. 
kein Recht zur Verwertung derselben, sondern lediglich zur Nutzung und zum Gebrauch, weswegen auch eine Fruchtziehung gemäß § 99 Abs. 2 BGB ausscheide. ${ }^{570}$ Darüber hinaus sei regelmäßig auch ein Recht zur Vermietung oder Verpachtung der Software ausgeschlossen, sodass der Nutzer auch keine mittelbaren Sach- oder Rechtsfrüchte gemäß $\S 99$ Abs. 3 BGB ziehen darf. ${ }^{571}$ Dies gelte erst recht für digitale Spiele, welche im Gegensatz zu herkömmlicher Anwendersoftware nicht auf einen produktiven Einsatz ausgerichtet sind, sondern der Unterhaltung dienen. ${ }^{572}$

Insgesamt ist damit die Anwendung der pachtrechtlichen Vorschriften auf die Pflicht zur Überlassung des Zeitspiels abzulehnen.

\section{b) Mietvertragliche Einordnung}

Gegenstand eines Mietvertrages können nur bewegliche oder unbewegliche Sachen i. S. d. $\S 90$ BGB sein. ${ }^{573}$ Eine dem $\S 453$ Abs. 1 BGB vergleichbare Norm, welche die mietrechtlichen Vorschriften auch auf Gegenstände Anwendung finden ließe, die keine Sachen gemäß $\S 90$ BGB darstellen, fehlt in den $\S \S 535$ ff. BGB. Zwar kann die Anwendung des Mietrechts auf die datenträgergebundene Überlassung eines Spielclients unproblematisch bejaht werden, da mit der ständigen Rechtsprechung des BGH und der überwiegenden Literaturansicht die auf einem Datenträger verkörperte Software als Sache gemäß $\S 90$ BGB einzuordnen ist. ${ }^{574}$ Fraglich ist aber, ob die $\S \S 535$ ff. BGB auch auf die unkörperliche Überlassung des Zeitspielclients Anwendung finden. Problematisch ist daran nämlich, dass der Besitz an dieser Sache nicht vom Veräußerer überlassen wurde, sondern die Sache erst im Endgerät des Nutzers - durch Speicherung auf einem Datenträger im Wege der Vervielfältigung - entstanden ist.

Nach dem im Jahr 2007 ergangenen ASP-Urteil ${ }^{575}$ des BGH kommt es aber auf eine Besitzüberlassung des Mietgegenstandes für die Anwendung der mietrechtlichen Vorschriften nicht an.

Dieser Entscheidung lag ein Fall zugrunde, in welchem die Klägerin der Beklagten die entgeltliche Nutzung einer Buchhaltungs- und Warenwirtschaftssoftware ermöglichte, welche auf einem zentralen Server abgespeichert war. Die Beklagte konnte auf

570 Vgl. Koch, ITRB 2001, 39, 41; Henssler, MDR 1993, 489, 491; LG Köln, CR 1996, 154, 155.

571 Röhrborn/Sinhart, CR 2001, 69, S. 71.

572 Vgl. Striezel, Virtuelle Gegenstände, S. 212.

573 Palandt/Weidenkaff, § 535 BGB, Rn. 2; Staudinger/Emmerich, § 535 BGB, Rn. 2; MüKo BGB/Häublein, § 535 BGB, Rn. 62.

574 BGH, NJW 1990, 320, 321; NJW 1993, 2436, 2438; NJW 2007, 2394, 2394; Palandt/Ellenberger, § 90 BGB, Rn. 2; Henssler, MDR 1993, 489, 490; Bösert, Nießbrauch, S. 144; Bydlinski, AcP 1998, 287, 307; König, Computerprogramm, Rn. 432; Topel, CR 1993, 198, 199; Lutz, Softwarelizenzen, S. 25; Marly, BB 1991, 432, 433 f.; Koch, Computer-Vertragsrecht, Rn. 27; Jauernig/Mansel, vor. § 90 BGB, Rn. 3; Hoeren, Softwareüberlassung als Sachkauf, S. 57; ders., CR 1988, 908, 911; ders., GRUR 1988, 340, 345; a. A. Müller-Hengstenberg, CR 2004, 161, 164; Diedrich, CR 2002, 473, 475; BeckOK BGB/Fritzsche, § 90 BGB, Rn. 26; Pres, CR 1994, 520, 520.

575 BGH, NJW 2007, 2394, 2394. 
diese Software über das Internet zugreifen, ohne dass die Installation einer gesonderten Clientsoftware vonnöten war, was allgemein als ASP (Application Service Providing) bezeichnet wird. ${ }^{576}$

Der BGH wandte auf die Vereinbarung das Mietrecht gemäß den $\S \S 535$ ff. BGB direkt an. ${ }^{577}$ Das Gericht erläuterte, dass die Anwendung des Mietrechts nicht voraussetze, dass eine Besitzverschaffung erfolge, sondern lediglich, dass der Gebrauch der Mietsache überlassen werde. ${ }^{578}$ Da der vertragsgemäße Gebrauch der Software im Fall des ASP keine Besitzverschaffung voraussetzte, genügte es, dass der Nutzer über eine Internetverbindung auf die Software zugreifen konnte und ihm damit der Gebrauch eröffnet wurde. ${ }^{579}$

Zwar setzt die Nutzung eines clientbasierten digitalen Spiels im Gegensatz zum ASP den Besitz des Spielclients voraus, da eine Nutzung des Spiels ohne Installation der Software auf dem Endgerät des Nutzers nicht möglich ist. Jedoch kommt es nicht darauf an, wie dieser Besitz dem Nutzer verschafft wurde, also ob die Sachherrschaft an einer spezifischen datenträgergebundenen Softwarekopie überlassen wird oder ob die Softwarekopie als Vervielfältigungsstück auf dem Endgerät des Nutzers erstmals entsteht. Denn wenn es schon im Sinne des ASP-Urteils für die Ermöglichung des vertragsgemäßen Gebrauchs einer Mietsache nicht darauf ankommen muss, ob auch der Besitz an dieser Sache verschafft wird, kann es erst recht keine entscheidende Rolle spielen, wie der - an sich erforderliche - Besitz an der Mietsache verschafft wird.

Damit finden die mietrechtlichen Vorschriften auf die Überlassung des Zeitspielclients Anwendung.

\section{Der Support der Online-Komponenten}

Nachdem festgestellt worden ist, dass auf die Pflicht zur (unkörperlichen) Überlassung eines digitalen Spiels die mietrechtlichen Regelungen Anwendung finden, soll an dieser Stelle untersucht werden, woraus sich eine Pflicht zum Support der OnlineKomponenten des Zeitspiels ergibt.

\section{a) Pflicht gemäß $§ 535$ Abs. 1 Satz 1 u. Satz. 2 BGB}

Der Support der Online-Komponenten des Zeitspiels könnte von der Gebrauchsüberlassungs- und -Erhaltungspflicht gemäß $§ 535$ Abs. 1 Satz 1 u. Satz 2 BGB umfasst sein.

Die Gebrauchsüberlassungspflicht sieht vor, dass der Vermieter dem Mieter den vertragsgemäßen Gebrauch der Mietsache ermöglicht. ${ }^{580}$ Darüber hinaus muss der Ver-

\footnotetext{
576 Ebd.

577 Ebd.

578 Ebd., 2395; dem zustimmend Staudinger/Emmerich, § 535 BGB, Rn. 15; MüKo BGB/Häublein, $\S 535$ BGB, Rn. 67; Marly, Softwarerecht, Rn. 744; Roth-Neuschild, in Auer-Reinsdorff/Conrad, Handbuch IT- und Datenschutzrecht, § 13, Rn. 18.

579 BGH, NJW 2007, 2394, 2395

580 Palandt/Weidenkaff, § 535 BGB, Rn. 14; NK-BGB/Klein-Blenkers, § 535 BGB, Rn. 63.
} 
mieter den vertragsgemäßen Zustand der Mietsache für die Dauer des Mietverhältnisses aufrechterhalten. ${ }^{581}$ Diese Grundsätze gelten auch für die mietweise Überlassung von Software. Der Vermieter muss die Software während der gesamten Dauer des Mietvertrages in einem vertragsgemäßen Zustand erhalten. ${ }^{582}$

Was vertragsgemäß ist, bestimmt sich vorrangig nach der Vereinbarung der Parteien. ${ }^{583}$ Sofern daher beispielsweise keine Vereinbarung hinsichtlich der Pflicht zur Stromversorgung einer Wohnung getroffen wurde, ist der Vermieter nicht selbst zur Stromversorgung verpflichtet. ${ }^{54} \mathrm{Er}$ muss aber grundsätzlich dafür Sorge tragen, dass die Wohnung zumindest an das Stromnetz angeschlossen ist, sodass der Mieter selbst mit einem Stromversorgungsunternehmen kontrahieren kann. ${ }^{585}$

Dieser Aspekt lässt sich auch auf den Support der Online-Komponenten von Zeitspielen übertragen. Sofern die Online-Komponenten erst aufgrund eines gesonderten Vertrages zur Verfügung gestellt werden sollen, ist der Vermieter des Spiels nicht bereits aufgrund des Mietvertrages zur Etablierung und Aufrechterhaltung der ClientServer-Kommunikation verpflichtet. Er muss nur dafür einstehen, dass das Zeitspiel als solches grundsätzlich zur Realisierung der Online-Komponenten in der Lage ist, also eine entsprechende Programmierung dahingehend aufweist.

Dafür, dass der Support der Online-Komponenten nicht zwingend dem Mietrecht unterfällt, spricht außerdem, dass zusätzliche Leistungen in Bezug auf die Software, wie z. B. die Durchführung von Programmpflege oder die Erbringung von Programmupdates oder Hotline-Services, durchaus anderen Vertragstypen unterfallen können. $^{586}$

Wäre der Support der Online-Komponenten des Zeitspiels von der Gebrauchsüberlassungs- und Erhaltungspflicht erfasst, hätte dies zur Folge, dass die Vertragsautonomie der Parteien stark eingeschränkt und die Etablierung unterschiedlicher Geschäftsmodelle hinsichtlich des Supports von Online-Komponenten am Markt praktisch ausgeschlossen wäre. Denn durch eine mietrechtliche Einordnung des Supports wäre die Vereinbarung eines gesonderten Vertrages über den Support der Online-Komponenten, der noch dazu eine zusätzliche Vergütung vorsieht, nicht möglich.

Eine mietvertragliche Einordnung des Supports der Online-Komponenten würde darüber hinaus auf Bedenken stoßen, da der Vermieter strenger haften würde als der Dienstverpflichtete eines Dienstvertrages, welcher grundsätzlich nur ein Bemühen schuldet.

581 Palandt/Weidenkaff, § 535 BGB, Rn. 36f.; Staudinger/Emmerich, § 535 BGB, Rn. 20.

582 NK-BGB/Schmidl, Anh. IV zu $\S$ 535-580a, Software-Vertragsrecht, Rn. 89; von dem Bussche/Schelinski, in Leupold/Glossner, Münchener Anwalts Handbuch IT-Recht, Teil 1, C., IV, Rn. 343.

Staudinger/Emmerich, § 535 BGB, Rn. 35; MüKo BGB/Häublein, § 535 BGB, Rn. 65. Vgl. Schmidt-Futterer/Eisenschmid, § 535 BGB, Rn. 541.

Ebd.

586 BGH, NJW 2007, 2394, 2395; vgl. NK-BGB/Schmidl, Anh. IV zu §§ 535-580a, Software-Vertragsrecht, Rn. 89 f. 
Aus diesen Gründen scheidet eine Erfassung des Supports der Online-Komponenten von der mietrechtlichen Gebrauchsüberlassungs- und -Erhaltungspflicht gemäß $§ 535$ Abs. 1 Satz 1 u. Satz 2 BGB aus.

\section{b) Pflicht gemäß $§ 611$ Abs. 1 BGB}

Der Support der Online-Komponenten der Zeitspiele unterscheidet sich in technischer Hinsicht nicht vom Support der Online-Komponenten anderer Arten digitaler Spiele, weshalb er auch hier als dienstvertragliche Pflicht einzuordnen ist. ${ }^{587}$

Der Erwerber des Zeitspiels hat - vergleichbar mit Inklusivspielen - ein berechtigtes Interesse daran, zumindest für die Dauer des Mietverhältnisses das Zeitspiel samt Online-Komponenten nutzen zu können. Denn die Nutzungsmöglichkeit auch bei Zeitspielen kann ganz oder teilweise vom Support der Online-Komponenten abhängen. Ohne eine Pflicht zum Support der Online-Komponenten stünde es im Belieben des Publishers, den Support der Online-Komponenten zu erbringen oder nicht. Der Erwerber des Spiels liefe dann Gefahr, im Besitz einer weitgehend wert- und funktionslosen Spielkopie zu sein, weil die Nutzungsmöglichkeit des Zeitspiels weggefallen ist. Der Erwerber ist darüber hinaus in der Regel auch nicht in der Lage, eine Pflicht zum Support mit dem Publisher oder gar mit Dritten zu vereinbaren. Falls eine Regelung über den Support im Vertrag fehlt, kann daher eine entsprechende Pflicht wie auch bei den Inklusiv- und Konsolenspielen im Wege der ergänzenden Vertragsauslegung ermittelt werden. ${ }^{588}$

Für den Fall, dass der Veräußerer des Spielclients mit der Person, welche den Support der Online-Komponenten erbringt, identisch ist, liegt ein typengemischter Überlassungsvertrag vor, welcher miet- und dienstvertragliche Elemente vereint. Falls der Veräußerer des Zeitspielclients und die für den Support der Online-Komponenten zuständige Person verschieden sind, kommt zeitgleich mit dem Abschluss des Überlassungsvertrages ein separater Supportvertrag zustande. ${ }^{589}$

Wie bei den Konsolenspielen kann auch bei den Zeitspielen der Support der OnlineKomponenten erst aufgrund eines gesonderten, entgeltpflichtigen Abonnementvertrages geschuldet sein. Ein Beispiel hierfür stellt das EA Access-Abonnement dar, welches die Inhaber einer Xbox One-Konsole mit dem Konsolenhersteller Microsoft $t^{590}$ abschließen können. Es eröffnet den Spielern Zugriff auf mehrere digitale Spiele des

587 Siehe zur dienstvertraglichen Einordnung des Supports oben, S. 80 ff.

588 Siehe dazu oben, S. 52 ff. und S. 93 ff.

589 So auch bei den Inklusivspielen, siehe dazu oben, S. $61 \mathrm{ff}$.

590 So die Bedingungen der EA Access Terms, zweiter Absatz, abrufbar unter https://www.ea.com/eaaccess/terms.html. 
Publishers $E A$, die sich die Nutzer auf ihre Konsole herunterladen können. ${ }^{591} \mathrm{Um}$ jedoch den Support des Online-Mehrspielermodus dieser Spiele erhalten zu können, ist zusätzlich der Abschluss einer Xbox Live Gold-Mitgliedschaft erforderlich. ${ }^{592}$

In dem zuletzt genannten Fall verbietet sich eine ergänzende Vertragsauslegung dahingehend, dass eine Pflicht zum Support des Online-Mehrspielermodus bereits im Überlassungsvertrag entsteht. Auch kommt dann kein unentgeltlicher Vertrag über den Support des Online-Mehrspielermodus zeitgleich mit dem Überlassungsvertrag zustande.

\section{MMOG}

Bei MMOG gibt es verschiedene Formen der Überlassung des Spielclients. Dies kann am Beispiel des digitalen Spiels World of Warcraft des Publishers Activision Blizzard verdeutlicht werden.

Der Spielclient dieses Spiels kann sowohl unentgeltlich, für unbegrenzte Dauer ${ }^{593}$ als auch gegen Entgelt, für eine nur begrenzte Zeit ${ }^{594}$ erworben werden.

Die Typologisierung der Pflicht zur zeitlich unbegrenzten Überlassung des MMOGSpielclients weicht nicht von der Einordnung der Pflicht zur Überlassung des Free-toPlay-Spielclients ab. ${ }^{595}$ Auch hier liegt eine Schenkung vor. Ebenfalls stimmt die vertragsrechtliche Einordnung der Verpflichtung zur zeitlich begrenzten Überlassung des MMOG-Spielclients mit derjenigen der Überlassung des Zeitspielclients überein, sodass die Pflicht zur zeitlich begrenzten Überlassung des MMOG-Spielclients als mietvertragliche Pflicht zu typologisieren ist. ${ }^{596}$

Hinsichtlich des Supports der Online-Komponenten ist zwischen der unentgeltlichen, dauerhaften Überlassung einerseits und der entgeltpflichtigen, zeitlich begrenzten Überlassung des Spielclients des MMOG andererseits zu unterscheiden.

Im letzteren Fall gibt es hinsichtlich des Entstehens und der Typologisierung der Pflicht zum Support der Online-Komponenten des MMOG keine Abweichungen zu den Zeitspielen. ${ }^{597}$

Im Fall der kostenlosen, dauerhaften Überlassung des MMOG-Spielclients ist zwischen den (eingeschränkten) Online-Komponenten zu unterscheiden, die bereits nach

591 Siehe zum Ganzen Cavalli, EA unveils Xbox One subscription service, EA Access [update] (2014), abrufbar unter https://www.engadget.com/2014/07/29/ea-unveils-xbox-onesubscription-service-ea-access/.

Ebd.

593 Hierbei handelt es sich um die sog. „Starter-Edition“, mit der der Spieler unbegrenzt, jedoch mit eingeschränktem Funktionsumfang und nur bis Level 20 spielen kann, vgl. die Informationsseite des Publishers hierzu, abrufbar unter https://eu.battle.net/support/de/article/3226.

594 Ausführliche Informationen dazu enthält die Informationswebseite Gamona, abrufbar unter http://wow.gamona.de/wow-spielzeit-kosten/.

595 Siehe dazu oben, S. 86 ff.

596 Siehe dazu oben, S. $97 \mathrm{ff}$.

597 Siehe dazu oben, S. $100 \mathrm{ff}$. 
dem Download des Spielclients kostenlos Support erhalten, und solchen, die erst nach Abschluss eines entgeltpflichtigen Abonnementvertrages Support bekommen. Der Support der zuletzt genannten Online-Komponenten stellt eine sich aus dem Abonnementvertrag ergebende und als dienstvertragliche Pflicht einzuordnende Leistung dar. ${ }^{598}$

Wie bei Free-to-Play-Spielen, bei denen der Erwerber keine virtuellen Gegenstände kauft, ist jedoch auch bei kostenlos überlassenen MMOG-Clients eine Pflicht zum Support der Online-Komponenten zu verneinen. Da der Erwerber keine Investitionen in den Erwerb des Free-to-Play-Spielclients getätigt hat, steht er ohne den Support der Online-Komponenten wirtschaftlich nicht schlechter da als in dem Fall, in welchem er den Spielclient gar nicht erst erworben hätte.

\section{Ergebnisse für Unterabschnitt C.}

Die unterschiedlichen Geschäftsmodelle der Abospiele erfordern eine differenzierte rechtliche Einordnung des Überlassungsvertrages, welcher der Veräußerung des jeweiligen Spielclients zugrunde liegt.

Bei Konsolenspielen finden auf die Pflicht zur Überlassung des Spielclients - wie auch bei Inklusivspielen - die kaufvertraglichen Regelungen Anwendung. Bei Zeitspielen und zum Teil auch bei MMOG sind auf die Überlassungspflicht die mietvertraglichen Vorschriften anzuwenden. Die dauerhafte, unentgeltliche Überlassung des Spielclients bei MMOG ist dagegen - wie bei Free-to-Play-Spielen - als Handschenkung einzuordnen.

Ob eine Pflicht zum Support der Online-Komponenten besteht, hängt von der Art des Abospiels ab. Für den Fall, dass über den Support der Online-Komponenten keine vertragliche Regelung getroffen wurde und hierüber auch kein entgeltpflichtiger Abonnementvertrag abgeschlossen werden muss, entsteht eine entsprechende Pflicht im Überlassungsvertrag oder - bei Personenverschiedenheit von Veräußerer der Spielkopie und Erbringer des Supports - in einem separaten Supportvertrag.

598 Siehe dazu die Erläuterungen zum Support der Online-Komponenten von Zeitspielen, S. $100 \mathrm{ff}$. 
Eine Ausnahme gilt jedoch für unentgeltlich und dauerhaft überlassene MMOGSpielclients. Der Erwerber dieser Spielclients muss - wie bei Free-to-Play-Spielen keinerlei Gegenleistung für den Erwerb und die Nutzung des Spiels aufbringen. Ohne den Support der Online-Komponenten ist er damit wirtschaftlich nicht schlechter gestellt als in dem Fall, in welchem er den Spielclient überhaupt nicht erworben hätte. Eine Pflicht zum Support der Online-Komponenten ist hier daher zu verneinen.

Open Access Dieses Kapitel wird unter der Creative Commons Namensnennung 4.0 International Lizenz (http://creativecommons.org/licenses/by/4.0/deed.de) veröffentlicht, welche die Nutzung, Vervielfältigung, Bearbeitung, Verbreitung und Wiedergabe in jeglichem Medium und Format erlaubt, sofern Sie den/die ursprünglichen Autor(en) und die Quelle ordnungsgemäß nennen, einen Link zur Creative Commons Lizenz beifügen und angeben, ob Änderungen vorgenommen wurden. Die in diesem Kapitel enthaltenen Bilder und sonstiges Drittmaterial unterliegen ebenfalls der genannten Creative Commons Lizenz, sofern sich aus der Abbildungslegende nichts anderes ergibt. Sofern das betreffende Material nicht unter der genannten Creative Commons Lizenz steht und die betreffende Handlung nicht nach gesetzlichen Vorschriften erlaubt ist, ist für die oben aufgeführten Weiterverwendungen des Materials die Einwilligung des jeweiligen Rechteinhabers einzuholen.

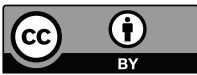

